Papers

of the

East-West

Population Institute

No. 71

\title{
Surveys of migration in developing countries: a methodological review
}

Sidney Goldstein and Alice Goldstein

五

East-West Center

Honolulu, Hawaii 
PAPERS OF THE EAST-WEST POPULATION INSTITUTE, published about eight times a year, facilitate early dissemination of research findings and state-of-the-art essays on the demography of Asia, the Pacific, and the United States. Annual subscription rate, $\$ 12$.

NOTE TO CONTRIBUTORS: The Population Institute considers unsolicited as well as commissioned manuscripts for the Paper Series. Appropriate topics are population estimation and analysis, causes and consequences of demographic behavior, urbanization and population distribution, and population policies and programs. All manuscripts are reviewed. In selecting manuscripts for publication, the Institute considers quality of scholarship and usefulness to public officials and other professionals in the field of population; it also seeks contributions reflecting diverse cultural and disciplinary perspectives on population. The series can accommodate articles not necessarily suited for journals because of unusual length or treatment of subject. All copy must be typed double-spaced. For additional information on manuscript preparation, write to the Senior Editor, East-West Population Institute.

\section{OTHER SERIAL PUBLICATIONS OF THE EAST-WEST POPULATION INSTITUTE:}

Working Papers are circulated for comment and to inform interested colleagues about work in progress at the East-West Population Institute. They are intended to complement evidence of completed work as reflected in Papers of the EastWest Population Institute and the Reprint Series. \$1 per copy.

Reprint Series brings selected articles originating from Institute research but published elsewhere to the attention of population specialists who might not otherwise see them. Single copies available upon request.

Asian and Pacific Census Forum is a quarterly periodical reporting on census, vital registration, and population survey activities in Asia and the Pacific. The Forum contains technical articles on a range of topics related to demographic measurement, and reviews of new publications in the field. Issued in August, November, February, and May. Annual subscription rate, $\$ 5$.

Serial publications except Working Papers are available without charge to libraries serving population specialists and to professionals and scholars in the field of population. Requests describing the nature of the research or program and the intended use of the publications should be addressed to the Publications Office of the Institute.

East-West Population Institute

East-West Center

Director Lee-Jay Cho

1777 East-West Road

Honolulu, Hawaii 96848

Senior Editor Sandra E. Ward Production Assistant Lois M. Bender 


\section{Surveys of migration in developing countries: a methodological review}

Sidney Goldstein and Alice Goldstein

Number 71 - April 1981 
SIDNEY GOLDSTEIN is Professor of Sociology and Director of the Population Studies and Training Center at Brown University, Providence, Rhode Island. ALICE GOLDSTEIN is Senior Research Assistant at the Population Studies and Training Center at Brown University.

Second Impression

\section{Library of Congress Cataloging in Publication Data}

Goldstein, Sidney, 1927.

Surveys of migration in developing countries.

(Papers of the East-West Population Institute ; no. 71 )

"Revised version of a background paper prepared for the International Statistical Institute expert group meeting on methodology of migration measurement (London, 25-27 September 1979)."-Pref.

Bibliography: p.

1. Underdeveloped areas-Migration, Internal.

2. Demographic surveys. 3. Migration, Internal-Statistical methods. I. Goldstein, Alice. II. International Statistical Institute. IIl. Title. IV. Series. HB1952.G64 304.8'2'091724 


\section{CONTENTS}

Preface $v$

Abstract I

Data sources on migration 5

Purpose of sample surveys 9

Technical-statistical considerations 15

Definitions of migration $\quad 50$

Identification of persons who migrate 66

The determinants of migration 7]

The impact of migration $\quad .79$

Overview 86

Appendices 90

Bibliography 101 


\section{APPENDICES}

1 Migration history format used by Malaysian Family Life Survey 90

2 Migration-occupation history format used by Speare 92

3 Life history format used by Balan, Browning, and Jelin 94

4 Life history matrix used by Lauro 96

5 Migrant classification scheme developed by Caldwell 98

6 Variables collected in migration surveys as listed by Todaro 99 


\section{PREFACE}

This is a revised version of a background paper prepared for the International Statistical Institute Expert Group meeting on Methodology of Migration Measurement (London, 25-27 September 1979). The cooperation of a number of researchers in making copies of research instruments and reports available is gratefully acknowledged, as are the suggestions offered by participants in the Expert Group meeting and reviewers of the manuscript. 
ABSTRACT Sample surveys have been used in many less developed countries to study migration. This review examines these studies-their purpose, theoretical relevance, scope, research design, sampling procedures, definition of migration, coverage of other forms of movement, attention to determinants and consequences, and policy relevance. The authors demonstrate the tremendous diversity of such surveys and describe the wide range of information they collect on how many people move, who moves, why they move, where they move, and how long they stay. But the frequent lack of comparability among studies on most of these dimensions helps to explain both the difficulties encountered in attempting to reach generalizations about the patterns and impact of population movement in the developing nations and the limited value of most of the surveys for policy formulation. Nonetheless, the variety of study designs can serve to provide a wide range of experiences on the basis of which more sophisticated approaches can be developed.

As stressed in the 1976 Presidential Address before the Population Association of America (Goldstein, 1976), rapid population growth in the less developed regions of the world, substantial increases in the size of the urban population and in the levels of urbanization, and a sharp rise in the number and size of big cities all argue for increased attention to population movement as a key component in population dynamics and in urban and rural development. The need to monitor such movement has been accentuated by continuing and substantial increases in the rural populations of many countries. Ever-growing pressures are placed on limited resources, and extensive rural-to-rural movement as well as rural-to-urban shifts are observed. Yet serious obstacles hamper efforts to assess the role of population movement both in the growth of rural and urban places and in relieving or exacerbating the wide disparities in the quality of life between and within urban and rural locations. Foremost among these obstacles are the limitations inherent in the conceptual treatment of population movement as a demographic process and in the corresponding lack of appropriate data for assessing movement.

On the positive side, some evidence does suggest that government concern with problems of population distribution and rural-to-urban 
migration is moving into the forefront. About half of the 158 governments covered by the United Nations in the 1979 Monitoring Report on World Population Trends and Policies regarded the spatial distribution of their populations as entirely unacceptable and in need of substantial modification (UN Department of International Economic and Social Affairs, 1980:72). Only 12 percent regarded their spatial distribution as entirely acceptable, requiring no intervention. Perhaps more telling is that the degree of concern varied inversely with development level (judged by average life expectancy): only 12 percent of the more developed countries reported their spatial distribution as entirely unacceptable, compared to 59 percent of the less developed countries. Government concern with problems of population distribution and rural-to-urban movement has become widespread. Indeed, governments now seem to express more concern about distribution and migration patterns than about excessive rates of population growth.

The recognition by so many governments that population growth and distribution are closely linked and that both factors must be included in integrated development planning certainly justifies giving high priority to research on population distribution and movement. Serious deficiencies still characterize the conceptualization and measurement of population movement and its effects on settlement patterns and development. Although some less developed countries have begun to collect migration information as part of their census programs, the use of such information for analy tic purposes, and particularly for the assessment of urban growth and urbanization, is severely restricted by the limited number and kinds of tabulations made (Elizaga, 1972; Goldstein and Sly, 1975a, 1975b; United Nations, 1974). Some of these deficiencies have been overcome by specialized surveys focusing on migration, and such surveys will receive the major attention of this paper.

Because most specialized surveys concentrate on small areas or individual communities, such as a big city, their value for generalization is restricted. Furthermore, they of ten seriously neglect major segments of the population that are essential to the full evaluation of the migration process-those who have moved about in rural areas, those who have returned to rural areas from urban locations, and those who have not moved at all. We are beginning to realize that the migration process is much more complex than traditional published census information suggests (Morrison, 1970; Hugo, 1978; Chapman, 1978). 
Concomitantly, it is urgent to know much more about the magnitude of the opposing streams of movement, the extent of circulatory and repeat movement, the selected character and impact of movement on places of origin and destination, and the degree to which commuting serves to complement or substitute for migration.

Increasingly, "social scientists working in Third World countries are questioning the uncritical application of Western derived and tested theory to the explanation of social and economic phenomena in such context" (Hugo, 1978:296). Hugo argues forcefully that it is highly debatable whether mobility patterns in Third World countries will inevitably evolve along some predetermined path already blazed by Western countries. Indeed, as Janet Abu-Lughod $(1975: 202)$ has most effectively pointed out, "substantive work on migration ... has yielded a far greater degree of diversity than prior theoretical formulations could have anticipated." Review of the now extensive literature on population movement leads to ready agreement with her conclusion that the findings point strongly to diversities over time, across space, within the monolithic category called "migrant," and over the paths followed to adjustment.

What is particularly clear from a general review of the literature is that although considerable progress has been made in the last few decades, improvement in the quantity and quality of information on population movement has not kept pace with the increasing significance of movement itself as a component of demographic change. Beyond the statistics collected in standard census-type surveys, a wide range of data is needed to permit assessment of the volume, form, and characteristics of movement, and the motivation for it, in relation to the larger processes of development and modernization. Concurrently, we must benefit from the methods, perspectives, and insights provided by the extensive experience in research on fertility as well as by the expertise of the various social science disciplines.

Only through a concerted approach can we understand how the various facets of redistribution relate to each other; how they relate to changing levels of fertility and mortality, and to population composition; how they are affected by changes in social, economic, technological, and political conditions: and, in tum, how they affect these conditions in the places of origin and destination of the movers. Such an approach calls for an attack on data deficiencies on several levels: (1) continuing and maximum exploitation of existing data sources in 
censuses, ongoing surveys, population registers, and other administrative records and systems; (2) continuing refinement of concepts, and development of stronger and fuller models and theories as a prerequisite to new, extensive data collection efforts; (3) use of every opportunity to incorporate attention to migration into all systematic efforts to collect data on the dynamics of population change, whether in the form of national demographic surveys, KAP-type studies, or international efforts such as the World Fertility Survey; (4) consideration on a regional and international level of the development of specialized national comparative surveys that would allow maximum testing of basic concepts and of the impact on movement of differences in level of development, urbanization, and policies with respect to migration and urban growth; (5) a continuing, in-depth review of research already undertaken as a basis for assessing the strengths and limitations of the methods and concepts employed and of the experience gained in designing, implementing, analyzing, and utilizing these studies.

In 1976, it was pointed out that

As redistribution proceeds in both more and less developed regions, it provides us with new challenges to demonstrate our research ingenuity and new opportunities to apply our knowle dge to help achieve realistic and effective development policies. The study of redistribution has suffered far too long from neglect within the profession, within government agencies responsible for data collection, within foundations and other groups responsible for funding research, and among those responsible for planning the future and anticipating the consequences of their plans for the welfare of their people. It behooves us to rectify this situation in this last quarter of the twentieth century, when redistribution in all of its facets will undoubtedly constitute a major, and increasingly important, component of demographic change (Goldstein, 1976:433).

Reacting to these challenges, and to the greater importance attached to population distribution problems and policies by individual governments and the United Nations, the International Statistical Institute (ISI) convened an expert group meeting in London in September 1979. Their purpose was to recommend the objectives, methodology, and general approach to be adopted in devising an international program of migration surveys for developing countries. This review served as a background paper for that meeting. The paper was not, however, a proposal for a specific design for such surveys, except insofar as this is implicit in the evaluation of the survey procedures reviewed. Nor should the fact that the ISI has had a major role in the World Fertility Survey be taken as evidence of indiscriminate endorsement of the 
WFS approach and methodology for migration surveys. The in trinsic differences between fertility and migration as components of population dynamics and the vastly different levels of experience gained in these respective topics obviously significantly affect how each process can and should be surveyed.

With this context, the specific charge for this paper was to review past experience by describing the methodologies employed and evaluating their efficacy for migration surveys for as wide a range of developing countries as possible within the limited time available. It was stressed that the presentation should be factual rather than prescriptive, and that survey results were to be considered only in relation to methodological issues. This is not a review of findings. Although attention to both internal and international migration was encouraged, the primary emphasis was to be on the former. As it happened, only a limited literature was available on surveys of in ternational migrants in developing countries, but even this literature was not evaluated because of time and space limitations.

The time limitation affected the review in two other respects. It restricted the coverage very largely to reports published in English, reflecting lack of easy access to reports published in other languages. Similarly, efforts to obtain copies of research instruments and unpublished reports in the time available also met with only limited success. Furthermore, the overall assessment was complicated by the failure of most published reports to include questionnaires or to describe the research design adequately. In the absence of a complete inventory of all migration surveys, it is not possible to give a statistical profile of the types of studies undertaken, their areal coverage, or their substantive foci. The assessment that follows is therefore based largely on impressions gained from a fairly extensive review of the literature, and should be seen as illustrative of the kinds of approaches used and the types of problems encountered. Within this framework, extensive use is made of examples provided by specific studies.

\section{DATA SOURCES ON MIGRATION}

The major sources of information on migration are censuses, population registers, and sample surveys, although, for in ternational migration, border statistics must be included as a major data source for some countries. Given the focus of this review on the use of sample surveys, extensive assessment of the use of censuses and population 
registers is not necessary. However, because of their importance as sources of information on internal migration, their frequent use either in conjunction with sample surveys or as the basis for designing the samples, and because their shortcomings often provide the justification for development of sample surveys, a brief overview of censuses and population registers is in order. A concise, comprehensive description of censuses and population registers is included in the United Nations manual on measuring in ternal migration:

Censuses: Census data have been and still are the major source of information on internal migration in most countries of the world.... The cerisus data on internal migration are obtained directly by including a question on migration, and indirectly through estimation procedures that use data presumably obtained for other purposes. The usual direct questions on internal migration have to do with: place of birth; place of last residence; duration of residence in the place of enumeration; place of residence on a specific date before the census.

On the basis of the answers to any of these questions, the total population in an area may be classified into two groups: migrants and non-migrants. . . . the criterion for such classification will depend upon the nature of the inquiry. Thus, migrants may be those who are enumerated in a place different from their place of birth, or those whose place of last residence is different from the place of enumeration, or those who resided in the place of enumeration for a period that is less than their age or those who resided $x$ years ago in a place different from their place of residence at the time of the census.

Population registers: The practice of recording changes of residence exists in some countries. Where such registrations are made on a routine basis covering the whole country and where these records are used to prepare statistics on population movements, the registration system is potentially an excellent source of data for the study of internal migration. Although, at the present time, there are several coun. tries where accurate statistics on internal migration are obtainable from population registers, published data on internal migration are meagre, being largely confined to the volume of in-migration and out-migration for component areas. The importance of population registers as a source of data on internal migration lies not so much in its widespread use at the present time as in its future potentialities (United Nations, 1970:3-4).

In contrast to national censuses and population registers, both of which are government enterprises, sample surveys can be undertaken either by government agencies or by individual scholars or research institutions. Periodic sample surveys have become an important source of demographic information in many countries. In a few-generally more developed-countries, these surveys have been used to collect direct information on internal migration, especially as a means of providing current information during the postcensal period when 
information is needed to supplement the more limited data collected in national censuses or registers.

Censuses and sample surveys clearly differ in their advantages and limitations for providing data on population movement. Again, as a recent United Nations evaluation summarized it:

In any given situation, the trade-offs between geographical and subject-matter detail required, anticipated sampling and non-sampling errors and anticipated costs have to be assessed carefully. For example, the census may more efficiently provide the small-area statistics that are needed but it is not suitable as a vehicle for inquiring into reasons for migration or similar topics that require timeconsuming questioning. Household sample surveys, particularly those designed for the investigation of migration alone or in conjunction with only a few other topics, offer a more suitable vehicle for questioning in detail and are also useful for the collection of migration histories. Because censuses are usually held decennially or, at the most quinquennially, they can provide information only infrequently. Household sample surveys repeated at frequent intervals can provide more current information...

One of the drawbacks of the use of a field inquiry of either type is that at best it does not permit assessment of the flow of migration on a continuous basis because in-migration coverage is restricted solely to net residual in-migrants in the population at the time of the inquiry and information on out-migrants collected at the place of previous residence is dependent on proxy response, which is often inadequate for household members who have left the area and even more so when an entire household has left. Field inquiries also suffer from memory lapse and other types of response errors associated with any retrospective inquiry in a "flow" phenomenon (UN Department of International Economic and Social Affairs, 1978:14).

Todaro (1976) has explicitly documented that the survey approach, supplemented where necessary by census information, offers the most promising avenue for future policy-oriented, econometric migration research. His argument can easily be extended to migration research in general. According to Todaro:

(1) Surveys can be specifically designed to collect the kinds of social, economic, demographic, and psychological variables that are crucial to measuring either selectivity or adaptation of migrants.

(2) Unlike censuses, field surveys give more adequate coverage to such economic variables as wages, self-employment, cash transfers, job probabilities, and other variables relevant to the testing of specific migration models.

(3) Surveys can be designed to classify information more easily according to carefully delineated rural and urban areas and thus facilitate the direct study of rural-urban, rural-rural, urban-rural, and, where appropriate, even urban-urban migration.. 
(4) Moreover, the more frequent intervals at which sample surveys can be conducted provide opportunities for both a more accurate time series and more up-to-date information.

Nonetheless, a series of caveats must be kept in mind when interpreting and evaluating the results of field surveys (Todaro, 1976). Appropriate questions include:

(1) Is the universe being sampled meaningful for the overall purpose of the survey?

(2) Is the sample size adequate?

(3) Does the survey distinguish between independent and dependent migrants-that is, those who move voluntarily and those who accompany the independent migrant simply because they are members of the unit making the move?

(4) How appropriate is the decision-making unit that is identified in the survey for purposes of interviewing? Is it to be the individual, and, if so, is the head of the household always the best person to serve as respondent, or can any adult member of the household serve as a legitimate proxy?

(5) Does the definition of migration distinguish between longdistance and local moves and how are these differences defined? Furthermore, does the survey distinguish adequately between different types of moves in terms of permanency of separation of the individual from the place of origin and the nature of the interaction between the mover and the community of origin?

The extent of detail and the accuracy of the questionnaire are also of crucial importance, even though copies of questionnaires are rarely included in survey write-ups. Likewise, it is rare to find reference to the specific questions on which classification of individuals as migrants and analysis of the variables affecting movement are based. Yet, as Todaro has correctly insisted, the questionnaire must be designed in a meaningful and appropriate manner for any migration study based heavily on field surveys to be of general use. He also argues that because the field survey method is subject to problems of unreliable recall and emotional distortion by respondents, it is essential that surveys distinguish between recent and earlier migrants. Therefore, he insists that qualitative measures should be utilized only in conjunction with appropriate quantitative measures and carefully constructed crosscheck questions.

Although researchers may differ with some of the specific 
recommendations; the need for concern with the quality of data obtained in sample surveys is certainly legitimate. Yet the extent to which authors demonstrate such concern by evaluating the quality of their data before subjecting them to analysis-sometimes very sophisticated analysis-gives reason for concern. This review suggests strongly that far too many researchers who rely on field surveys for collection of data on population movement either are not adequately familiar with survey research methodology and techniques or, if they are, choose to ignore the problems inherent in such methodology. Coupled with the pressing need for high quality data, this limitation argues for caution in using the results of many sample surveys, for better training of individual scholars to undertake migration research, and for the development of more sophisticated designs for such surveys.

Within the framework of the advantages and disadvantages cited above, sample surveys can be superior instruments for conducting migration research. They offer the possibility of attention to:

- characteristics at the time of the survey compared with those before migration or in the immediate postmigration period;

- reasons for migration;

- longitudinal analysis, including both retrospective re-creation of migrant residential histories, and follow-up contacts to assess further migration;

- the ability to link changes in residence to other changes associated with the life cycle;

- experimentation with various definitions of population movement and the use of various time and space intervals as bases for assessing migration;

- incorporation of a larger number of nondemographic variables;

- concurrent assessment of the links between migrants and nonmigrant members of their households and community of origin;

- concurrent assessment of the links between the migration behavior of the individual and other demographic processes such as fertility, job mobility; morbidity, and even mortality.

\section{PURPOSE OF SAMPLE SURVEYS}

The most striking impression created by this "state of the art" review is the tremendous range in the types of studies undertaken. Sample size may vary from a handful of cases to thousands; the geographic focus may extend from a single neighborhood, to a large city, to an entire 
nation; the sample design can vary in sophistication from virtually indiscriminate selection of households to highly complex sampling procedures; the analysis may involve very limited use of qualitative data and single-variable tabulations or employ high-powered statistical procedures. The conceptual framework of some surveys involves testing complex models; that of others is detectable only by examining the simple tables that describe the study population. Studies reported in the literature are also characterized by significant variation in purpose. For many, no explicit purpose is stated, and one may detect the author's motives only by examining the kinds of questions asked or the kinds of tabulations and analyses undertaken. For others, the goals are quite explicit, whether spelled out directly and in great detail or clearly evident from the models or hypotheses tested.

Two common themes underlie virtually all of these studies. First is the relations among migration, urbanization, and development, as illustrated by Balan, Browning, and Jelin's The Study of Men in a Developing Society. The authors state that "concern with migration, occupational mobility, and the process of stratification derives from the links they have with basic structural transformations in a society undergoing the process of industrialization" (Balan, Browning, and Jelin, 1973:4). The second theme is articulated by Caldwell, who, in the introduction to his book African Rural-Urban Migration, stresses data gaps by stating, "It was important also that initial concern should focus on matters of real importance about which information was urgently needed. One such topic was rural-urban migration and urbanization" (Caldwell, 1969:1-2). Equally significant is his statement that "it was felt that the rural-urban migration stream could be better understood if many detailed questions could be asked of migrants and non-migrants in rural emigrant and urban immigrant areas. Investigations of population samples in depth, and the asking of many intimate questions, can often be more easily undertaken in unofficial inquiries of this kind than by government" (Caldwell, 1969:2).

In short, a large proportion of the sample surveys of migration arise from concern about the vacuum of data on population movement, even when censuses and register systems are available. Caldwell states this concern very well. The arguments presented in the various studies, however, suggest that recognition of this need has been stimulated by the increasingly accepted view that migration plays a major role-both in creating the problems of the rapidly growing cities of developing 
countries and in serving as a mechanism for achieving a better distribution of population.

For example, the Longitudinal Study of Economic, Social, and Demographic Change in Thailand (Prachuabmoh et al., 1971) stressed the need to go beyond census data, in both frequency and intensity of analysis, to assess ways in which demographic changes result from efforts at social and economic development and how these changes in turn affect social and economic development. Migration was therefore given equal importance with other demographic processes in that survey. In prerevolutionary Iran, the need to supplement the census by obtaining statistics on population growth for use in planning led to the development of surveys to estimate fertility, mortality, and migration (Statistical Centre of Iran, 1976). Likewise, village studies in Indonesia were undertaken not to estimate the overall scale of movement, but to probe the dimensions of the process of population movement and identify conditions in the village that produce movement to the city (Hugo, 1978:118).

Often, these purposes are manifest in quite specific hypotheses or models. Rempel and Todaro's (1972) study of migration in Kenya, for example, was designed to obtain information on income and employment of rural-urban migrants in order to test hypotheses relating migration and urban unemployment. Conning's (1972:151) study in Chile tested a specific hypothesis, that "for communities in a small rural region, the ratio of rural-urban to all migrants from a given community is directly related to its level of differentiation." In Taiwan, Speare (1971) designed his study basically to test Sjaastad's (1962) model that migration is an investment for which the migrant expects to receive returns sufficient to offset the costs of moving, but Speare also investigated the comparative importance of monetary and nonmonetary costs in affecting the decision to migrate. Chapman's (1975, 1976) work in Melanesia illustrates a whole school of anthropological and geographical investigations that aimed to test various models of mobility as circulation and to assess how microlevel findings can be aggregated to produce macrolevel patterns. Such studies also serve to test the complementarity of demographic, geographic, and anthropological procedures.

As interest in migration has increased, a growing number of sample surveys have been undertaken to develop and test new procedures. For example, one goal of the Thai Longitudinal Study was to determine 
whether longitudinal studies are feasible in developing countries (Prachuabmoh et al., 1971). Given the heavy reliance on retrospective data in migration surveys, a growing number of studies have experimented with the life history matrix as a device for improving the quality of retrospective data (Lauro, 1979; Corno, 1979; Balan, Browning, and Jelin, 1973). Others, interested in the links between rural and urban places, have attempted to improve methods of identifying out-migrants from rural locations and some have gone on and tried to trace such individuals to their urban destinations. Still others, interested in the links between migration and other demographic processes, have tried to improve both the quality of the data collected and the sophistication of the analy tic procedures, in order to allow fuller and better-integrated use of fertility and migration information and to assess the ways in which one process relates to the other (Butz and DaVanzo, 1978; Jones and Spoelstra, 1978).

Given the emphasis of many studies on investigating the relation between migration and development and the problems of urban destinations, it is understandable that a substantial proportion attempt to determine the social and economic characteristics of migrants before movement, the reasons for migration, differences in characteristics of migrants and nonmigrants at destination, the adaptive mechanisms used by migrants at place of destination, and the links that migrants maintain with place of origin, including the return movement of some. These efforts often include concern with factors that influence a person's decision to move and the extent to which migration is responsive to policy instruments so that present flows can be changed.

Consistently, authors have concluded that the literature on internal migration in less developed countries is very diverse and that the type of study undertaken often depends much more on the data available than on the relevance of those data for policymaking (e.g., Yap, 1975: 2 ). In many instances, the researcher is not able to examine rural-urban migration directly and must draw inferences from interstate migration studies or from the number of unskilled migrants in large cities. The value of some studies may also be further limited because of small sample size, poor measurement of the relevant variables, problems with statistical estimation, and the inability to make regional comparisons for lack of parallel studies elsewhere. Yet, as Yap (1975:2) has indicated, "the sheer number of studies, particularly when one takes into account those based on census and vital statistics data, does permit certain generalization." 
In the last few years several major studies with a strong comparative focus have been initiated. One is the Comparative Study on Migration, Urbanization, and Development, a series of national migration surveys in the Asian-Pacific region sponsored by the UN Economic and Social Commission for Asia and the Pacific (ESCAP). These surveys, currently in the planning and pretest stage, are intended to fill gaps in census data through a series of comparative studies of the relationships of migration and urbanization to development (United Nations ESCAP, 1979). ${ }^{1}$ They will give particular attention to the demographic and socioeconomic characteristics of migrants and nonmigrants, motives for moving or not moving, and the demographic and socioeconomic consequences of movement in both origin and destination areas. The results are intended to provide information for use in formulating and evaluating population distribution policies.

Another comparative study was undertaken by the International Labor Office (ILO). Its research on migration and employment involves detailed surveys of rural and urban households in India, Guyana, Ecuador, and Nigeria to ascertain the determinants of migration and the interaction between rural-urban migration and socioeconomic change (Oberai, 1978). A third set of comparative surveys, sponsored by the comparative urbanization research project at Brown University, used the same core questionnaire in surveys of migrant adjustment in both urban and rural locations in less developed countries (e.g., Corno, 1979; Green, 1978a). These studies will be described later in the discussion of study design.

The extent of attention given to migration in sample surveys has differed tremendously, reflecting variations in specific purposes. In some, where migration is treated as one of a host of social and demographic background variables, it is restricted to just one or two questions. A case in point is the limited attention given to migration in the core questionnaire of the World Fertility Survey (1975). In other instances, however, migration may be recognized as an important component of demographic change, and the research design and instrument may treat it as one of a series of dependent variables, such as the Thai

1 ESCAP has published a series of manuals covering various aspects of the proposed research, including Survey Organization and Monitoring, Core Questionnaire, Manual for Interviewers, Manual for Supervisors, Manual for Interviewer Trainers, Sample Design, and Manual for Office Editors and Coders. These should be of particular value to scholars contemplating similar projects elsewhere. (See United Nations ESCAP, 1980.) 
Longitudinal Study (Prachuabmoh et al., 1971). Because of the higher priority accorded other components of change, particularly fertility, migration receives less attention in the analysis phase of such studies. The marginal treatment of migration is perhaps best illustrated in population growth studies, many of which are notorious for assessing only birth and death rates, to the complete exclusion of population movement. This is true even though such surveys must generally collect information on in- and out-migration in order to identify changes in household composition correctly as attributable to either births or deaths (e.g., Marks, Seltzer, and Krotki, 1974). Moreover, in some general population surveys the sampling procedures may be designed to insure maximum coverage of fertility; by focusing on women, or on selected areas, the sample design may fail to provide adequate coverage for the identification of migrants. Although information on population movement may be compiled as part of a basic data collection operation, it is frequently not seen and exploited as a valuable source in its own right. Instances where such positive use of population movement data has been made, examples of which will be discussed later, are few indeed.

There are, of course, numerous studies in which migration constitutes the key, and often the exclusive, focus and for which extensive research instruments have been developed. The ILO studies (Oberai, 1978 ) and the proposed ESCAP studies are extreme examples. For these surveys, the interview schedules encompass about 50 pages of questions on various aspects of the migration process and the characteristics of the respondents. In this review assessing the methodology of migration surveys, greater reliance will be placed on studies whose major focus is on migration, although use will also be made of those giving it less attention to illustrate some of the problems as well as the opportunities.

Nonetheless, it is important to stress that the purpose for which a study is undertaken and the priority given within it to population movement obviously have a major influence on the methodology employed. For example, if a survey aims to obtain accurate estimates of the level of various types of mobility, large-scale, representative surveys are needed to insure sufficient cases within the various types and to allow inclusion of different categories of origins and destinations. Expanded coverage of population movement in regular censuses would go far toward meeting this need. By contrast, if the purpose is to gain 
insights on the determinants and consequences of movement for both individuals and places, a series of small-scale, intensive case studies may well be more appropriate. A major problem of migration research is that often the survey design is not related to the purpose of the study or, as suggested earlier, the purpose itself is not explicitly formulated.

It is legitimate therefore to question the need for more migration surveys, given the plethora of studies already completed. In answer, it must be stressed that there is indeed no need for just any type of migration survey. Rather, future studies must be designed to fill particular gaps in information, including studies that attempt to assess intrinsic population mobility rather than arbitrarily defined migration; that provide the optimum opportunity for comparison of findings with completed and ongoing studies elsewhere for developing generalizations and testing theories; and that produce information of direct relevance to policy for particular countries and, through comparative assessment, for other societies as well.

\section{TECHNICAL-STATISTICAL CONSIDERATIONS}

To date a disproportionate number of sample surveys of population movement have focused on single communities or sets of communities rather than entire nations. In part, th is reflects the frequent availability of national statistics on migration through censuses or population registers, even though intensity of coverage may be restricted; in part, it reflects a limited perception of the need for information on population movement and therefore the low priority accorded such analyses by government agencies responsible for national surveys. As a result, migration surveys that have been undertaken have been disproportionately organized by individual scholars or university centers, and have necessarily been restricted in scope. In part, too, the small number of national surveys reflects the very nature of population movement and the kinds of data needed for its full assessment. Because close interaction is assumed between the process of movement and the places of origin and destination, it is essential to be able to relate individuals to particular origins and destinations, or at least to particular types of places. In a national survey, this ability might be severely restricted by a sampling design that would frequently yield very few migrants in individual locations.

In a migration survey, sampling design presents problems very 
different from those of fertility surveys. Whereas a very high proportion of all women bear children, a much lower proportion of either men or women are likely to migrate. Therefore, al though a single community survey and a simple cluster sampling technique will often be adequate for fertility research (while recognizing that levels will vary some), a similar sampling design could be quite inappropriate for gaining general insights into migration patterns and levels. Because migrants may be very unequally distributed-reflecting differentials in opportunities at origin and destination-focus on a single community or even on randomly selected areal clusters within a community may yield atypical results. Migrants may be seriously over- or underrepresented in specific locations and the particular factors that attract them to one specific area or stimulate their out-movement from it may be very different from those affecting movement to or from other areas. The purpose of the study, then, must be considered in choosing a sampling design if coverage is to encompass the types of population needed.

A significant dilemma that confronts migration researchers is the play-off in value between a national or regional survey that can provide an overview of population redistribution patterns and an in-depth or local study that can relate movement to characteristics of particular areas. An in-depth study, by focusing strongly on a particular location or on a limited number of locations, may provide a much greater opportunity to assess the interplay of individual and environmental factors affecting both the decision to move and the adaptation process. Such a narrow focus, however, sacrifices the degree to which findings can be generalized to all parts of the country.

As interest grows in the extent to which population movement can be channeled away from certain types of destination (particularly big cities) to other locations such as small towns or other rural places, studies covering a wider range of areas will be needed. In particular, greater attention to both the place of destination and the place of origin will be called for. As later discussion will document in more detail, a disproportionate number of studies have, by their very local focus, concentrated on migrants at their destinations to the substantial and sometimes complete neglect of the population and the characteristics of the places of origin.

To date, virtually all national surveys of migration seem to have been part of more general demographic surveys, particularly those 
focused on fertility. For example, an analysis of migration in the Philippines (Hendershot, 1976) was based on data from the 1973 National Demographic Survey of the Philippines, which had as its primary goal the collection of data for implementation and evaluation of family planning programs. Although the study encompassed some 8,000 households, the secondary priority given to migration in the original survey seriously affected the quality of the migration data. The National Longitudinal Study of Social, Economic, and Demographic Change in Thailand is another example of a nationwide survey that collected migration information as part of a wide range of questions on social, economic, and demographic variables (Prachuabmoh et al., 1971). In contrast to the Philippine study, the Thai Longitudinal Study did devote considerable attention to migration at the data collection stage. Although considerable use has been made of these materials, however, they have not yet been fully exploited because in coding, higher priority was given to fertility information than to the information on movement.

Like the Philippine survey, the Malaysian Family Life Survey was undertaken primarily to collect detailed information on fertility, but the survey of 1,262 private households distributed among 52 geographic areas of Peninsular Malaysia also collected a rich body of retrospective migration information from all the ever-marnied women included in the survey and from their husbands (Butz and DaVanzo, 1978). The 1966 Special Demographic Survey in Korea provides another example of a national survey encompassing migration; it was undertaken one and a half months after the 1966 Census, together with a postenumeration survey, to obtain supplementary data on fertility, mortality, family planning, and internal migration (Yu, 1972). The treatment of migration was superficial, being restricted mainly to such items as place of birth, place of residence five years earlier, reason for move, frequency of move during the previous five years, and basic background demographic data-and not including information on social or economic variables.

Caldwell's (1969) study of rural-urban migration in Africa attempted to obtain national coverage of Ginana by interviewing almost 14,000 individuals distributed among 45 rural locations. Because the areas included in the study were chosen for their distinct migration characteristics, they do not technically represent a national sample. A smaller urban sample was selected to supplement the rural sample and to 
check on its results. Most of the respondents in the urban sample were selected from Accra, because it was both "close to the University" and regarded as a prototype of developing urban areas in Ghana. The Accra sample of 2,148 persons was supplemented by approximately 1,000 individuals in three other urban areas.

In contrast to the paucity of national surveys, there exists a wide range of studies of individual communities or sets of communities. In some of the reports on these studies, the reasons for selection of the particular community are either explicitly stated or clear from the nature of the problems investigated. For example, Ekanem and Adepoju's (1976) study of two medium-sized towns in Nigeria, llorin and Calabar, was intended to exemplify centers in transition from static to generative industrial status, where migration was playing a key role. Interest in such centers focuses on their potential as alternative destinations that might relieve the pressures of heavy in-migration on big cities. In other studies, however, the decisions underlying the geographic scope and the choice of particular areas are much less clear.

As one might expect, a disproportionate number of studies focus on the big cities themselves, including, for example, Santiago (Elizaga, 1966), Seoul (Green, 1978a), and Lagos (George and Eigefoh, 1973). This reflects recognition of the key role_of migration in their rapid growth, and the assumption that in-migration exacerbates their problems. The Thai National Statistical Office, motivated in part by such concerns, has undertaken an annual survey of migrants to Bangkok (National Statistical Office, 1978). Given the major role which concern with urban problems plays in stimulating research on migrants to urban places, it is not surprising that a number of studies concentrate on particular areas of a single city-quite frequently on squatter settlements or slum areas. Chi and Griffin's (1976) Study of Marginal Settlements in Puerto Limon, Costa Rica focused on a total of 300 respondents distributed among two squatter areas and one resettlement area.

Attention is certainly not restricted to migrants in urban locations, as Caldwell's "national" study of rural areas of Ghana demonstrates. At the other extreme are microstudies-detailed investigations of single villages. Chapman's (1975) attempt to develop a mobility register over five months in two small communities in Guadalcanal to identify all moves is an extreme example, which encompassed 58 households and 331 individuals in all. In many studies, the number of sites is extended to increase either the number of respondents or the 
range of environmental conditions (e.g., Hugo, 1978). However, to the extent that their major purpose is to identify either the conditions leading to out-migration or the number and characteristics of the outmigrants themselves, surveys focusing on rural areas are presented with a particularly difficult set of challenges; because researchers are often not able to interview the migrants themselves, they must rely on other key informants and secondary sources of information (Chaudhury, 1978; Rengert and Rengert, 1972; Visaria, 1969; Stoeckel, Chowdhury, and Aziz, 1972; Conning, 1971).

In short, any attempt to classify existing studies of population movement faces innumerable difficulties because of the extensive range in geographic coverage-from a few cases in a single village, where the interest is on all types of movement, to national surveys encompassing a wide range of rural and urban places, in which movement (defined in a very limited fashion) may be only one concern among many others. The extent of this variation will become more evident as we focus on specific aspects of the research designs used.

\section{Sample design}

One of the most frustrating aspects of attempting to review the literature in order to assess research designs is the limited information provided by authors on specific sampling procedures. Perhaps the most sophisticated sampling procedures followed (for understandable reasons) are those in which the migration component was part of a larger national study. Much greater care seems to be exercised in the sampling design of national surveys because they are often undertaken by national statistical of fices or other national agencies, rather than individual scholars who must depend on their own sampling expertise or on the cooperation of local officials.

For example, in the Malaysian Family Life Survey 49 of the 52 geographic areas were selected by probability sampling methods from among five strata of urban-rural residential units that had been subdivided into primary sampling units in 1966-67; an additional three areas were chosen purposively to give representation to Indians and fishing communities (Butz and DaVanzo, 1978). Based on addresses available for each of the 52 areas, a total of 2,088 dwelling units were selected randomly, from which 1,262 households with eligible respondents were identified by screening. Since the major focus was on fertility, households had to contain at least one ever-married woman under 50 years of age to qualify for inclusion in the survey. 
In Speare's survey of Taiwan, three samples were established: (1) migrants who had moved to Taipei City within the last five years; (2) other persons aged 20-39 living in Taipei City, who had either been born there or moved there more than five years before the survey; (3) persons aged 20-39 living in townships and cities outside Taipei City (Speare, 1976). "All three samples were obtained through a threestage sampling plan. In the first stage, 36 sample towns and city districts were selected from a list stratified by type, location, and size of area. For the second stage, lists of all the lins (small areas of approximately 30 households each) were prepared for each township or city district. Random selections were made from these lists to provide a total of 70 sample lins for Taipei City and 90 for the rest of Taiwan. In the final stage, one in two recent migrants to Taipei, one in four other residents of Taipei, and one in six residents outside Taipei aged 20-39 were selected to be interviewed" (Speare, 1976: 23-4). The method of selecting respondents from within households is not, however, specified.

Sampling procedures for the Thai Longitudinal Study also involved three stages (Prachuabmoh et al., 1971). For the rural sample, the first stage involved random selection of one district from each of the 15 strata into which the eligible districts had been stratified on the basis of the percentage of the population in each district not engaged in agriculture. Within each stratum, the selection probability was proportional to the nonmunicipal population of each district. The second stage involved selecting three villages from the nonmunicipal areas of the district; again, the probability of selection of any given village was proportional to the number of households it contained. The final stage was the selection of households within each village. Thirty-five households was the projected sample size for each village. They were selected randomly from a household list that had been obtained from the district office and updated by the field staff just before fieldwork began. The sampling ratio for each village differed, depending on the total number of households.

The urban sample for the Thai Longitudinal Study was also selected in three stages. After exclusion of four municipal areas, the remaining 112 areas were stratified by region, with Bangkok-Thonburi constituting one region having a probability of selection equal to one. In the other four regions, the municipal areas were ranked in order of population size, and areas were selected with probability proportional 
to size; the goal was to select as large a number of up-country (outside Bangkok-Thonburi) municipal areas as could be handled with available resources. Using a list of blocks already selected for a national sample by the National Statistical Office, the Longitudinal Study selected systematically, with a probability proportionate to the number of households, two blocks from each municipal area. For Bangkok, 32 blocks were chosen, in order that the ratio of Bangkok blocks to total blocks (32:56) would be about the same as the ratio of Bangkok's population to the total urban population. Between Stages 2 and 3, the staff visited the sample blocks to correct and update maps. Households were chosen in Stage 3, and at that time new dwellings, constructed and occupied since the map correction, were identified for inclusion in the sample. Using the constant sampling fraction $(0.0034483) \mathrm{cal}-$ culated to give a total expected sample size of about 2,000 households, interviewers were provided with the sampling ratio to be employed in each block once the total number of households had been ascertained; using a random start, individual households were then selected. Within each household, the head of household and all ever-married women were eligible for in terviews.

Many studies, national and local, have found it necessary to screen before selecting the final sample. Sometimes this procedure was followed to obtain disproportionate numbers of particular categories of respondents. For example, if the study design called for comparisons of recent and long-term migrants as well as natives, reliance on random sampling may have provided inadequate numbers of recent migrants. For this reason, in Green's (1978a) study of migration to Seoul, recent migrants were sampled at twice the ratio of long-term migrants. In the Monterrey study (Balan, Browning, and Jelin, 1973), the universe was defined as the resident male population, $21-60$ years of age, in the metropolitan area. Although a two-stage stratified cluster sample of approximately 1,800 cases was the goal of the study, the sample was designed to overrepresent older men and respondents from upper socioeconomic areas in order to assess the interrelations between migration and social mobility.

In some studies, a more purposive sampling approach has been used. For example, Ekanem and Adepoju's (1976) studies of Ilorin and Calabar relied on prior classification of areas within the two towns as consisting heavily of natives, migrants, or mixed populations. The desired sample of 1,500 households was then divided among the three 
zones of each city in accordance with a predetermined proportion that reflected an estimate of how the population of the city itself was distributed.

Other studies have relied on prior surveys as the basis for selecting samples. For example, in surveying recent migrants to Santiago, Herrick (1965) used a labor force survey to identify respondents active in the labor force, resident in Santiago less than ten years, and not engaged in domestic work. Similarly, Chamratrithirong (1979) used the 1976-77 migration survey of Bangkok Metropolis, conducted by the National Statistical Office, as the basis for his follow-up study of migrants. He selected the first male and the first female migrant identified on each sample block by the NSO Survey, with the added criteria that respondents be aged 15-44 and that no two migrants should come from the same household.

Special interests or conditions may sometimes account for the particular sampling procedures followed. The desire to identify potential migrants led Conroy (1977) to choose his sample from among 1,200 students in terminal classes of primary, secondary, and vocational schools in Papua New Guinea. These were later followed up. This approach offered several practical advantages: the concentration of the potential study population made data collection easier; the study was supported by the school authorities; and follow-up would be facilitated by both the cluster character of the study population and information obtainable from schools on later location of the respondents.

Kim and Lee's (1979) survey in Korea illustrates the use of population registers to sample migrants. Two rural areas in a depressed province and three different types of urban locations were surveyed to assess the adaptation of migrants in the city and return migration. The respondents were selected from registration records that included returnees and identified out-migrants among those born in rural areas. Evidently the registry records were not sufficiently complete to provide an adequate sampling frame for return migrants. Kim and Lee therefore supplemented the list with on-the-spot listings and sampling, but made no claim for the representativeness of the sample. Hugo (1978) selected a sample of 14 villages in West Java on the basis of their prior identification as major sources of migrants to Jakarta and Bandung. First, the major source areas of migrants were identified. Then, lists of out-migration villages in each region were used to select one or more villages with representative movement patterns. By 
contrast, other studies (e.g., Benyoussef et al., 1974) have selected sample villages randomly, and determined urban study sites by the destinations of rural out-migrants.

Lee and Barringer (1978) also used registries to sample in Korea, where they covered three urban locations (primate city, administrative center, and a small regional center). Although their report provides minimal details about sampling procedures, two observations emerge: reliance upon registries evidently led to underrepresentation of squatter settlements and shanty towns; and the need to rely on heads of households as the basis for the sample collections from the registries tended to eliminate newly arrived individual migrants who had not yet established their own households-thus biasing the sample in favor of older, more stable individuals. Such a criterion for selection also has the effect of greatly reducing the likelihood of female migrants' being included in the sample unless they enter it through their relationship to the head of the household. Although it is not possible to ascertain the exact degree, reliance on such lists has the same limitations as reliance on units selected by cluster or other forms of areal samplingrestriction to migrants who have remained in the place of destination and omission of those who have either returned to place of origin or moved else where. In the absence of a concerted effort to identify such out-migrants, either through screening and tracing or through parallel surveys in other locations, there is a danger that responses will be biased in favor of migrants with characteristics conducive to greater stability. Such a bias may favor successful migrants, al though it could well be that it also favors migrants who are marginal and not sufficiently motivated to move elsewhere or to return to place of origin. Indiscriminate reliance on registries and other household or individual listings maintained by village/neighborhood officials could the refore lead to particularly serious errors in identifying the numbers of various types of migrants and their socioeconomic characteristics.

Premi's (1976) study of migration from urban areas is an attempt to cover out-migrants. He relied on a 25 percent sample of the 1971 Indian Census listing to identify household units, from which he solicited information on out-migrants from relatives. He also sought information from neighbors on households ( 39 out of 446) that no longer existed following out-migration, but found that neighbors could not give adequate information on the out-migration of total households. An earlier listing, such as a census, promises a potential universe from which 
identification of out-migrants can be made; Premi's experience, however, testifies that learning more about these out-migrants will be difficult unless they leave close relatives behind. Those who do may not be representative. This problem may be even more serious when the sample of out-migrants is selected on the basis of screening existing households by means of a sample survey (Visaria, 1969).

Several other considerations about sampling procedures warrant citing, such as the age range encompassed. Some studies have relied on a general sample of the population, covering the full age distribution. This procedure probably leads to inadequate numbers in many cells, since movement tends to be concentrated in selected age groups. As mentioned earlier, some studies have at tempted to overcome this problem by oversampling in those age groups in which mobility occurs less frequently (Balan, Browning, and Jelin, 1973). Others have screened their potential samples for age and restricted the final selection to age groups characterized by the highest rates of mobility. They thus obtain a more homogeneous sample that is concentrated in age groups likely to have a disproportionate number of recent migrants.

This approach has the serious limitation of excluding migrants who moved earlier and might serve as a useful standard against which to measure the mobility, selectivity, and adaptation of more recent migrants. Yet, the long-term migrants in these restricted age-group samples may be atypical, since they would have had to arrive at younger ages and would contain a larger percentage of persons socialized in the place of destination. Furthermore, if substantial numbers of the original migrant cohort had either moved again or died, those covered in the survey could be atypical of the entire group. To the extent that many samples of migrants are derived from fertility surveys, they are generally age-selective within the range of 15 to 44 years, which tends also to be characterized by peak migration. If husbands qualify for inclusion under this criterion, they may be somewhat older. The Malaysian study estimates, for example, that husbands were, on the average, about five years older than wives, who were eligible on the basis of being ever-married women under age 50 (Butz and DaVanzo, 1978). Again, however, the need for caution in basing a sample on selected age groups must be stressed; groups must be selected not only because studies elsewhere have identified individuals in the particular age range as the most mobile, but also because there is convincing evidence that this is true of the study area under consideration. This 
caution is particularly appropriate to studies designed to test the ex-tent and character of nonpermanent migration, where age patterns and sex selection may vary considerably from those of more permanent movement.

Another sampling consideration is the choice of respondent within the household. As suggested earlier, practices have varied considerably and for quite different reasons. Surveys that are a by-product of fertility surveys obviously rely upon the ever-married woman as the key respondent, although sometimes she may be asked about the mobility experience of her husband or he may be interviewed separately. Even when the focus is primarily on migration, several alternatives are open and many restrictions are often imposed. Reliance on particular data sources as the basis for the sampling frame (for example, household registers) may dictate that the head of the household be the respondent, although this need not necessarily be so (Green, 1978a). Other members of the household can be selected, either if lists cover all adults, or if provision is made for random selection from within a unit chosen initially on the basis of identification of the head of the household.

When area sampling is used, as opposed to readily available lists, the investigator has more choice and considerable variation exists as to the options followed. Frequently, all eligible adults in a sampled household are regarded as qualified respondents, with the minimum age for qualification generally between 15 and 20 . In such instances, either all adults in the household are interviewed (a rare situation) or information on the mobility of all adults is obtained as part of the household roster; particular individual members are then selected for more intensive interviews through use of some predetermined criteria or sampling procedures based on the Kish selection table or some variation of it. Some studies (e.g., Balan, Browning, and Jelin, 1973) restricted respondents to males, but many selected respondents of either sex.

Surprisingly little consideration is given in published reports to the rationale for selecting a particular category of respondent. Only in more recent-and usually theoretical-treatments has concerted attention been given to who makes the decision to migrate and whether, it is more appropriate to choose the head of the household as the major respondent rather than randomly select one or more adult members or to cover the household as a unit. But if the head of the household is not the appropriate respondent, who, then, should be interviewed? 
Should screening to assess the decision-making process precede respondent selection for in-depth in terviews?

\section{Sample size}

In view of the differences already observed in sample design, in geographic scope of surveys, and in selection of respondents from within sample households, it is not surprising that the size of samples available for analysis varies widely among the studies reviewed here. Since some studies do not specify the number of cases, a categorical range is not possible. On the whole, sample size ranges from a few hundred in studies of one or two villages or one or two areas of a big city, up to more than 10,000 in national or comparative studies. Among studies of a big city or several villages or urban areas, however, sample size falls within a surprisingly narrow range-between 1,500 and 2,000 households or individual respondents. Although the reason for using this particular sample size is not always given, it is frequent enough for one to conclude that it represents "a sample size judged adequate for our purposes" (Balan, Browning, and Jelin, 1973). Concern about costs and logistics, coupled with the realization that sufficient cases are needed to yield an adequate number of migrants, as well as adequate numbers in specific subcategories of migrants, generally dictates the size of the sample.

In many instances, the lack of logistic support from a government agency has necessitated the use of smaller samples. Small numbers sometimes help explain the corollary restriction of a sample by sex and/or age to more homogeneous groupings (Speare, 1971; Corno, 1979). Clearly, however, the number of cases must be carefully evaluated in relation to the purpose of the study and the nature of the study population. In rapidly growing urban places, a high proportion of the population is likely to be migrants, but even this will vary, depending on the definition of migration employed. For some locations, if a lifetime definition is used, migrants may well constitute as much as 80 percent of the adult population and especially of selected age groups. In rural areas, in contrast, these percentages are likely to be much lower. Moreover, the volume of persons identified as movers from rural areas will obviously differ according to the time reference used. Given extensive short-term and seasonal migration, a definition that insists on continuous absence for at least 12 months will identify fewer migrants than one drawing the line at six months, and certainly 
far fewer than studies that regard movers as anyone absent for as little as one night (Mantra, 1978). The definition to be employed should be an important consideration in determining overall sample size.

\section{Frequency of survey}

The very nature of the migration process argues strongly for repeat surveys, both to identify out-migrants from and in-migrants to a community and to allow following migrants to their destinations to assess the adaptation process and the extent to which additional movement results from failure or success. Furthermore, longitudinal surveys are needed because single-round surveys cannot be expected to obtain the data necessary for full assessment of the migration process. Singleround surveys in places of origin are unable to interview out-migrants and must therefore rely on other informants to identify individuals who have moved away during a specified period. Most of ten, these in: formants are close relatives, usually members of the same household as the migrant. As noted in Premi's study (1976), however, when the entire household has out-migrated, the possibility of obtaining accurate and comprehensive information from responsible informants is, at best, very much reduced.

In single-round surveys focused on destinations, a different problem arises. Here, migrants interviewed, regardless of the definition used, include only those who still reside in the community. Those represented may be atypical of those who entered earlier and left before the survey was undertaken. Particularly for studies that focus on migrant adjustment and on the impact of migrants on destinations, the inability to include those who have either returned to place of origin or moved on to new destinations must inevitably raise doubts-about the extent to which the behavior and contribution of those who remain reflect the full impact and significance of migration, and whether their experience is typical of that of all in-migrants.

Practical considerations frequently dictate that migration sample surveys be single-round surveys, for several major reasons. Undoubtedly, cost considerations are important, particularly when so many surveys are undertaken by individual scholars and small research institutions rather than by government agencies. Perhaps even more important is the complexity of the research operation that would be required to follow respondents. Migration itself contributes to loss of follow-up in longitudinal surveys, especially if respondents have records of prior 
migration since there is a greater-than-average probability that such individuals will move again (Chamratrithirong, 1979). Any effort to maintain contact with respondents in a sample is a challenging endeavor, and the difficulties are compounded in less developed countries where reliance on devices used in more developed countries to maintain contact with respondents (e.g., depending on the post offices for forwarding addresses and other forms of written communication) is less feasible. Judged by the literature revie wed here, very few studies to date have had either the resources or the stamina to pursue such a design. Thus, by far the greatest number are single-round surveys in which data on migration are obtained either directly from the migrants or from members of their immediate households.

\section{Retrospective data}

Single-round surveys of the migration behavior of respondents or members of their households must necessarily use a retrospective approach to the measurement of migration since the move has already occurred by the time the survey is undertaken. The researcher must therefore decide how to collect the retrospective data and what points of time to use for reference. Wide variation characterizes both the types and uses of retrospective data collected. Questions, modeled heavily on census procedures, usually cover place of birth, residence at a fixed prior date, place of last previous residence, or duration of residence and are asked of respondents and/or members of the household. Noteworthy, perhaps, is the core questionnaire prepared for the World Fertility Survey (1975), which illustrates an alternative measure by its one question on migration: "In what kind of area did you live mostly when you were growing up, say to age 12 ? Was it in the countryside, in a town, or in a city?" Clearly, the purpose of such a question is different from those worded in terms of birthplace or residence at a fixed point in time.

Unfortunately, evidence in the literature is inadequate to ascertain the extent to which investigators consider carefully the most appropriate retrospective question to be asked if only one or two such questions are to be used to classify an individual as a migrant. What is clear is that the volume of migration observed in any given country is greatly affected by the nature of the survey questions. Answers are obviously colored by what the respondent considers to be his or her usual place of residence. Beyond this, if population movement is 
measured on the basis of the question "Where were you born?" the amount of movement recorded will generally be considerably greater than if the question were "Where were you living five years ago?" The older a person is, the more opportunity there has been to move in the interval between birth and the time of the survey. Place of birth tabulations will therefore generally identify more persons as migrants, in the absence of a significant retum movement to the place of origin, than will questions about place of residence at a fixed prior date. With the possible exception of a duration of residence question-"How long have you been living in this place?"-most survey questions on migration are likely to underenumerate the total volume of movement during any given period because the nature of the question does not provide information on moves made in the interval between the time references used. This shortcoming affects the place of birth question in particular.

With retrospective data, another basic concern is about the rural/ urban definition of place of origin. Respondents are of ten unable to describe their place of origin as rural or urban, since the character of many places has changed over time and what may have been rural at the time of out-migration may be urban at the time of the survey. Moreover, in many countries, the definition of what constitutes an urban or rural place is often not clear-cut. For these reasons, reliance upon respondents may lead to considerable response error, particularly where urban boundary lines are not meaningful to respondents and where changes have been frequent.

In recent years, noticeable efforts have been made to improve the quality and quantity of retrospective data on population movement both through the kinds of questions asked and through efforts to cope with the conceptual problems noted earlier. These have taken several forms. Paralleling the heavy reliance on pregnancy and marriage histories in fertility research, residential histories are being used by a growing number of scholars to re-create the migration experience of respondents and overcome the limitations inherent in using one or two traditional retrospective census-type questions. Beginning with either birth or a key point in the life cycle, related usually to completion of education or entrance into the labor force, respondents are asked to indicate all places in which they have lived for a specified minimum number of months. The detail requested varies from one study to another as does the specificity of the locational information. 
Appendix 1 shows the residential history form used in the Malaysian Family Life Survey, together with the questions asked. The interviewer begins by asking the respondent whether or not he or she has ever lived in any place other than the place of interview for three months or more, and, if so, proceeds to identify where the individual was born and where the individual was living at the time of the fifteenth birthday or at the time of marriage if that preceded the fifteenth birthday. From that point on, every shift in residence is recorded until current residence is reached. For every move, the respondent's age at the time and the year and month are recorded. In this way, within the respondent's ability to re-create the residential history successfully, a complete record of all changes in residence is ascertained, allowing exploitation of these materials in conjunction with other histories obtained for the individual. This questionnaire does not ask the reason for each move, but only for the last move.

A fuller migration history is illustrated by the form used in Taiwan by Speare (1976; see Appendix 2), which provided the model for the comparative urbanization studies undertaken by the Population Studies and Training Center of Brown University. Speare started his history with the time when the respondent finished junior school, left school, if that was earlier, or at age 15 if uneducated. A minimum of six months' residence in a particular location was the criterion for listing. In addition to place and length of residence, the Taiwan form ascertained the number of different dwelling units of the respondent in particular cities or towns; who the head of the household was for the longest period of residence; what other adults lived in that household; and whether the family owned or rented the dwelling unit. Occupation and reasons for leaving were also included. In contrast to the Malaysia form, the Taiwan study attempted to obtain reasons for moving for each change of residence. This procedure provides a richer body of data for discovering how various causal factors operate to affect mobility patterns as the individual moves through the life cycle, and also for relating the reasons for choosing the particular types of location the individual moves to or from. It also allows assessment of the extent to which the same motivating factors operate across an individual's life cycle; exclusive reliance on the reason for the last move could give a distorted picture.

Introduction of occupation into the residential history is the first step toward development of a life-cycle matrix. Various studies have 
obtained occupational histories, either because they were specifically interested in job mobility or to reflect the key role of job changes in residential mobility and the desirability of concurrently assessing changes in residence and changes in jobs. Collecting mobility and occupational histories within a single format facilitates such analysis, although Speare's format does not, in the full sense, represent a residential-occupational history since it calls for information only on the job held longest at a particular place of residence; it may therefore omit a large number of jobs held for shorter periods at a single location.

The life history matrix itself has not been used as extensively as the residential history. Yet, experience to date in Mexico (Balan et al., 1969), Colombia (Como, 1979), and Thailand (Lauro, 1979) suggests it to be a promising means of obtaining precise retrospective information on mobility behavior. As a concisely formulated instrument for ordering, stimulating, and cross-checking an individual's recall of personal life cycle events, the life history matrix can encompass information on a wide range of demographic variables. For example, the Monterrey study (Balan et al., 1969) used a life history form to obtain data on migration, education, marital status, family formation, health impairment, work, and income (see Appendix 3). As the life cycle changed, the emphasis on questions asked shifted, beginning with place of work, and moving to education, then mobility. Migration was generally related to the other changes. The Monterrey experience suggests that the life history format stimulates more accurate recall than do other types of questions, and that it also has the great advantage of creating closer rapport with the respondent.

A major advantage lies in the ability to check inconsistencies during the interview; but the greatest advantage is that all of the events for which data are collected can be more easily entered into the analysis to assess their interaction. This advantage is especially important for assessing mobility, since it permits much more meaningful analysis of the relation between movement and other life cycle events and changes in environmental conditions (see Appendix 4). Moreover, if changes in residence are identified for short intervals with some degree of success (whether this can be done remains to be checked qualitatively), the life history matrix has the further advantage of allowing assessment of changes in types of migration in relation to both the life cycle and a host of other variables. In short, the life history matrix seems to have particularly strong potential as a mechanism 
for obtaining retrospective information on population movement, because it allows more comprehensive coverage together with linkage of the movement to other life events. Moreover, it has, as Lauro (1979:295-6) put it, "a distinct advantage [in] that interviews could be relatively unstructured within the context of highly structured data recording and coding procedures."

Although the life history matrix seems to be particularly promising because of the wealth of material it collects, the potentially greater accuracy of the information, and the opportunities to link residential and other changes, to date experience with this approach is still limited; particularly challenging is the need to develop methods that atlow fuller exploitation of the data. In studies completed so far (Balan, Browning, and Jelin, 1973; Lauro, 1979; Perlman, 1976), only a small fraction of the material collected has been analyzed, of ten not going beyond simple cross-tabulations that do not take advantage of the opportunities provided; the longitudinal data available would permit analysis of the relations among demographic processes, and, in turn, their relations with changes in the social and economic environment. Fortunately, growing attention is being given to the methodological concerns associated with the life history approach to migration research (Pryor, 1979). The new methods, coupled with the increasing use of such an approach in ongoing or planned surveys, should provide new opportunities to test the value of the life history matrix for the study of population movement.

The attempt to obtain retrospective data as part of a migration survey is not restricted to residential histories. One of the major reasons for incorporating retrospective questions into a survey is to assess the characteristics of the migrant, the household, and the community before migration occurs, in order to compare those situations with conditions and characteristics after migration and assess whether migration has led to positive or negative changes. It is partly for this reason that the residential history and especially the life history matrix include a wide range of variables subject to change in the course of the individual's life cycle and associated with mobility itself. By having comparable data for the life cycles of nonmigrants it should be much easier to evaluate whether changes characterizing migrants are attributable to the migration process, or simply reflect changes in more general conditions in the community and society at large. Ideally, such comparisons with nonmigrants would have to include both those at the destination and those remaining in the place of origin. 
In collecting life histories from respondents, the proposed ESCAP survey core questionnaire makes some distinction between "longterm" and "short-term" residence. The individual respondent is asked to indicate all places lived in since age 15 for at least one year. In addition, the respondent is asked to identify all residences of shorter duration if the move to that location was for reasons of "work, to look for work, or to study" (United Nations ESCAP, 1980, Manual II). This distinction is based partly on the assumption that individuals have greater difficulty reporting short periods of residence, especially those that occurred early in their lifetime. It also assumes that work-and study-related moves are probably easier to remember and of greater policy relevance. Information on all such moves is collected, therefore, regardless of the length of residence in any given location. For each residence, the life history goes on to ascertain the economic activity of the respondent and education, marital status, and fertility, as well as up to two changes per year in each.

For all last moves, under either the long-term or short-term criterion, additional information is obtained through questions on the reasons for the move, decision making related to the move, accompaniment by other relatives at or following the move, job search and assistance received in adjustment, links maintained between destination and place of origin, and comparisons of status and satisfaction before and after the move.

In further recognition of the importance of both short-term residence and economic activity, as well as other forms of movement, the ESC.AP questionnaire augments and complements the detailed life history data by collecting detailed information on mobility and other activities during the 12 months preceding the survey, regardless of their duration. This includes information on occupation and industry, the location of the job, residence, journey-to-work time and means of transportation, the full- or part-time character of the job, and the income derived from it. In addition, information is collected on circular movement during the preceding 12 months for other regular jobrelated purposes; here the purpose of the move, its destination, and its frequency are ascertained. Availability of these data will allow in-depth assessment for the one-year period of all forms of movement, including migration, circulation, and commuting for job and nonjob purposes. Together with the life history data, the in-depth documentation of recent mobility patterns allows for comprehensive attention to all forms 
of movement and assessment of these in relation to other characteristics of the respondent and the various places included in the survey.

Unfortunately, such rich comparative data on the migrant's condition before and after the move are seldom collected. In their absence, some authors have attempted to re-create the "before" situation by making concurrent studies of the areas of origin. In Speare's (1972) Taichung migration survey, for example, migrants were males who had registered and moved to Taichung from one of the four surrounding counties during 1966-67. To obtain fuller insights for comparing migrants and nonmigrants and into the pre-migration situation, the study included a control group of male residents of the four counties from which the migrants had come. The questionnaire tried to elicit all factors entering in to the cost-benefit equations that Speare was trying to evaluate.

\section{Repeat surveys}

Under ideal conditions, adequate information on migration should be collected projectively rather than retrospectively. Yet few studies have been able to follow such a design. Of those that have, a disproportionate number have been population growth surveys, in which information on migration is collected not so much because of a major interest in migration, but rather as a basis for obtaining accurate estimates of births and deaths and the appropriate base populations for calculating vital rates. Repeat surveys-in which the same individuals are traced over time, with attention to mobility as one of the major components-are rare and therefore provide limited experience for assessing either the difficulties or the advantages that may be encountered.

Repeat surveys can take either of two forms or a combination of both: (1) repeated, independent surveys of the same area to assess change through comparison of the cross-sectional results obtained from independent surveys; (2) individual panel follow-up surveys in which the respondents sampled in the initial survey are reinterviewed to establish changes in household composition; and (3) a combination in which the original sample is reinterviewed, with new units added to provide representation for new households created or entering the area since the last interview and to replace households not available for reinterview.

It is very rare indeed for repeated, independent surveys of the same 
area to be undertaken for purposes of assessing migration. Perhaps the data collection efforts most closely resembling such an operation were the 1968 and 1973 National Demographic Surveys of the Philippines. In both, information was collected on population flows. Unfortunately not all the reports describing the surveys and specifying the migration material contained in them are readily available. From those reports that were available, it appears that in formation on migration was not comparable from one survey to another. In the 1968. survey, respondents were classified by province of birth and of residence in 1960 , 1965 , and 1968 , which allows determination of residence at four points in time and specification of three changes in residence (Bello Feitosa, 1975). In 1973, according to Hendershot (1976), migration could be determined only by comparison of residence in 1973 with birthplace. Moreover, because of the classification system used, some persons who moved were classified as stayers because they had not changed type of residence at the two points in time (e.g., movers from rural to rural places were not considered migrants).

Another example of a repeat survey is the study of six villages in Maharashtra State, India (Dandekar and Bhate, 1975). The initial survey was undertaken in 1954, but because of a shortage of qualified personnel, most of the data collected then were not analyzed. A second survey, conducted in 1965-66, was designed specifically to take advantage of the earlier data and used a very similar, though expanded, questionnaire. All households in the six villages were interviewed in both surveys, and attempts were made in 1965-66 to account for every individual enumerated in 1954, as well as to identify all newcomers to the villages. The authors indicated that the only problems arose in cases where the entire household had been dissolved because of out-migration. Nonetheless, some information on these migrants was available from the first survey and some could be gleaned from neighbors still in the village. Migration was not specifically defined by the study, but by implication (apart from births and deaths) anyone who was enumerated in 1954 but not present in 1965-66 was considered an out-migrant, and anyone interviewed in 1965-66 but not resident in the villages in 1954 was an in-migrant.

A more common form of repeat survey at tempts to test dual record systems. In one such effort in the Philippines, a baseline survey of rural and urban samples totaling about 91,000 persons was undertaken in 1971 in Cagayan de Oro City and surrounding areas (Madigan and 
Herrin, 1977). A continuous recording system involving bi-monthly visits was established. Concurrently, a survey scheduled to be taken every six months was initiated. After the first two survey rounds, subsampling was used. The two systems operated completely independently. Migration was defined as a move across the boundary of any sitio (a small quasi-political subdivision; there were 123 in the rural areas covered but only one in the urban area-the city itself). To qualify as a migrant, a person had to intend to stay in the new locality or away from the old locality for 90 days. The study thus attempted to include short-term migration and multiple moves within the measurement system. Each migrant was covered by both the recording and the survey systems for in- and out-movement. The survey collected reasons for migration, origin and destination, intended length of stay, and selected demographic characteristics. Evaluation of the results suggests that migration, especially out-migration, is less likely to be detected by the survey system than by the recording system. The survey was also unable to pick up as many moves of short duration or as many multiple moves by the same individual as the recording system. Although a major limitation of this approach was seen to be its narrow geographic scope, the data do provide insigh ts into the varied kinds of migration and their patterns for the area, and can therefore provide administrators with important knowledge of the dimensions of movement.

Since the first dual record system was established in 1962 in Pakistan (Linder and Lingner, 1975), its value for reporting births and deaths has been reported in a number of other countries (Chanlett and Fichet, 1976). Its value for migration data lies mainly in the records compiled from the repeat household interviews in the test area. Information on in- and out-movement is obtained to help ascertain accurately the factors accounting for population change and to provide data on the base population for computation of crude and specific rates (Marks, Seltzer, and Krotki, 1974). In several studies, even though the data necessary for evaluating the role of population movement in demographic change have been collected, their use for analytic purposes has been very limited and sometimes nil.

The Liberian Population Growth Survey (Liberia: Ministry of Planning and Economic Affairs, 1972, 1973) made fairly extensive use of migration data collected from a national sample of every household in 100 villages and 100 urban blocks. The dual system consisted of (1) 
monthly visits to each household by local resident registrars to record changes, and (2) staff-supervised checks every six months. The monthly checks consistently recorded more migration than did the six-month enumeration, but, regrettably, field verification was of ten not possible because the migrants were not present and neighbors could not give the information. For the country as a whole, in- and out-migration did not balance, probably because urban migrants were more likely to occupy formerly vacant land, which would not have been included in the original sample. Rumford and Greene (1979) used the Chandrasekar-Deming formula to assess the accuracy of the migration records by using the data on age, sex, reasons for move, length of stay, and classification of origin and destination as rural or urban. They found that the rate of coverage for any combination of variables for in- and out-migration was always greater for the monthly enumeration than for the semiannual, and the differences were always greater in urban areas.

The 1961-63 Multipurpose Sample Survey of Morocco was designed mainly to get estimates on births and deaths, but information on migration was obtained between rounds one and two as a byproduct of efforts to account for discrepancies between results. Analysis suggested that there were as many cases of error as of mobility and that erroneous inclusions or exclusions of cases in rounds one or two could affect the accuracy of the mobility estimates. In part, the problems arose from inadequate information as to how permanent the absences recorded in rounds one or two actually were. This survey collected no information on origin or destination. Its main value lies in the argument its author presents in favor of developing a survey design with special attention to migration (Sabagh, 1969).

The Statistical Centre of Iran (1976) has undertaken longitudinal national surveys that have identified out-migration. Based on seven rounds of interviews conducted at six-month intervals, the authors of the reports indicate that "important for the success of the survey is the interview technique in which the in terviewer... reads the name of each person on record and asks whether he or she is still living in the household or has moved out or died ... he [also] asks whether there are other persons living in the household, either newly arrived residents, newborn children, or persons previously omitted" (Statistical Centre of Iran, 1976:4). This description gets to the heart of this form of repeat survey. Although the data collected in population growth surveys 
seem promising for the opportunity they provide for gaining insights on the volume and direction of movement, perhaps their greatest value for migration lies in the chance to assess the accuracy of survey data as opposed to more frequent recording of in- and out-movement. Available evidence raises some serious doubts about survey accuracy, especially as related to short-term migration. Fuller exploitation of these data for methodological purposes and for their potentially wider use seems very much in order.

The Longitudinal Study of Social, Economic, and Demographic Change in Thailand (Prachuabmoh, Knodel, and Pitaktepsombati, 1973) was one of the most ambitious efforts to pursue longitudinal research. The first rounds of that survey (rural in 1969; urban in 1970) have already been described. For the second rounds (rural in 1972; urban in 1973), interview teams returned to all but one of the original sample areas to interview the following responden ts: (1) all former respondents who could be found; if a respondent had moved from his former address but still lived in the general vicinity, an attempt was made to find and reinterview him; (2) new residents in households that had been part of the first sample, as long as they qualified for inclusion using first-round criteria; (3) appropriate residents of a supplementary sample of new addresses chosen from a list of houses not included in the list used to select first round samples. Most of these were new constructions, but some had been erroneously omitted from the first round.

The longitudinal samples were composed simply of all former respondents who were reinterviewed. The second-round cross-sectional samples consisted of all residents of houses included in the first round plus residents of new houses selected. The interview schedules used for the second round were modified versions of the first-round questionnaires. Most questions were retained for the sake of longitudinal analysis.

In some villages, changed conditions made it difficult for interviewers to reach certain households, and as a result some were missed or interviews had to be conducted at a central location. In urban places, clearing and construction caused some loss to follow-up; to the extent that new construction was much greater than in rural areas, the cross-sectional segment of the follow-up survey in urban places had to be considerably expanded. The greater density of urban housing made it more difficult to locate former sample units, particularly in instances 
where house-numbers had been changed by the municipalities. This problem was particularly pronounced in slum and squatter areas. The greater frequency in urban locations of "temporary" residences usually associated with construction work also presented challenges to followup.

In all, about 80 percent of the rural panel of both household heads and eligible women were reinterviewed in the second round of the longitudinal study. Of the 199 cases lost to follow-up (excluding those in one district intentionally excluded because it had become politically sensitive), 116 were lost due to out-migration, by far the single largest factor. In the urban sample 62 percent of the household heads and almost a similar proportion of the eligible women were followed up. This much lower follow-up rate reflects both the considerably greater difficulty encountered in urban places because of the problems associated with identifying the original household units, and the greater degree of migration and intraurban residential mobility characterizing towns and cities. Of the 827 cases lost to follow-up among household heads, 549 were attributable to residential mobility and migration. To the extent that these out-migrants are atypical of the total population, their loss contributed significantly to biasing the results of the second round, especially in urban places. The system of replacing these losses with new respondents helped to cancel some of this bias, but a full evaluation of the characteristics of the replacements compared to the losses is needed before the conclusion can be accepted that the crosssectional nature of the samples was preserved in the second rounds:

Since residential mobility (Goldstein, 1977:712) constituted the most important reason for loss to follow-up, the effects of such losses take on added significance when migration is a key variable in an analysis. This concern is reinforced by the fact that the rate of loss was greater for migrants than for nonmigrants and greater for recent than for long-term migrants, even with controls for other key variables. Compounding this selectivity, the losses were greater among those of lower fertility; and the fertility of the migrants who were lost, especially the recent migrants, was lowest of all. The selective loss calls for caution in using the panel data to assess either intersurvey mobility or the relation between migration status and fertility among women reinterviewed in the second urban round.

In 1979, what might be considered a third survey round of the Thai Longitudinal Study was undertaken. By this time, ability to follow up 
the initial sample of respondents was further reduced, because of the long time lapse between rounds and the lack of any systematic attempt to maintain contact with respondents. The possibility of assessing changes over a ten-year period, especially in fertility behavior, was nonetheless sufficiently attractive to lead to the decision to draw part of the sample of the 1979 National Study of Family Planning Practices, Fertility, and Mortality from villages and city blocks included in the 1969-73 Longitudinal Study. Some of the respondents from the Longitudinal Study sample were thus reinterviewed, but new respondents in these areas were also contacted. To date, the migration data collected in the National Study, which were similar in content to those obtained in the earlier rounds of the Longitudinal Study, have not been analyzed or evaluated sufficiently to allow determination of how representative the combined sample is. Such an evaluation may not be feasible until the results of the 1980 Thai Census become available. It seems likely that respondents belonging to the original Longitudinal Study sample would bias the results toward higher rates of stability, given their availability for follow-up interviews. This, in turn, would affect the overall representativeness of the total sample.

The Malaysian Family Life Survey was conducted in three rounds extending from August 1976 to August 1977, but it was not designed as a longitudinal study (Butz and DaVanzo, 1978). Rather, the three rounds were designed to collect different kinds of data from different respondents and to update some of the information collected in the previous round. Questions were grouped according to desired respondents and reference periods rather than the conceptual similarity of groups of questions. As already indicated, the major sources of data on migration were retrospective histories. As best as can be judged from the preliminary publications, no organized attempt was made to assess migration between the first and third rounds, although it was relevant because of the need to follow up the same households. Personal communication with the organizers of the studies suggests that respondents continued to be interviewed as long as they remained within the sampling areas, even if they had changed residences within these areas. Of the total sample of 1,440 cases, 38 are indicated as lost to follow-up because of movement. This considerably smaller loss compared to the Thai Longitudinal Study could largely be attributable to the shorter time involved and the more frequent contacts.

The National Statistical Office of Thailand, recognizing the 
importance of migration in the population growth of Bangkok and the need for information on such movement for planning purposes, began in 1973-74 a series of annual studies of in-migration. The initial survey and those conducted in the following two years used a single-stage sample design. The migrants who were initially identified in a screening operation were not interviewed, however, until after a lapse of six to seven months. The experience with this procedure was very poor. For example, in November $1975,4,994$ households were identified as containing in-migrants, but at the time of interviewing, in June 1976, only 1,626 households could be identified as containing the same inmigrants as reported seven months earlier. Of the remainder, 1,132 households had moved in their entirety; 955 reported they had never had in-migrants; and no contact could be made with migrants in 1,282 of the households (National Statistical Office, 1977:25). In recognition of this problem, beginning in November 1976 migrants were interviewed at the same time as the screening survey (National Statistical Office, 1978).

Data from that survey were used, in turn, by Chamratrithirong (1979) as the basis for a longitudinal study. He selected a sample of 498 male and female migrants aged 15-44, and supplemented it with a sample of 300 nonmigrants. An initial in terview was followed by letters every month for a period of five months with questionnaires to be returned. This technique achieved a response of approximately 40 percent from the migrants, and 79 percent from the nonmigrants. Six months after the first contact, those migrants who were identified as not having moved in the interval were reinterviewed; the original nonmigrants were not reinterviewed. The mail questionnaires returned indicated that 69 of the original in-migrants had moved again. These individuals were not reinterviewed. Reinterviews were thus attempted of those migrants who had failed to return any of the monthly questionnaires and those who had returned the questionnaires but continued to live at the same address as at the initial interview. The reinterviews, together with the mailings, were able to account for 90 percent of the original migrant sample, although in some instances, when persons could not be interviewed directly, information about their onward movement was obtained from other members of their household or from neighbors. Chamratrithirong's experience with this methodology indicates the very low response level that can be expected from a mail questionnaire. It also confirms that neighbors can be useful in providing information on onward movement. 
As suggested earlier, a number of studies of individual villages have relied heavily on longitudinal designs as a basis for assessing mobility behavior, particularly when efforts have been made to encompass the full range of movement from daily commuting for purposes of work, shopping, and schooling to permanent migration. Chapman's (1975) study of Guadalcanal and Mantra's (1978) study of Indonesian hamlets are examples. In both, variations of mobility registers were maintained, for five months in the former and nine months in the latter. Records were kept of individuals who left the community for more than a minimum number of hours ( 24 for Chapman; six for Mantra), as well as information about origin and destination, reasons for the move, and return movement. Such longitudinal designs can be implemented only in villages where "control" of the exits is easy and the total number of persons to be observed is comparatively small. Yet such studies are important because of the insights they provide into the wide range of movement that occurs, in terms of interval, permanency, purpose, and destination.

A final variation on the longitudinal design is that exemplified by Conroy's (1972, 1975, 1977) and Curtain's (1975) studies of Papua New Guinea students in terminal classes of primary, secondary, and vocational schools. In interviews in 1968 information was collected on employment aspirations and expectations with respect to settlement area after leaving school. The primary school students were followed up by mail in 1969-70. By March 1971, half had left their villages. In June 1972, 50 responden ts who had moved to Port Moresby were contacted and interviewed. A further attempt in January 1974 located a great majority of the original sample. This study obviously focused on a very select segment of the population and dealt more with future mobility which was then followed than with past movement. Whether it would be possible to execute a parallel design in other developing countries remains to be demonstrated.

\section{Identification of out-migrants}

Given the growing interest in the relation between migration and rural development, much recent migration research has emphasized the importance of assessing the impact of out-migration and return migration on rural areas. Both the earlier concem with the contribution of migration to rapid urban growth and the greater ease of conducting sample surveys of migrants at destinations probably account 
for the much greater stress placed on studying migrants to urban places. The interest in rural out-migration poses particular research challenges. Aside from the initial problem of ascertaining who the outmigrants are, especially if they leave no relatives or close friends behind to report their out-migration, are the difficulties of ascertaining why these migrants moved, where they presently are, and how well they have adapted. These difficulties have been met in various ways.

The dual record systems discussed earlier in conjunction with longitudinal study designs provide a mechanism for assessing the extent and characteristics of out-migrants from a particular area. To the extent that such a system is designed to focus on migration, it can collect information on destination, reasons for move, intended length of stay, and relevant background characteristics (Madigan and Herrin, 1977). It holds particular promise because the out-migration is likely to be detected close to the time at which it occurs (although there is some evidence to suggest that short-duration and multiple moves may be missed). The information about destination, motive, and intent to stay should be more accurate. Moreover, since a dual record system can obtain background characteristics from the out-migrant directly before the move, the value of the data will be enhanced. Much more experimentation needs to be done, however, with such materials. Only a few dual record systems have focused on migration directly or exploited the data obtained to the maximum degree possible (e.g., Madigan and Herrin, 1977; Rumford, 1972).

Perhaps the study that deals most thoroughly with out-migration is that undertaken by Caldwell (1969) in Ghana. Recognizing that the important decisions about migration must occur at the rural end of the process even if the major motive for migration is the "pull" of the town, the demographic unit attached to the University of Ghana, with which Caldwell was affiliated, decided that the chief effort at studying rural-urban migration should be put into an examination of the sending area. Concurrently, smaller and nearly identical surveys were to be made in one or more of the receiving towns, as a check on the main survey and perhaps to gauge changes occurring in the migrants. It was also decided that the survey should supplement the 1960 population census and postenumeration survey and should therefore collect either intricate quantitative data, which censuses cannot handle, or questions of opinion and experience, which censuses choose not to handle (Caldwell, 1969:16). Finally, on the basis of pretests indicating that 
comparatively few families ever migrate in their entirety, the decision was made to conduct a "census" of all household "members" regardless of whether they were living in the village or in town at the time of the survey. In all, the survey covered 1,782 households containing 13,776 persons in rural sample areas and 585 households including 3,167 persons in urban areas. The major focus of the investigation was on those members of the rural population who had transferred to more urban centers. The Caldwell report includes great detail on the decisions involved in designing the questionnaire and identifying the appropriate migration categories to which household members belonged. It is difficult here to summarize adequately the decisions made. Without doubt this survey provides a valuable model for other studies of rural out-migration.

It is important to note that "the household was defined by common cooking arrangements and residence, except that where separate residence of spouses was normal the definition was confined to cooking arrangements. Absent persons were regarded as part of the immediate household if they were so regarded by household members, and if they had been born in the household to those who are heads of the household at the time of the survey or alternatively had been reared by them in the household or usually lived there but were temporarily absent at the time" (Caldwell, 1969:23). Basically, household interviews were conducted with one or two elders as the main respondents, but others in the household were consulted, particularly when questions referred specifically to them.

Although the survey aimed to secure information about all absentees, Caldwell suggested that the method failed to get information on certain types of migrants: (1) where the family of origin of the migrant could not be located because the entire family had moved; (2) where the family of origin had so changed that it no longer regarded the migrant as having originated in it; (3) where the position of the migrant had altered so that he, or more commonly she, was no longer regarded as a member of the household (Caldwell, 1969:36-7). In all, Caldwell estimated that probably less than 3 percent of the number in the survey universe were omitted owing to loss of entire family units. The effect of changes in the family of origin was also very small except for the migrant patterns of the elderly. Of the three categories, the most complex problem was that of relatives who were no longer considered members of the household or had never been so considered. 
This problem applied especially to females who, once married, were frequently assumed to be members of other households. The effect was to raise the sex ratio of the rural-urban out-migrants. Similarly, children born of permanent absentees after the initial migration seemed rarely to be considered members of the rural household even if their mothers had returned to the village for their birth. Overall, however, Caldwell concluded that "most of the provisos listed do very little to jeopardize the validity of the rural survey ... because the absentees omitted, babies, women, or old men, are likely to be those who made the most complete break and who are contributing least in the way of visits, money, or goods to their village of origin" (Caldwell, 1969:40). On the basis of his survey, Caldwell developed a series of migration categories that include temporary and permanent outmigrants and constitute a model for other studies attempting to focus on rural ou t-migration (see Appendix 5).

A number of other studies have attempted to identify out-migrants (Chaudhury, 1978; Premi, 1976, 1980; Sovani, 1959; Stoeckel, Chowdhury, and Aziz, 1972; Conning, 1971; Visaria, 1969) but none has provided as thorough an assessment of the problems involved and the experience gained as Caldwell. In particular, little attention is given to such basic questions as: Who is to be regarded as an original member of the household and therefore qualifies as an out-migrant if absent? What problems were encountered in ascertaining the destinations and current residences of out-migrants? Who is the individual most qualified to provide information on the motives for migration and its likely permanence? Chaudhury indicated that out-migrants covered in his survey of 68 villages in Bangladesh were away from their household at least six months, but neither indicated the basis for classifying them as household members nor told the reader who the respondents were. Conning $(1971,1972)$, using a 1966 survey of seven communities in Chile, focused on the first out-movement of persons aged 12-29, to increase the likelihood that parents were available to provide the information. Reasons for migration could be ascertained only indirectly, and it is not clear whether all persons who moved out were included in the migration rates, or only those who left to seek employment or education. Premi (1980) attempted to identify migrants from six Indian towns that were centers of out-migration. To avoid duplicate reporting of out-migrants, he found it necessary to restrict information gathering to persons who were the children or 
unmarried brothers of the household heads. Restriction of the respondents to such close relatives also enhanced the quality of the data on characteristics of the migrants and reasons for the move. In those instances where an entire household had left, neighbors were asked to provide information on the number of persons involved, the household composition, and the destination, but no detailed characteristics could be elicited.

Sovani (1959) covered over 43,000 households in a sample of areas affected by dam construction in India, but the major stress of his study was on the number of household members who could be spared without affecting current household.economic activity; he was therefore as much interested in the potential and seasonal migrant as in the actual or permanent migrant. Stoeckel, Chowdhury, and Aziz (1972) relied on a registration system to identify out-migrants from 111 villages in one area of Bangladesh. Daily visits to each household were followed by weekly checks to ascertain if the individual had returned once a departure was recorded. After six months' absence, the individual was classed as an out-migrant. The records of out-migrants between April 1968 and May 1969 were linked to a census to obtain characteristics of out-migrants. Information on reasons for migration and destination was usually obtained from relatives. In a sense, the general approach of this Bangladesh study was analogous to the registration system that is part of the dual record approach; it is an interesting example of how various data sources can be meaningfully integrated.

Lauro's (1979:192-4) study of a Thai village was an interesting experiment in re-creating out-migration rates by gathering genealogical data in an attempt to reconstruct the village's demographic history. Although the data proved generally unreliable for early periods, data on out-migrants within the decade preceding the study were gathered from household members who had remained in the village, from neighbors, and from the evidence of abandoned house sites. The genealogical records were supplemented by information from the life history matrices for those residents who had moved out and then returned. Lauro suggested that, on the whole, the incompleteness of the genealogical data resulted in underenumeration of out-migrants.

Visaria's (1969) study of the interrelations between migration and fertility used 15 villages in two districts of India and one village in another district; from this one village, he tried to follow all migrants whose destination was Bombay. Migrants were defined as all 
individuals absent from the village continuously for six months. Visaria's efforts to obtain information on entire households that moved met with little success, but he argued that since most migrants move individually and leave close relatives in the villages, they are identifiable in rural surveys. Of the 215 women in Bombay identified as migrants from the one special village covered in the rural survey, Visaria was able to match 56 for data collected in the village on number of children. He found that the mean number of total children reported in the village was understated, and the mean number of surviving children overstated, suggesting a lack of communication between the migrants and the villagers. Byerlee, Tommy, and Fatoo (1976) collected the names and addresses of out-migrants from a sample of rural areas of Sierra Leone and then attempted to contact them in their destinations. About 40 percent of the out-migrants were successfully interviewed, but their number was augmented by the names they supplied of other out-migrants from the home villages living in the same neigh borhoods.

Interested in testing whether higher fertility was associated with increased migration, Hendershot (1973) selected a 25 percent sample of ever-married women, stratified by age and the presence or absence of husband, in four rural communities in the Philippines. The study focused on out-migrants among the teen-age children of women 40-60 years of age. The out-migration rate was the number of children so identified over the number of children ever born to the respondent women. Whether results may be biased by restricting out-migrants to children who still have living mothers in the rural areas is not fully assessed in the article.

Hugo's (1978) study of Indonesian mobility patterns was based on purposive selection of 14 villages from the main source areas of movers from rural West Java to the cities of Jakarta and Bandung. In each village, stratified samples of households were picked to include ten community leaders, adequate numbers of households that contained only stayers, as well as sufficient households from which persons had moved in the preceding ten years. For the latter, Hugo reconstructed the household membership by asking for the names of all persons who had lived in the household at any time in the last ten years, but had since moved. He ascertained their sex, age, marital status, present residence, and mobility status (migrant, circular migrant, or commuter). The migration histories obtained included information on occupation, 
education, marital status at time of migration, and reasons for movement. A particular value of Hugo's study, as noted earlier, is the strong attention given to short-term movement, in contrast to most other studies interested in movement only if it involved an absence that exceeded a specified minimum period.

A strong case for studying rural areas was made by Oberai (1978). Maintaining that no single well-established method has been developed for analyzing the social and economic implications of migration, he stressed the need for microanalysis using detailed retrospective information. At the household level, data on production patterns and technologies employed in farming were used to compare households that had experience with out-migrants with those that did not. In particular, Oberai outlined a set of hy potheses in which out-migration is a function of the man-land ratio, degree of inequality, village employment opportunities, displacement of labor resulting from technological change, and various other selectivity factors.

The questionnaire for the internal migration survey in selected villages of Ludhiana district in Punjab-part of the comparative survey program being carried on by ILO (Oberai, 1978)-includes a section on out-migration from households. Previous members of the household who had left since 1961 to live or work elsewhere were considered out-migrants. However, neither commuters, nor women who moved out on account of marriage, nor students were considered outmigrants. The questionnaire asked about the characteristics of outmigrants before they left the village, reasons for the move, the condition of the household before the move, some of the links between the out-migrant and the household, especially with respect to remittances in both directions, and the uses to which such remittances were put in the village, as well as the impact of the out-migrants' departure on the household. A section on potential migrants, defined as members of the household aged 12 or more who were planning or considering outmigration, was included. For such individuals, information was collected on planned destination, reasons for the move and the choice of destination, expectations with respect to work, and source of information about opportunities. The coverage of the Ludhiana questionnaire is thus much more comprehensive than most studies attempting to identify out-migrants and potential migrants, although several other studies of rural areas, including the Thai Longitudinal Study, have made similar efforts. 


\section{Use of multiplicity to identify out-migrants}

This review has pointed to a number of studies that rely on informants in existing households in rural areas to report the out-migration of other household members or even of neighbors. In almost all such study designs, the approach used is somewhat crude. Recently, efforts to develop more sophisticated methods relying upon social networks (multiplicity) as the basis for estimating vital events and mobility have been initiated. In contrast to the conventional household survey, in which only events occurring to household members are studied, the multiplicity survey approach allows persons who experience vital events and mobility to be counted at more than one housing unit (Sirken, 1970). The additional households eligible to be covered by the multiplicity survey (usually those of specified relatives) are defined by the particular multiplicity counting rule adopted for the survey. The multiplicity of every move enumerated is ascertained (thereby. providing the data needed for appropriate weighting) by asking the household respondent supplementary questions to determine how many : different housing units are eligible to report a mobile individual. Multiplicity rules thus offer a strategy for enhancing the efficiency of a survey by increasing the proportion of housing units for which movement can be enumerated. Although some types of response errors may increase owing to the reporting of events by relatives, certain types of coverage bias encountered in a conventional survey-due to the absence of households in the survey population to report an event-may be reduced because of reliance upon kinship networks.

The overall strategy of the multiplicity sample survey is to select from the set of all possible counting rules the particular one that minimizes the joint effect of sampling and measurement errors. The collection of information on various characteristics of each event covered and of the person concerned, whether resident in the hou sehold or elsewhere, allows assessment of the events in relation to background characteristics. Although use of multiplicity in research on population movement remains to be fully tested and demonstrated, it would seem to have considerable potential value for the study of out-migration, especially when the entire household moves as a unit.

At present, the only work being done on this technique in a less developed country is that of Flieger (1979) in metropolitan Cebu City, Philippines. Preliminary tests suggested that respondents may know more about their neighbors' than their relatives' migration; on this 
basis the recommendation was made to seek information from respondents about neighbors' migration-where neighbors are defined as the two households living closest to the respondent or the two neighbors with whom the respondent has the most contact. The difficulty of defining exactly which neighbors to specify for purposes of the multiplicity survey, however, has led to reconsideration of the multiplicity rule to be employed (personal communication). In the final rules adopted, mothers and sisters of migrants were asked to supply the information. This work in the Philippines will be followed with much in terest, especially for the insights it provides on obtaining more adequate coverage of out-migration through sample surveys.

The value of the multiplicity approach to identify migrants was also explored on a limited basis in Rhode Island (Goldstein and Goldstein, 1979), using a two-stage research design. First a sample of persons who had changed address in the three years preceding the survey was identified and information was gathered from them on their mobility and on any relatives they had living in the state (Round 1). In turn, these relatives were asked about the mobility of their parents, siblings, and children (Round 2). The movers listed in Round 2 should have included the migrants sampled in Round 1. Evaluation of the accuracy of Round 2 responses in comparison to those obtained in Round 1 was undertaken in terms of kin relationships, recency of move, and type of move. The results indicate that respondents had a low awareness of their relatives' movements, that moves of females were more likely to be reported than those of males, that recent moves were more frequently cited, and that moves between communities were more likely to be reported than intracity mobility. Further assessment of the multiplicity approach must be made using larger samples and covering a broader range of movement including especially out-migration from the survey area.

\section{DEFINITIONS OF MIGRATION}

Perhaps one of the most acute problems of migration research is the matter of definitions, that is, what moves should be regarded as migration and worthy of attention by researchers and policymakers. Both within and between countries, comparability of studies of internal migration is seriously hampered by variations in definitions. Virtually all discussions of definition point out that, from a demographic point of view, the process of migration involves three elements: (1) an 
area of origin which the mover leaves and where he or she is therefore counted as an out-migrant; (2) the area in which new residence is established-the destination or place of in-migration; and (3) the period over which migration is measured. The period may vary from a definite fixed interval, ranging from as low as a few hours or days in some studies to as many as five or ten years in others, to an indefinite time such as the lifetime of individuals at a given date. Interest may also extend to the number of moves made within a particular period or over an entire lifetime.

Yet some definitions go beyond these criteria to include intentions with respect to the permanent or temporary nature of the move, regardless of how long an individual has already been away from the last previous residence. Still others incorporate the motives for the move, arguing that those who are "passive" movers should not be classified as migrants because their mobility behavior is largely if not entirely a function of someone else's decision to move. This definition would sometimes exclude wives, and in most instances children. Still others would qualify migration in terms of a minimum distance, the crossing of a specified political boundary, or a change in environmental conditions. Thus, for some researchers, movement with in the same village or town qualifies as migration; for others it does not. For some the move has to involve crossing a provincial or state boundary, so that a move from a village to an urban place within the same province would not qualify as migration. For yet others the move must involve a change in type of residence, such as rural to urban, so that even though great distances may be crossed, changes between urban-or between ruralplaces would not qualify.

The problems of comparability plaguing official definitions become accentuated in sample survey research, partly because the researcher has greater flexibility to devise definitions; partly because the specific questions to which the research is addressed call for different emphases in the criteria used; and partly because individual studies allow much greater attention to the significance of time, distance, and place in local areas or particular cultures. Another important motive underlying many variations is the attempt to demonstrate that the traditional definitions followed in official statistics frequently mask a considerable amount of population movement and preclude relating population movement in a meaningful way to social and economic change at places of origin or destination. Yet, the net result of so much 
variation in definitions is that the volume and character of population movement detected by different studies cannot be easily compared. It is very difficult to assess the extent to which movement affects the individual mover, the places of origin and destination, or the general development efforts.

\section{Origin and destination}

Perhaps the clearest delineation of origin and destination in the migration literature is that between international and internal migration. Although few studies concern themselves with both, inevitably, studies dealing with internal migration must decide whether to include persons living in the survey areas who have moved there from other countries, and those focusing on out-migration have to consider whether to include persons who move abroad. To the extent that many studies adopt the assessment of internal migration as their goal, international migrants are by definition excluded.

Such a clear dichotomy may no longer be justified since the lines between internal and international migration are becoming increasingly blurred. In some areas, the two processes are closely interrelated, with intemal migration serving as one step in the process toward eventual international movement. In other countries, international migration has taken on increased importance as a substitute for or complement to internal movement (Kritz and Gurak, 1979). In still other areas, especially in Europe and the Middle East, temporary migrants (Gastarbeiter) are increasingly able to choose destinations outside their own country (e.g., Kuhn, 1978; Choucri, 1977). Moreover, the considerable volume of refugee and illegal movement presents new challenges in survey research as well as concern with the extent to which an exclusive focus on internal migration may be artificial and yield misleading results in any assessment of relations between movement and development.

For research that includes international migrants within its scope, a major decision with respect to origin/destination is the extent of subclassification of areas outside the country into which immigrants or emigrants should be grouped. In the study of migration in Liberia (Liberia: Ministry of Planning and Economic Affairs, 1973), surrounding countries were individually listed, and all others were grouped into a single category. For other studies, proximity might not be a major criterion, as, for example, migration to the Middle East from sending countries such as Korea. 
For studies restricted to internal migration, the aggregation of areal units is also basic. Place of birth or origin of move at a fixed date may be recorded as village, town, district, or province. Other things being equal, the smaller the areal units used, the larger will be the volume of migration recorded, since the opportunity to cross a boundary generally increases as the size of the areal unit decreases. Thus, if movement from village of residence is measured, more movement will generally be recorded than if the question concerns movement from a province. Many individuals might have moved from village to village within a province, yet correctly report that they were still living in the same province and therefore qualify as nonmigrants.

Studies of internal migration have focused to a large extent on movement between rural and urban places, even when the emphasis has been on rural out-migration. A basic problem for these studies is that countries differ in how they delineate places as rural or urban, if they do so at all; even when standard definitions are used nationally, individual scholars of ten choose to use different criteria in their own classifications. Moreover, to the extent that migration research is of ten retrospective, changes in rural/urban status create additional difficulties because changes in size, in rural/urban character, and even in official definitions will affect comparability over time and make it difficult for the researcher, and especially for the respondent who is often asked to provide accurate classification by rural/urban status and size of locations of origin and destination at earlier points in the migration history.

Since so many surveys are undertaken in limited local areas, rural and/or urban origins and destinations generally cannot be subdivided by specific locations. At best, a distinction is made between the primate city and other urban locations or between origins and destinations in various regions of a country. In part, this lack of refinement reflects that information obtained on origin may be for gross areas and not allow further subdivision. In part, isolating the primate city and grouping all other urban places into a single category reflects the importance of the primate city in the urban hierarchy of many countries. Both the variation in practice and the general absence of refinement are worth stressing; to the extent that the purpose of much migration research is to assess the impact of migration on places of origin and destination and the role of such places in the migration process, their aggregation into gross categories diminishes the insights 
that can be gained on the interrelations between characteristics of such places and movement.

In the study of Monterrey (Balan, Browning, and Jelin, 1973), for example, place of origin was determined by where the individual spent the greatest time between the ages of 5 and 15. For that location and others mentioned in the migration history, the urban/rural classification was based on the census classification closest to the year of an event, and "urban" was defined as places of 5,000 persons or more. By contrast, in Caldwell's (1969) study of Ghana, rural areas of origin were limited to those with populations under 15,000, and destinations were classified as urban either on the basis of their urban status or because individuals moved to take urban-type jobs; if the job was urban in character, the move counted as rural-urban migration even if the destination had fewer than 5,000 persons. Moreover, there was no interest in additional moves between urban places once the individual was identified as having moved from a rural to an urban place. In Elizaga's (1966) study of migration to Santiago, origin was identified as the last place of residence before Santiago, classified by size. Places of 20,000 or more were defined as urban; rural places were subdivided into those of 5,000-19,000 persons and those with less than 5,000. In research on the Philippines (Bello Feitosa, 1975), stress was placed on a "change in life conditions" as the basis for defining a migrant, who was therefore any person who had moved between an urban and a rural place at any point between the four time references (birth, 1960,1965 , and 1968). As a result, a nonmigrant was anyone who resided in one category at all four points in time, even though he or she had moved during the intervals.

The Liberian research (Liberia: Ministry of Planning and Economic Affairs, 1973) counted as migration not only movement to or from a village or to or from urban places but even movement within a village or town. In contrast, the Iranian studies of population change (Statistical Centre of Iran, 1976) did not count changes of residence within town or village as migration, nor movement in or out that occurred within one year. Still another contrast, the study of population change in the Philippines measured movement in terms of change in sitios (Madigan and Herrin, 1977:63-73). Since the large city consisted of a single sitio, an individual had to move into or out of it to be classified as a migrant; but because the ru ral sample consisted of 123 sitios, it provided much greater opportunity for movement to be 
classified as migration. A similar problem arose in a study of Lagos (George and Eigefoh, 1973), where anyone moving into or out of the sample area was considered a migrant to or from Lagos, even though the move was between parts of that city; in contrast, the Nigerian census procedure classifies an individual as a migrant only if he or she was born outside Lagos.

\section{Temporal reference period}

Most sample surveys have used a census-ty pe approach in classifying individuals as migrants on the basis of either birthplace, residence at a fixed point in time, or a fixed duration of residence. In many instances, the specific number of months or years selected seems quite arbitrary, and inconsistency in criteria used is more characteristic than use of a standard reference period. In several cases, the periods chosen do parallel the census procedures, and this allows coordinated analysis of the sample survey and the census. But, in contrast to census procedures, various studies also impose a minimum period of residence in order to exclude what they regard as "temporary" migrants.

Speare's (1976) study of migration to Taipei illustrates the use of a definition modeled on census procedures. The sample was selected to distinguish between migrants who had moved to Taipei with in the last five years (classified as recent migrants) and other persons living in the city-those resident five years or more (long-term migrants), and those born there (natives). A similar procedure was followed by Goldstein, Pitaktepsombati, and Goldstein (1976) in analyzing the migration data from the Thai Longitudinal Study. "Recent" migrants were those who had moved to their present location (either a municipality or a rural locality) within the previous five years; long-term migrants had moved five or more years before the survey.

A particular advantage of survey data-especially those that include complete residential histories-is the opportunity to subdivide migrants, however defined, by duration of residence in particular locations. For example, in research on Thailand (Tirasawat, 1978), migrants we re subdivided into those living in current urban place of residence for less than five years, five to 14 years, and 15 years or more to assess the impact of differential length of residence on adjustment. In a study of migrants to Surabaya, Indonesia, McCutcheon (1978) also distinguished between recent (within five years) and long-term (five years or more) migrants to the city, but her category of lifetime residents included 
both those born in Surabaya and those who had moved there before age 15. Consistent with the position of the Monterrey study, McCutcheon maintained that those who moved to Surabaya at a young age were probably not very different from the native-born population, since an important segment of their socialization occurred in the city.

Yet other definitions have been used. For example, in his study of migrants in Bangkok metropolis, Chamratrithirong (1979) classified as migrants all those who had moved to the area within the two years preceding the survey, regardless of where they were born; only 1 percent were in fact Bangkok-bom. This meant that nonmigrants included all Bangkok-born individuals and all who had lived in the city for at least two years. A still shorter interval was used by the Lagos study (George and Eigefoh, 1973), in which anyone who had moved in or out of the sample area of Lagos for more than 31 days was defined as a migrant. In his study of Taichung, Speare (1972) also used a short interval, defining migrants as anyone who had moved to Taichung and lived there at least three months but not more than one year.

Some researchers have argued for a more "sociologically" relevant basis for defining individuals as migrants and for ascertaining place of origin (e.g., Freedman and Mueller, 1977). The Monterrey survey is an interesting effort to confront the question of how to distinguish between natives and migrants. As the authors effectively put it,

Place of birth is the most common criterion to separate natives and migrants in many studies, particularly those based upon census data. Therefore it appears that 70 percent of our men fall into the migrant category. But we are not satisfied to rely upon the 'accident' of birth to make this extremely important, for our purposes, distinction. A man born a few weeks before his parents migrated with him to Monterrey would be classed as migrant al though all his sentient experience took place in that metropolitan center. We believe that a sociologically more relevant distinction is required ... community of origin-where the individual spent the largest part of his formative years, taken here as the period between the ages 5 and 15 . It is during this age interval that individuals acquire their basic orientation to the world outside the family circle as well as the fundamentals of their formal education. In the representative sample, 16 percent of the men were born outside Monterrey but grew up in that place. We chose to call this group natives by adoption. Using as a criterion community of origin, 54 percent of our representative sample are to be considered migrant (Balan, Browning, and Jelin, 1973:61-2).

Following the model of the Monterrey study, Simmons and Cardona (1972) based their definition of migrants to Bogota on both 
place of birth and age at arrival in the city; but in a later study of Bogota by Corno (1979), in which life histories were the major source of information, a migrant was defined as anyone born in Colombia but outside Bogota or someone born in Bogota who lived for three or more consecutive years outside Bogota, but not outside Colombia. Inclusion of the latter as migrants was rationalized on the grounds that those born in Bogota but living elsewhere for a substantial period (three years or more) faced adjustment challenges once they returned. Their previous residential experience in Bogota was, however, taken into account as a predictor of adjustment.

A long inventory of definitions used could be made, but the above illustrations give some indication of the range. At its extremes, the definition of migrants encompasses those who move into a location as little as 31 days before a survey to those resident for an indefinite period up to virtually their entire lifetime. This helps to explain why it is difficult to compare survey findings and why opposing conclusions are just as likely to reflect differences in definitions as anything else in the migration situation.

\section{Temporary versus permanent movement}

The difficulties of comparability do not end here. As already noted, a growing body of research and literature stresses that the emphasis on permanent migration, however defined, masks a considerable amount of movement that is relevant to full assessment of social, economic, and demographic change in places of origin and destination. This includes the interest in return migration that is part of the growing concern with circular migration, seasonal movement, and commuting.

For example, Caldwell's classification system draws a primary distinction among three groups of the rural population: (1) those who have never migrated; (2) those who have returned to rural areas after one or more migrations to the town; and (3) those who are still away in town at the end of the survey (see Appendix 5). Caldwell's analysis of return migration is based on questions asked of respondent households in the rural survey and of rural-to-urban migrants covered in the urban survey. For example, the former were asked, "When do they finally come back to the village to stay for good?" and the latter, "When do you mean to go back to your village and not come to Accra (or the other towns) again?" (Caldwell, 1969:188). Caldwell argues that 
The anticipation of ultimate permanent return to the village is an integral part of most rural-urban migration and in most subsequent urban residence in Ghana. It plays a major role in determining saving and sending patterns and the maintenance of personal relationships as well as deciding the need for journeys to make periodic revisits while living in the town. It helps to explain all kinds of aspects of urban society, for rural-urban migrants form a substantial part of such a society.... Although the migrant may have always regarded the town as a kind of temporary working sojoum, nevertheless there is a good chance that he will have remained there until old age or sickness, or both, dictate his return home. However, he usually does not retum to the village as a stranger (Caldwell, 1969: 198-9).

In other studies of return migration, definitions again vary. In the Monterrey study's use of life history data, return migration was defined as any return to a former residence (Feindt and Browning, 1972). In the use of statistics from the National Demographic Survey in the Philippines, the return migrant was classified as any individual who reported himself born in a rural place but was an urban resident in either 1960 or 1965 and lived in a rural area again at the time of the survey in 1968 (Hendershot, 1976). In Simmons's (1970) study of migration in Colombia, a return migrant to a rural area was anyone who had lived in Bogota at least one year before moving back to the village. But in Agarwala's (n.d.) study of India, a return migrant had to have been away from the village of birth at least three months before returning to it. In con trast, the survey of Iran (Statistical Centre of Iran, 1976) did not count as migration any move that involved a return to the place of origin within one year of departure. Thus, return migration is treated very differently by different scholars, in some cases being the basis for exclusion of a move as migration and in others for particular attention to it, with the time period over which a return move is counted varying significantly.

Regardless of the time interval or the spatial units used in determining whether migration has occurred, a key concern in many studies is the intended permanence of the move. Many persons may have moved over very short distances but intended the move to be permanent, whereas others may have traveled much greater distances but considered the change in residence only temporary, intending either to return to their place of origin or to move on to some other destination. For example, Chamratrithirong's (1979) study of migrants in Bangkok demonstrates the prevalence of temporary movement, at least as perceived by the migrants. Over 40 percent of the men in his 
sample and just over half the women did not register their residence in the city because they did not consider their stay permanent. Yet this research also demonstrates the importance of the wording of questions. Although almost half the respondents thought of themselves as temporary residents, only 21 percent indicated that they had actually thought about leaving Bangkok.

In official definitions of migration, "permanence" is often a major criterion for determining whether or not migration has occurred, yet the criteria for determining permanency itself vary considerably from study to study, with some drawing the line at six months, others at twelve months, and still others at shorter or longer intervals. This very much affects the comparability of surveys and argues strongly for standardization of definitions or at least the collection of data in such a format that a higher degree of comparability can be obtained if desirable.

The full range of mobility has been explored increasingly in research in Africa, Melanesia, Asia, and other developing regions of the world (Chapman, 1978). These studies suggest that many movements involving the interchinge of people between points of origin and destination begin and ultimately terminate in the same community and consequently involve no change in permanent place of residence. It is these repetitive and perhaps cyclic movements that have been termed "circulation."

The idea of population movement as circulation was first conceptualized in the 1940s by Godfrey Wilson (1941-42) and later amplified by J. Clyde Mitchell (1961). The interplay of centrifugal and centripetal influences reflects the desire of movers to hold strongly to their local heritage while attempting to benefit from the money economy by engaging in temporary employment outside the village. Growing attention to circulation has led to the suggestion that far from being transitional or ephemeral, such movement was a "time honored and enduring mode of behavior, deeply rooted in a great variety of cultures and found at all stages of socioeconomic change" (Chapman and Prothero, 1977:5). The concept has been applied to a considerable variety of movements, usually characterized as short-term, repetitive, or cyclic, and lacking any declared intention of a permanent or longlasting change in residence. These characteristics have led circulation to be largely ignored or undetected by censuses and possibly even population registers (see also Gould and Prothero, 1973). 
A review of the literature on such movements suggests strongly that there is no consistency in what is to be regarded as permanent or temporary, nor in what kinds of moves fall under the label "circulation," even when their temporary character is quite clear. Quite consistently, as sample surveys have made efforts to reduce the geographical or political units for which population movement is measured, as well as to reduce the time intervals, levels of mobility detected have risen; the extent of circulation, whether defined in terms of brevity of interval or purpose of move, has been shown to be far greater than ever revealed by censuses. The use of residential histories as well as research designs that allow direct and prospective observation has provided a more sensitive means to better assess the temporary or permanent character of the move, the sequence of moves over time, the links maintained between origin and destination, and the relation of the various types of movement to development in both rural and urban places.

A number of efforts have been made to refine the coverage of migration by specifying the places of prior residence in much greater detail than before. On the temporal level, movement involving much shorter periods has been considered. For example, Graeme Hugo (1978) attempted to gauge mobility patterns of households over a ten-year period by obtaining information on the mobility experience of all persons residing within the households at the time of the survey and by relying on a form of "family reconstitution" of all persons who had resided in that household during the previous ten years. For all such individuals, migration histories and information concerning circular migration and commuting were obtained. Hugo adopted six months of continuous residence in the city as the basis for classifying a mover as a permanent migrant. Those living in the city but returning to place of origin within six months were classified as circular migrants; but, given the emphasis on intention to return, Hugo also allowed individuals who had been absent from the village for much longer periods but intended to return to qualify as circular migrants. Adoption of an absolute time standard was therefore a source of frustration and points to the problems inherent in developing a clear operational definition of migration that can distinguish between it and circulation.

Similar difficulties are inherent in attempts to distinguish between circular migrants and commuters. The latter were defined by Hugo as persons who regularly, though not necessarily daily, went to a place 
outside the village to work or to attend an educational institution but returned to the village on most nights. By contrast, Mantra's (1978) study of villages in Indonesia defined permanent migration as an intentional shift of residence across a hamlet boundary for a period of at least one year and circulation as any movement in which a boundary was crossed for more than one day but less than one year. Commuting consisted of absence from the hamlet for more than six hours but less than one day. At the other extreme, the study of movement in Thailand by Singhanetra-Renard (1977) allowed individuals who had been away from their village for as long as 20 to 40 years to still be regarded as circular migrants because of their intention to return home. These differences among scholars concerned with the appropriateness of earlier definitions of migration-who have therefore developed new criteria with respect to boundaries, minimum time units for classifying moves, and distinguishing between commuting, circulation, and migration-illustrate the failure to date to achieve standardization of concepts in order to facilitate comparative analyses.

Evidence from a number of studies in developing countries documents the need to examine commuting and circulation in all efforts to assess population movement and redistribution. In this respect, censuses can be of only limited use because of the minimal number of questions on movement that they can include. Sample surveys, by contrast, can provide maximum opportunity for comprehensive assessment of all forms of population movement and their relations to both urbanization and rural development. The possibility is enhanced by the increasing reliance of surveys on life histories and the life cycle matrix. The extensive attention to be given to such movement by the proposed ESCAP surveys has already been noted.

\section{Potential migrants}

In addition to recording past movement or observing actual movement, various studies have attempted to ascertain the migration expectations of nonmigrant members of households. For example, in his study of migration decisions in Taiwan, Speare (1976) devoted a section of the questionnaire to the migration expectations of nonmigrants residing outside Taipei. These questions were quite typical of those in other migration surveys and included attention to whether a respondent had ever considered moving and, if so, where to. For those who had not considered movement, the reasons were ascertained, as were the 
reasons for those who had. For those who decided not to move, the reasons for the negative decision were also obtained. Only 9 percent of the respondents indicated that they had considered moving to Taipei in the past five years and another 8 percent had considered moving elsewhere; over 80 percent reported that they had not considered any move at all. Speare's study, directed at the decision-making process related to movement, went on to ascertain in considerable detail the nature of the respondents' contacts with the potential destination, the cost of the move, and their sources of information about job opportunities in Taipei.

The ILO in ternal migration survey of Ludhiana (Oberai, 1978) also included a section on potential migrants, who were evidently identified as part of the initial household inventory. The first direct question addressed to potential migrants was "When do you think you will leave?" The questionnaire then ascertained the destination, reasons for the choice, and reasons for the out-migration. A series of questions follows, probing about employment at the destination, the extent to which the move would involve other family members, and contacts with relatives and friends at the destination. The Thai Longitudinal Study also had a section on potential migration and screened for all potential migrants in the household by asking, "At the present time, would you or any members of your household like to move away to another place?" If the answer was yes, the name of the household member, the relationship to head of household, the reasons for the move, the extent to which they were definite, and, if definite, the destination, timing, and permanence of the move were ascertained. Overall, experience in analyzing the data suggests that the question did not yield very useful material, possibly because the respondents did not feel qualified to report for other members of the household.

The proposed ESCAP migration questionnaire includes an entire section on future mobility. For those who indicate they do not want to move from their present residence, as well as for those who once considered moving and changed their mind, the reasons for not moving are obtained. For those indicating a desire to move, information is collected on reasons, choice of destination and reasons for this preference, source of information about the place, and expectations with respect to jobs and other activities, date of move, and anticipated length of residence. In the pretest of these questions, some respondents were reported to have had difficulty coping with questions about 
future behavior. Yet, it was recognized that insights gained may be of particular value to policymakers in identifying conditions that may facilitate both retention of population in current place of residence, or channeling movers to particular locations, if either of these should be policy goals.

The value of questions on propensity to move needs further assessment, but most likely this can only be achieved effectively if there is a follow-up survey to ascertain the extent to which desires and plans do in fact materialize. Such evaluations have been undertaken for some surveys in developed countries (Speare, Goldstein, and Frey, 1976) and have demonstrated the usefulness of such questions as predictors of mobility. Their value in less developed countries remains to be fully demonstrated. As Speare (1976:77) stresses, "a longitudinal study, covering perhaps a two-year period, would provide a significant improvement in measurement enabling variables to be measured prior to migration," but, as he also points out, because only a small percentage of the population is likely to move within a two-year period, a relatively large sample would be needed.

\section{Household versus individual movement}

A major decision in all migration studies is defining the unit for which migration is measured. The issue is particularly complex. In many instances, when families or households move in their entirety, the household or family is the appropriate unit for evaluating both the patterns of movement and the underlying reasons, even though the process of adjustment may vary for each individual. Yet often, when movement follows an individual decision, related to such factors as work, marriage, and education, the moving unit is an individual or several individuals within a household rather than an entire household. Nonetheless, even in such cases, either the household as a unit or certain nonmigrant household members may enter into the decision making by selecting, or at least influencing, which members of the household move or remain behind. Growing evidence from microstudies and from theoretical work on questions of migration suggests that the volume, the type of movement, the particular family members who move, their destination, and whether their move is permanent or temporary may all be affected by family decisions. Indeed, consistent with multiphasic response theory, the decision whether to rely on movement or on changes in fertility behavior may be one way of adjusting household size to available resources (Stark, 1978). 
The census tradition of measuring migration in terms of individuals has probably very much influenced the predominance of studies that assess migration as an individual phenomenon. The reluctance of researchers to assess migration on more than an individual level, however, may reflect more than the census tradition; in part, it probably also stems from the complexity of the migration process itself and the difficulties that would necessarily be involved in attempts to assess the social-psychological dimensions of population movement at the household level as well. Some researchers have resolved the dilemma by focusing on the head of the household; others simply select individual members of households on a random basis (usually only adults, however defined) and obtain detailed information from them as individuals even though the questions of ten relate to decisions made by other members of the household. In such instances, and this is not discussed extensively in the literature, the respondents may well feel unqualified to provide accurate information. This limitation is particularly pertinent in situations where the major decisions about movement were made by another member of the household, such as a spouse or parent. The lack of attention to these problems argues strongly for more evaluative work on existing data and new efforts to assess who really is the most appropriate respondent and what is the most appropriate unit of analysis.

Perhaps the closest acknowledgment of this problem is in Caldwell's discussion of the fundamental difficulty the Ghanaian project faced in its effort to obtain migration information for the household as the unit. As he put it,

In a great number of households there was going to be no question of interviewing each member of the household separately. The family interview was going to be a mass affair and the number of family spokesmen was going to be few, in many cases one dominant old man as head of the household. It would certainly be possible to obtain a range of factual information about each member of the household, although the details would of ten be provided only as a product of family consultation. It was, therefore, possible to construct a kind of schedule within each household questionnaire linking each individual's migrant classification with such characteristics as sex, age, position in household, conjugal condition, education, literacy, and occupation.

With the main body of questions somewhat different tactics had to be employed. In many households, it was found impossible to use any thing but a common household questionnaire, so in the end that was what was used. But different parts of the questionnaire obviously referred to different members of the household: at times to those about to set off for the town, at other times to 
those wishing to do so, or definitely remaining in the village, or on temporary return from the town, or permanently returned, and so on. All such persons had been identified during the construction of the individual schedules. When questions referred specifically to them, the first attempt was made to interview them individually on these points. If this proved to be impossible, because the head of the household kept on taking over the conversation, the interviewer then asked his permission to put the questions through him to the members of the family concerned. This usually proved to be an acceptable alternative. However, in some cases, the head of the household merely quoted what he believed to be the position with regard to other members of the family.

The questions were concerned mainly with identifying where respondents fitted into the various migrant classifications, determining the various push and pull factors exerted by both village and town, discovering which kinds of migration were favored by the family, detecting the interrelation between village and town, studying the mechanism of the actual migration, plumbing the reactions to the urban environment, checking on the flows of money, and asking about ultimate satisfactions (Caldwell, 1969:16-17).

In the ILO study of Punjab, the questionnaire called for a complete inventory of all household members, and then proceeded member by member to ascertain the characteristics and motives of out-migrants, in-migrants, return migrants, and potential migrants; it then obtained information on the work activities of household members as well as about the household as a unit. It is not clear, in the absence of additional documentation, how the interview itself was conducted or how the specific attitudinal data reflecting the migration decision-making process were obtained. The questions seem to be directed specifically at individual household members, although in much greater detail for those present than for out-migrants.

The ESCAP study design (United Nations ESCAP, Manual VI, 1980) now being developed for use in several Asian countries calls for a multistage selection process, with the final stage to be selection of sample households from the enumeration area listing. Following the listing of all household members, a system for randomly selecting one household member between ages 15 and 64 to be the individual respondent is prescribed. The precise overall sample size will vary by country, but 14,000 households per country has been designated in the preliminary plans as the target sample size. The sampling scheme allows for a double-sampling technique as a means of increasing the number of interviews in specific migrant subgroups. It also allows for supplementing the national sample in order to create separate strata for areas with unique migration experiences that need adequate coverage because of their relevance to national policy. 
Within the sample households, the head of the household or another knowledgeable adult will be the respondent who is asked a series of questions covering usual residents of the household, nonusual residents (persons who stayed in the household the previous night), and persons who moved permanently from the household during the previous five years. For all usual and nonusual household members, a range of questions covering length of stay at current residence and purpose of move are to be asked as a means of screening the migration status of household members. For those who moved away during the previous five years, information will be collected on the present residence, reason for move, length of absence, and frequency of return visits. In addition, the usual census-type information on characteristics will be ascertained, including characteristics at time of outmovement for those who left. Collecting these data for all persons who were household members during the five years preceding the survey will allow evaluation of the mobility behavior of the unit as a whole or of selected members, in relation to both individual and household characteristics, including land holdings, business operations, housing, and exchanges of money and goods between household members and nonmembers.

From the individual respondent a much more detailed migration history will be obtained, as discussed earlier. Through the data collected as part of the household questionnaire and those focusing on the individual respondent, some indication can be obtained of the extent to which the move was that of an individual or a household. Clearly, most scholars are aware of the complexity of the migration process and of the severe dilemmas they face in deciding how to measure it, particularly with respect to the appropriate unit. Without doubt, if there are high priorities for experimentation in migration research, attention to the nature of the migrating unit itself rates among them.

\section{IDENTIFICATION OF PERSONS WHO MIGRATE}

Beyond the question of the volume of population movement and its relation to origin and destination, by far the greatest interest in migration research has focused on migration differentials (Thomas, 1938; UN Department of Economic and Social Affairs, 1973). This reflects an interest in both the extent to which a wide variety of social, economic, demographic, and psychological variables determine which individuals do or do not move, and the crucial questions of the impact 
of differential selection on the place of origin. Disproportionate selection of individuals with "positive." characteristics may well create problems for the population that remains behind even when out-migration may be a desirable way of relieving pressures on limited resources. Out-migration may also have positive effects in place of origin, if the characteristics of those who leave are not conducive to development and modernization-assuming those are the goals.

At the destination, there is similar and perhaps even greater interest in differentials between those moving in and natives-in part simply to ascertain the extent to which migration is selective, but more as the basis for evaluating the demographic, economic, social, and political impact of migration. Given the tendency of migration to be highly selective with respect to age and sometimes sex, considerable distortions in the age-sex structure can result at the destination if migration is unusually heavy. The potential impact on such variables as employment levels, demand for education, levels of education, political stability, and housing are sufficiently well known to obviate further discussion. Understanding migration, both as a process and for its impact on the socioeconomic-demographic structure of place of origin and of destination, and the implication that such structural changes have for development underlie the major attention given to analysis of census, registry, and survey materials on persons who migrate.

Interest in the process of migration extends as well to the extent of changes in the characteristics of migrants before and after they move. This reflects very largely the interest in how far migration has served to fulfill the motives underlying the move. Insofar as movement is frequently economically motivated, the question of who moves must necessarily be followed by questions on the extent to which the economic characteristics after the move represent an improvement over the previous situation. In cross-sectional surveys, premigration conditions must be retrospectively re-created; as earlier discussion of such questionnaires has suggested, several alternative methods of doing so are available, but a number of problems are also inevitable.

The research questions are even more complicated-at what point in the postmigration experience should the characteristics of migrants be assessed? The situation immediately after migration may not show the extent to which motives for movement have in fact been realized. If migrants are defined as resident in a place for one year or less, a survey may detect little more than the immediate postmigration situation. On 
the other hand, if the definition encompasses five-year or lifetime migration, the opportunities to measure changes in the postmigration period are greater, although comparability becomes difficult among migrants with different lengths of stay at the destination. For this reason, and because changes in opportunities at destination occur over time, migrants may have had quite different experiences. This problem applies to occupational as well as socioeconomic differences. Some studies (e.g., Balan, Browning, and Jelin, 1973) compare not only the situation of the individual migrant before and after the move but those of the individual and his or her parents, on the grounds that this provides a firmer basis for assessing changes in status.

Given the emphasis that Todaro (1976) and others have placed on migration as economically rational optimizing behavior, assessment of persons who migrate should ideally involve an initial rural survey with urban tracer follow-ups, including later interviews to generate accurate time series and cross-sectional information. The initial survey information would encompass not only those who have already left, but also potential and return migrants, to permit comparison of the variables affecting the migration decision. Todaro has prepared a comprehensive list of variables commonly collected in migration surveys (see Appendix 6). Since his list is directed mainly at econometric studies, there should be added a host of other variables of interest to sociologists, demographers, anthropologists, and political scientists-such as attitudes with respect to modemization, ethnicity, health; political involvement, and kinship structure. The length of the list indicates the enormous and complex challenges facing migration scholars who seek to identify who moves; how movers differ from others at destination and at origin; how characteristics of movers compare before and after migration, with a longer stay at destination, or with return to place of origin; and how characteristics of migrants in various streams differ.

Most studies include samples of both migrants and nonmigrants, largely reflecting the desirability of assessing the selectivity of migration at point of origin or differences at destinations in line with the needs specified earlier. Only a few studies have included attention to nonmigrants because of a primary interest in who these individuals are and what motivates them to remain stable, yet there is growing recognition of the need for such attention (Goldstein, 1976; De Jong and Fawcett, 1979; Goldscheider, 1971). The ILO Ludhiana study (Oberai, 1978) included a specific question- "Why do you prefer to 
stay in this village (city) permanently?"- that was asked of all persons 12 years old or over who were planning to do so. The questionnaire did not indicate, however; how these individuals were identified; evidently, it was done during the initial inventory of household members when migration status was ascertained. By identifying these individuals and their motives, it becomes possible to assess their characteristics against those who had left, returned, or in-migrated. Similar opportunities were provided in Hugo's (1978) Indonesian study. He asked the reasons for not migrating permanently to the city of those who circulated and commuted, thereby allowing comparison of the characteristics of both temporary movers and commuters with migrants, as well as of migrants with nonmigrants at origin.

A small test-study of migration in Kenya (Weisner, 1973) has suggested another way of obtaining information on differences between migrants and nonmigrants. Each of a sample of men who had migrated to Nairobi was asked to match himself to a rural nonmigrant of similar subclan, age, and education. Although the study was explicitly designed to assess the matching approach for studying rural-urban ties, the interviews with the men in the matched samples could also reveal differences between those who had moved to urban areas and those who had remained in rural places.

The Monterrey study (Balan, Browning, and Jelin, 1973) illustrates an attempt to combine census and survey data to ascertain who migrates in relation to the population at origin. Using census data for 1940 and 1960 and relying on classification of the country into zones, the researchers compared education and occupation of the migrants in Monterrey with those of the population in their places of origin at the time of the migrants' arrival in Monterrey. This procedure allowed assessing change in selectivity over time and enabled the authors to overcome one of the serious difficulties encountered by most studies that limit their analysis to migrants and nonmigrants at place of destination (e.g., McCutcheon, 1978; Green, 1978a). The differentials identified at the time of the survey do not necessarily indicate whether selectivity has changed over time since some of the earlier migrants may have either moved again or died.

A collection of brief summaries of research on migrant adjustment in Seoul, Surabaya, Bangkok, and Manila (Green, 1978a,b; McCutcheon, 1978; Tirasawat, 1978; Hendershot, 1978; Speare and Goldstein, 1978) shows some of the difficulties of using cross-sectional surveys as the 
basis for studying migration differentials and migrant adjustment, and at least one approach that can be employed to overcome these limitations. For both Seoul and Surabaya, the sample populations, composed of both migrants and natives, were drawn only from the cities themselves, the reby permitting the migrant/nonmigrant comparison only at destination. Retrospective data allowed some assessment of the situation at place of origin as well as changes in characteristics by duration of residence there. The inference from the static to the dy namic through such cross-sectional data has drawbacks and may be further affected, as noted, by the selective withdrawal of either successful or unsuccessful migrants. In contrast to the Seoul and Surabaya studies, the data for Bangkok and Manila are drawn from national sample surveys that allowed comparison of urban migrants not only with urban nonmigrants, but also with rural residents. But caution must be exercised here, too, since the characteristics of the population in rural places may not have remained static; therefore, the longer the in terval over which migration is measured, the less likely is it that the current characteristics or even the earlier characteristics of the migrants will be comparable to those of the population resident in the places of origin at time of the original survey.

Having information available about the characteristics of the place of origin at the time of migration partly copes with this problem. A more refined procedure, however, is that followed by Speare (1971). The period of migration covered by his study was limited to one year, so that combined coverage of migrants at destination and nonmigrants in the major places of origin permits closer coordination of the time during which migration actually occurred and thus fairer comparison of the characteristics of migrants and nonmigrants at both origin and destination.

Still another approach to assessing the situation before and after migration as well as comparing migrants and nonmigrants at both destination and origin has been by heavy reliance on the life history approach, especially the life history matrix. In collecting life histories among both migrant and nonmigrant populations at destination and place of origin, it is possible to achieve, through appropriate computer programming and analysis, a combination of assessments. Such data facilitate comparison of a host of characteristics of individual migrants before and after moving. Moreover, to the extent that detailed records are obtained on changes in these characteristics in the postmigration 
period, the impact of duration of residence on one or more of them is more easily determined. If comparable data are obtained for nonmigrants at destination, it then becomes possible, with proper controls for age and other crucial variables, to determine the extent to which migrants are experiencing changes at a slower or faster pace than the comparable nonmigrant population. Further, if similar data are obtained for the population at place of origin (at least those who are still there at the time of the survey) it is also possible to re-create their histories back to the time when the out-migrants left, with a view to both ascertaining more accurately the selectivity of out-migration and, through longitudinal analysis, determining the extent to which changes among migrants in the postmigration period differed from those of nonmigrants at origin over the same interval. The RETRO program developed by the Rand Corporation (Maclennan, 1978) promises to be of particular value for this type of analysis. Examples of efforts to use life histories in some of the ways outlined above are available in the work of Balan, Browning, and Jelin (1973) on the Monterrey project, and the work of Corno (1979) on Bogota, Lauro (1979) on a Thai village, and Perlman (1976) on. Rio de Janeiro.

\section{THE DETERMINANTS OF MIGRATION}

\section{Contextual data on places of origin and destination}

Closely related to the identification of migration differentials-that is, who migrates-is concern with the determinants of migration, on both a community and an individual level. Researchers recognize that information on characteristics of places of origin and destination, including some historical background, is essential to a full understanding of the migration process. Yet few scholars seem to have made concerted efforts to obtain such data and then use them analy tically to help explain migration patterns. Most seem content to describe the settings of their studies and then carry out their analyses without further regard to locational variables.

An exception to this relative neglect of contextual data is Hugo's (1978) study of population movement in 14. villages in West Java. Hugo provided a general overview of the physical, economic, and demographic situation in West Java, using a variety of government censuses and surveys as well as secondary sources. He then focused more directly on the agricultural situation in the survey villages, analyzing how they 
adjusted to environmental stress caused by agricultural involution and how migration was one response to the changes. To do so, he relied on work done by anthropologists in West Java as well as on his own observations. The resulting analysis forms an in tegral part of Hugo's discussion of the determinants of out-migration from the villages studied. Likewise, Dandekar and Bhate (1975) took advantage of information in a 1954 survey of six Indian villages to determine changes that had occurred in the subsequent 12 years in the economic, social, and structural conditions of the villages. They then interpreted demographic changes in light of the contextual changes, linking, for example, changes in occupational distributions to the introduction of certain government services and changes in in-migration patterns to economic development programs.

More general descriptions are provided by studies such as Corno's (1979) of the growth of Bogota within the general development of Colombia, especially the role of the capital city within the nation's urban structure. Similarly, Balan, Browning, and Jelin (1973) traced the development of Monterrey as an industrial center and of the rural areas and small towns of Mexico from which most of Monterrey's in-migrants came. In this analysis, extensive use was made of the 1940 and 1960 census data on migration to analyze changing patterns of migrant selectivity and to determine the economic situation in the various zones of Mexico. Both the choice of Cedral as an interview site because it was a source of migrants to Monterrey and the analysis of Monterrey's economic structure were based on census data.

Censuses have been most commonly used by the migration surveys reviewed here for help in identifying areas suitable for the specific kind of research to be undertaken or for providing contextual information against which to evaluate the characteristics of the migrants. Chi and Griffin (1976) and Simmons (1970) both used censuses to provide background information on general population characteristics. Chi and Griffin analyzed a 10 percent sample of the 1973 Census of Costa Rica to obtain data on the national population against which to compare patterns identified in the marginal settlements of Puerto Limon. Other studies, such as Herrick's (1965) and Visaria's (1969), reversed the approach and used surveys as a source of supplementary information to census and vital registration statistics.

Intercensal surveys and postenumeration surveys have also proved valuable sources of background information. Nagata (1974) used data 
from an intercensal survey in Malaysia to obtain information on intrazone migration, on migration to large cities, and on counterstreams of migration out of these cities. On the basis of this analysis, she proceeded with additional intensive fieldwork in two cities and one village to gather more detailed and subjective data. Fuller (1977) made use of commercial censuses available in Thailand to obtain information on the towns he studied in terms of the kinds of enterprises they contained, the types of services available, and the occupational structure. Young (1977) also used a variety of government data for background information against which to analyze out-migration from the Eastern Highlands of Papua New Guinea.

Studies concerned primarily with patterns of migration for village populations may consider the man-land ratio, the productivity of the land, land distribution patterns, and seasonal uses of land, as well as nonagricultural activity and total household income (Connell et al., 1977:8-15). Others consider the historical development of labor mobility in areas of large plantations (Richardson, 1975). Such data are also valuable for understanding the push and pull factors in rural-urban migration. In order to have appropriate background information for this aspect of their study, Suharso et al. (1976) conducted a special sample survey of the rural population of Indonesia. Questions were asked on ties to urban areas and on the economic situation of the villagers in terms of land ownership, occupation, housing, and income.

It is generally easier for studies of single, small villages to collect extensive information on pertinent historical developments, the cultural setting, the economic situation, and external changes that affect the village. Lauro (1979), for example, devoted a substantial portion of his analysis to such concerns. As a review of village studies by Connell et al. (1977) has stressed, it is necessary to ask whether greater in tegration of the rural population and the village economy in to the urban nexus stimulates or constrains movement. Included in any such assessment must be attention to familiarity with and use of transportation and communication networks, the impact of changing land tenure : patterns, the relation of migration to family size and structure in terms of village needs, the importance of household as opposed to individual decision making (Kim and Lee, 1978), and the roles of circulation and commuting as alternate forms of movement. Richardson's (1975: 215-19) investigation of migration patterns in Guyana highlighted the importance of labor circulation in villages with inadequate water 
systems and not enough job opportunities to supplement income from part-time paid work. He suggests that as the village infrastructure changes and as highway links are improved, the villagers' allocation of labor and mobility patterns are also likely to change. Cultural (ethnic) differences (Nagata, 1974) as well as village attitudes toward migration (Hugo, 1978) have also been considered. All these village studies illustrate the value of assessing the social and economic situation at both origin and destination.

On a larger scale, the Thai Longitudinal Study collected village profiles during the first rural survey. The data were not coded, however, and have not been available for use in any analyses of the household and individual data from the survey. The Malaysian Family Life Survey also collected a most extensive set of background data (Butz and DaVanzo, 1978). For each primary sampling unit, information was collected on schools, family planning clinics, job markets, and prices of relevant commodities; historical information was gathered on epidemics, floods, and education and heal th programs. Various spokesmen in each community provided this information, which was supplemented by external information sources. Such data were collected throughout the survey period and detailed profiles of each study area have been compiled.

The systematic approach of the Malaysian Family Life Survey seems to be exceptional. More often, contextual factors seem to be given only cursory attention, if they are considered at all, or they are not reported in the published results of the survey research. This is especially surprising, given the key interest in the in terrelations between movement and the characteristics of places of origin and destination, as well as in the impact of movement on these places. Not all studies are of such scope as to allow very extensive collection of background data; yet, as the few cited here have indicated, published government reports such as censuses, or other surveys, can provide valuable information with which to augment the analysis of the more detailed data gathered by sample surveys.

In emphasizing the inadequate attention given by survey research to the role of contextual factors as determinants of migration, stress must be given to the particularly noticeable gaps on the influence of social and cultural features. Reflecting the recognition of the importance of economic considerations on the decision to move, the economic aspects of the environment have been assessed much more 
intensively than have social, cultural, and political factors. As Amin (1974) and Titus (1978) have pointed out in their discussion of the center-periphery model of migration, movement may be affected not only by the degree of integration of specific regions into the world economy, but by sociocultural aspects of Western penetration, such as education and mission work, which may promote alienation from the autoch thonous culture and raise aspiration levels of the population with resulting rises in rates of migration (Titus, 1978:194-5). The extent to which social, cultural, and political considerations operate as stimuli for migration and the best ways to assess their impact in surveys remain to be more fully explored and tested.

\section{Individual determinants of migration}

Because data on individuals can be gathered more directly and easily in a survey than can data on places of origin or destination, a basic component of many migration surveys has been an effort to identify the individual determinants of migration. The most common and direct technique for obtaining such data is a question on the reason for the move, which may be open-ended-"Why did you move here?"-or formulated in terms of specific categories-such as seek work, study, marriage, official transfer, move with head, find seasonal work, and a general "other" category. The extent to which migrants recognize the categories as pertaining to their own motivations will depend partly on which reasons are specified; use of the "other" category seems to vary widely. In Liberia for example, most migrants stated only "other" reasons for migration (Liberia: Ministry of Planning and Economic Affairs, 1972, 1973) but in Bangkok, Thailand (National Statistical Office, 1978), less than 5 percent answered "other."

The detail with which the categories are differentiated will affect the resulting data and the possible insights to be gained. In Liberia, where "official transfer" was not a choice, civil servants and others who had been reassigned to new locations responded in terms of "work" or "other"; in Thailand, "of ficial transfer" was a possible choice. Such a distinction in reason for move may be important if reasons are then cross-tabulated by characteristics designed to indicate the socioeconomic status of migrants, since persons who are officially transferred tend to be better educated and to hold white-collar positions.

An openended question from which categories are formulated 
according to answers given may avoid too gross an aggregation of reasons. Asking for more than a single reason may also provide additional insights. For example, Chamratrithirong (1979) tabulated both a single reason given by responden ts and multiple reasons for moving obtained with some probing. Although "looking for work" remained the primary reason, the importance of seasonal migration became much more apparent when respondents were able to state more than a single reason. Hugo (1978) also asked an open-ended question and recorded up to four reasons. His analysis indicates the importance of taking various forms of movement into account when analyzing motivation. Migrants were likely to give education or economic reasons; commuters and circulators hoped to find work to supplement local earnings.

In the absence of direct questions, motivation for migration in relation to job changes, furthering education, or change in marital status can be deduced from life histories or by collating information from migration histories, employment histories, and marital histories if enough detail is collected (Feindt and Browning, 1972). Such information, however, fails to provide any insights into the more subtle determinants of migration. Moreover, asking the reason for migration directly may very well lead respondents "to rationalize their decision rather than disclose the pressures and latent motives that may have forced it" (Mowat, 1977:21). Further insigh ts into determinants are therefore of ten obtained by asking questions designed to elicit how much information the migrant had about the destination, what contacts he or she had before the move, what personal social and kin networks existed at the destination, and what the migrant's perceptions were about the advantages and disadvantages of rural and urban life.

Migrants' perceptions were also investigated by Speare $(1971,1972)$ in his study of the costs and benefits of migration, which included questions on the perceived versus the actual monetary costs of moving and living in an urban area, and on factors that cannot be measured in monetary terms but must be entered into a cost-benefit model-employment status, home ownership, sources of information, and proximity of family all may enter into the individual decision on whether to move. Since, as Speare found, many persons make no cost-benefit calculations at all with regard to mobility decisions, the nonmonetary variables take on added significance. 
Caldwell (1969:88-124) also asked a series of questions related to push and pull factors to determine the respondents' attitudes toward migration as well as the quality of information they had received about the destination. Included were questions on what makes town and village life "pleasant" and "unpleasant" and on attitudes toward male and female migration. Most questions were open ended, such as "More people are going to the big towns. Why do you think this is so?" The Bangk ok Metropolis migration survey (National Statistical Office, 1978) also asked respondents about their "positive" and "negative" feelings about Bangkok in terms of work (income and security), living (housing and utilities), and environment (safety and traffic). The report does not, however, provide the exact wording of the questions. Other studies (Mowat, 1977) have presented respondents with a set of statements about the advantages and disadvantages of urban and rural life and ascertained the extent of agreement. All these approaches help to indicate some of the underlying determinants of migration.

Caldwell went a step further than most studies examining the determinants of migration by seeking information on reasons for nonmigration as well. Of migrants he asked, "Some people stay in the village all their lives. Why do you think this is so?" and of nonmigrants, "Why did you stay in the village?" The ILO questionnaire also asks. nonmigrants about their reasons for not moving. Similarly, Hugo (1978:197-9) asked Javanese villagers who circulated or commuted to urban areas why they did not move permanently to the city. The answers were tabulated in terms of family ties, village life is more pleasant, need to work in village, no housing in city, city is too expensive-indicating the social benefits of living in the village and the economic costs of set tling a family in the city.

Sources, amount, and quality of information about poten tial destinations also play important roles in the decision to move. Several studies have asked respondents about their sources of information (e.g., Speare, 1972; Mowat, 1977:34-5; Hugo, 1978). Hugo and Caldwell also tried to obtain some indication of how accurate such information was by asking villagers what they thought "life in the town is like" (Caldwell, 1969:122) and urban in-migrants if life in town was what they had expected.

Evaluation of answers to such questions, as well as to questions on reasons for past actions, must recognize that respondents may perceive their situation retrospectively quite differently from what it was at the 
time of the move. Similarly, studies seeking information on outmigration from families left behind or from neighbors will not be able to determine the reasons for migration with a great degree of accuracy, if the information is available at all. Premi (1976), for example, found that although neighbors were able to provide information on the characteristics of families who had out-migrated, they generally did not know either the reason for the move or the destination.

The relation to movement of land tenure, agricultural activity, and income in the village have also been investigated in some studies. By keeping a ten-month daily mobility register as part of a general population register in a small village in Liberia, Smith (1977) was able to relate individual weal th and involvement in the market economy to the amount of movement exhibited by individuals. Lauro's analysis of movement using the life history matrix related circular migration and commuting to the amount of land ownership (Lauro, 1979:257-9). Other studies have asked questions about land tenure, the quality of land owned (irrigated or unimproved), and inheritance patterns (e.g., Smith, 1977; Simmons and Cardona, 1972; Oberai, 1978; Suharso et al., 1976). Nagata (1974) and Simmons (1970) demonstrated the importance of relating these factors to the type of move (migration, circulation, or commuting) so that their influence can be properly assessed.

The complexity of the interplay of factors determining migration and the difficulties in assessing them are clearly demonstrated by the variety of approaches used. They also illustrate the importance of taking both contextual and individual variables into account, and of recognizing the role of both perceived and actual situations. Various data sources have been and can be employed to provide the necessary information, ranging from censuses and surveys to in terviews with key informants in villages and urban centers. Continued experimentation with the use of all manner of data is called for, as is further innovation with the kinds of questions asked in survey instruments. As Hugo aptly put it,

Research into the motives of migration should focus to a greater extent on the contextual factors influencing mobility which may not emerge from questions asking why an individual moved. ... Contextual factors such as the number, location and intensity of personal contacts at possible destinations need to be investigated. The operation of social norms and networks of various types and their 
connection with mobility or stability need to be investigated such that the precise nature of their influence can be determined. ... The adoption of a multi-causal approach to explaining migration and non-migration which attempts to integrate social and economic elements is a major route by which our understan ding of mobility decision making can be advanced (Hugo, 1979:44).

\section{THE IMPACT OF MIGRATION}

The greater attention given recently to migration as a demographic process has received major impetus from the rapidity of urban grow th in less developed countries, reflecting the view that population redistribution has been responsible for many of the problems faced by cities and that relocation in an urban environment takes its toll on individuals as well. Yet the factors that contribute to migrant adjustment or maladjustment remain to be definitively documented, as does the migrant contribution to such problem areas as urban natural increase; unemployment, crime, illness, political instability, and environmental deterioration. The impact of out-migration on places of originprimarily villages-is even less well charted.

In general, efforts to measure the impact of migration have focused on migrant adaptation, and the degree of adaptation is most of ten inferred from a comparison of migrant and nonmigrant characteristics and behavior. Implicit in such techniques is the assumption that living conditions and socioeconomic characteristics exhibited by the native, nonmigrant population form a valid standard against which to measure adjustment. At the simplest level, such studies have involved comparisons of occupation, employment status, and income before migration and at the time of the survey (Krausse, 1979; National Statistical Office, 1978; Elizaga, 1966; Mowat, 1977; Zaghhoul, Sallam, and Bayyoumi, 1973); some studies have asked about the occupation of the respondent's father; and a few have included first job after migration to the city as a variable for measuring adaptation (Hogan and Berlinck, 1976).

Housing factors have been analyzed as part of the adaptation process, in terms of quality of housing, house tenure, and clustering within the city (Green, 1978a; Petersen, 1971; Krausse, 1979). Of particular concern has been the role of squatter settlements in aiding individual adaptation. Migrants in three marginal settlements of Puerto Limon, Costa Rica, for example, were asked about their satisfaction with their current compared with their previous housing, and about their building skills; their satisfaction with community facilities such 
as sanitation, schools, transportation, church, markets, and recreation; and their social bonds (Chi and Griffin, 1976).

The impact of migration on health and health services utilization has been investigated. For example, both Corno (1979) and Chamratrithirong (1979) asked respondents whether they knew of and used modern health facilities. A UNESCO-sponsored survey in Jakarta attempted to measure the incidence of serious illness or disabling conditions among migrants (Mowat, 1977:68). The experience of that study indicates, however, that asking respondents about specific illnesses in the past is problematic, both because of memory lapses and because the respondent is often unable to identify the illness (Mowat, 1977:68). The study of Benyoussef et al. (1974) of the health effects of rural-to-urban migration in Senegal included a special survey of the Dakar respondents on biomedical and mental health in addition to a survey that obtained sociodemographic information. On the basis of all the information collected, Benyoussef developed adaptation scores and correlated these with health indicators. The resulting low correlations were attributed in part to the failure of the analysis to include measures of mortality and morbidity, and in part to the possibility that the urban sample was not properly representative.

Benyoussef's adaptation scores may also have failed to take into account all the critical variables. Several studies have developed constellations of variables to serve as indicators of adjustment, and these vary widely. Benyoussef et al. (1974) identified seven questions as being the best indicators: (1) length of residence in Dakar; (2) interpersonal relations among members of the same tribe; (3) attendance at clubs; (4) existence of relationships with nontribe persons; (5) the type of relationships-at work, home, or leisure; (6) the desire to meet nontribe persons; and (7) the number of leisure activities. McGee (1975), on the other hand, developed indices of adaptation of migrants in Kuala Lumpur from questions determining the respondent's urban experience before moving to Kuala Lumpur, including father's occupation, respondent's contacts in the city, intention to remain in the city, material possessions, rural ties (including remittances), and urban activities. Kim and Lee (1978), in their analysis of urban in-migrants in Korea, considered residential settlement patterns, occupational stability, housing conditions, amount of debts and/or savings, participation in organizations, and life cycle changes.

Chamratrithirong (1979), in analyzing the impact of migration to 
Bangkok, made a distinction between adjustment on the one hand and assimilation and in tegration on the other. Adjustment was measured in terms of use of the transportation system (migrants were asked if they knew how to get to various places in Bangkok); familiarity with important places (including employment office, district office, amusement park, zoo, major Buddh ist temple); and subjective migrant evaluation. Assimilation and integration were defined in terms of contacts and social relations between migrants and urban natives, extent of religious practices (comparisons of migrant behavior before and after the move), health care utilization, and economic factors (labor force participation, occupation, and employment status).

A number of studies have ascertained the migrants' subjective evaluation of life in the city. Caldwell (1969:172-80), for example, asked questions such as "Have you had as much money and been able to buy as many things as you hoped when you first came here?" Fuller (1977) asked migrants in Thai cities if they found their new places of residence sabai (comfortable) and sanuk (fun). Lopez-Nerney (1977) also used subjective evaluation as part of the indices of adaptation that she developed.

A most extensive analysis of migrant adaptation was undertaken by Simmons (1970) in his study of highland Colombia. Using a "synthetic cohort" approach, Simmons de fined four migrant categories-rural nonmigrants, recent migrants, earlier migrants, and urban-born nonmigrants - to measure extent of urban exposure. Retrospective information was obtained from the migrant groups pertaining to their characteristics at time of migration. A subset of married males ages 20-54 was interviewed even more extensively for information about their fathers' characteristics as well as their own, and about their knowledge of contraception and ideas on family size. Simmons's most innovative technique was the development of a series of scales to analyze migrant adaptability based on measures related to planning orientation, work, complexity, mental flexibility, and education (including exposure to media). In addition to an IQ test administered by psychologists, respondents were asked a wide range of questions, such as "Do you read a newspaper? Do you have someone else read a newspaper to you? How often?" A series of questions on how often and under what conditions the respondent discussed his or her work with supervisors was designed to assess self-direction in work. Questions to assess mental flexibility included, "Can you imagine what your life with respect to 
your work will be like in one year? . . in five years?" Planning orientation was measured through such questions as "Some believe that working hard and making plans is not worthwhile because in the end things are not going to change. Others say this is not true. What do you think?" Attitudes toward family planning and family size were measured by asking, for example, "If you had a choice, how many children would you like to have?" Respondents were also asked if they had discussed family limitation with their spouses. The indices developed from these batteries of questions were analyzed along the urban exposure continuum to allow inferences about changes in migrant behavior and attitudes.

Attempts to measure migrant adaptation, despite problems of definition and of precision, are likely to include some elements of a before-and-after analysis within their framework, in recognition of the importance of changes over time in any such study. Yet, even though the impact of migration on fertility levels is often a central concern of survey research, few studies have related the timing or number of births to the timing of migration. Relying on children ever born as the usual measure of fertility, most surveys have had to be satisfied with analyses of migrant selectivity in terms of fertility or with describing the correlates of fertility levels, rather than identifying the actual changes in fertility behavior that might be attributed to the impact of migration. Conclusions about changes in fertility behavior are then based at best on a comparison of migrant fertility with that of individuals at places of origin and destination; many studies content themselves with just describing differentials between migrant and nonmigrant individuals at destination. Whether the differentials were due to selectivity at origin or change in behavior in conjunction with migration are not determined. Elizaga (1966) simply ascertained how many sons were born to migrants and nonmigrants in Santiago, Chile. Zarate's (1967) investigation of Monterrey, Mexico, used urban/rural place of birth to assess fertility differentials. Paydarfar's (1976) analysis of the fertility of women in Shiraz used an array of 35 socioeconomic and demographic variables, including joint husband-wife migration status; based on extensive multiple regression analysis and path models, he concluded that migration had no effect on fertility when the other characteristics were controlled.

Efforts to refine such analyses have disaggregated the migrant group by duration of residence (usually five years and long term) and rural/ 
urban origin (place of birth and/or previous residence). Research on migration and fertility in Morocco (Sabagh, n.d.) suggested that recent migrants (within ten years) were associated with lower fertility than some nonmigrants and long-term migrants. Goldstein and Tirasawat's (1977) analysis of 2,001 ever-married women living in urban places in Thailand also distinguished between five-year and long-term migrants and rural/urban origin. That study also considered the percentage of women who had been pregnant in the two years preceding the survey, by migration status, as a way of getting further insights into the possible effects of migration on fertility.

A major attraction of the design of the Thai Longitudinal Study lay in the opportunity it provided to assess changes in the surveyed population during the three-year interval between the first and the follow-up surveys. This was to be achieved through (a) use of data on respondents reinterviewed in the second rounds and (b) the comparative data available on the respective cross-sectional samples from the two rounds, the second of which was to be obtained through a combination of follow-up cases, replacement for losses, and addition of new cases to represent the population entering the age range and areas covered in the first survey rounds.

As already noted, the follow-up rate of 63 percent for the urban sample brings in to question the value of the panel data for assessing postmigration changes. This is especially true of the interrelations between migration and fertility, since the loss to follow-up was greater for migrants than nonmigrants, for recent compared with long-term migrants, and for migrants with lower fertility. Additional movement, in short, seems very much affected by both a prior record of migration and having fewer children. The selective loss argues for caution in the use of these and possibly other panel data to assess the relation over time between migration status and fertility. Whether comparisons based on the cross-sectional samples allow more reliable insights remains to be fully assessed. Here, the need for caution also seems essential; in large part reliability will depend on the nature of the replacement methods used to maintain the representativeness of the sample. If these do not insure that the cases lost to follow-up are replaced by comparable units (and there are reasons to believe that they may notGoldstein, 1977) differences observed in the relation between migration and fertility may be atypical of those that characterize the full original sample, especially migrants at a later time. 
In her analysis of migrant values and fertility in Guayaquil, Ecuador, Scrimshaw (1975) used both a random survey and intensive anthropological research. The data on numbers of pregnancies and live births that were gathered in the survey showed little difference in the fertility levels of migrants and nonmigrants, but a considerable difference between urban and rural levels. These findings, coupled with those emanating from more intensive subjective research, led Scrimshaw to conclude that "migrants adapt to the city rapidly, and have fertility patterns similar to urban ones within the same generation" (Scrimshaw, 1975:326). Unfortunately, the type of questions asked to determine changes in values are not included in the published report, but the discussion suggests that questions were asked in rural and urban places on parents' aspirations for their children and on extent and type of contraception used.

As long as a cumulative measure of fertility-total number of children ever born, number of living children, number of pregnancies-is used, determination of changes in fertility behavior in relation to migration is difficult, if not impossible. More direct information on the timing of births in relation to migration might be obtained from the coordinated use of fertility histories and migration histories, such as those collected by the Malaysian Family Life Survey (Butz and DaVanzo, 1978). Use of the life history matrix holds similar promise (e.g., Balan, Browning, and Jelin, 1973).

If the impact of migration on the individual is difficult to assess, the effect of migration on places of origin and destination is even more problematic. Most work done in this area has used census data. Of the research reviewed, only a few studies touch on these issues, although many recognize the need to investigate the impact of migration on rural and urban places. That surveys fail to do so is not surprising, since their focus is usually on individual characteristics and behavior, at a single point in time. Even longitudinal studies seldom gather the contextual data needed to evaluate the impact of migration. If any attempt is made at such an assessment, it is generally inferred from a comparison of the characteristics of migrants and natives at origin and destination (not unlike the evaluation of migrant adaptation). Few studies have tried to develop questions designed to measure the process directly.

The most direct questions asked are related to the impact of migration on villages and deal with remittances (e.g., National Statistical 
Office, 1977; Suharso et al., 1976). Caldwell (1969) asked a series of questions of migrants in Accra, Ghana, about the amount of funds sent to the villages, the frequency of sending, and the identification of the recipien ts. He also asked about plans to build in the village-"Do you expect to build a house in the village? Have you built rooms on to the family house?" (Caldwell, 1969:145). That study also asked about goods such as food and clothing brought back during visits. Chaudhury, in his study of out-migration from villages in Bangladesh, asked family members who remained behind, "Do you receive any money from outmigrants of this household? Do you remit any money to out-migrants of this household?" (Chaudhury, 1978:11-12). Based on the answers received, he concluded that remittances were able to "raise the poor above the level of the poorest poor" (Chaudhury, 1978:13).

Hugo's (1978:248-89) analysis of the importance of remittances for village life was based largely on observations and discussions with informants, but it suggested possibly useful directions for survey questions. He saw evidence of strong ties between migrants and villagers, particularly during village-based festivals. He also found that remittances were more likely to be forthcoming from circulators than from permanent migrants, and that the most important part of the income sent by commuters helped to pay for the education of younger members of the household. Moreover, remittances helped to create jobs in the village by financing new construction; they led to a greater demand for consumer goods, which in turn fostered the importation of new ideas through exposure to the media; and they allowed for a better diet. On the negative side, Hugo's analysis suggested that migration may lead to a dearth of leadership since most migrants were men in their twenties. In an attempt to gauge the villagers' own perceptions, Hugo asked about the good and bad effects of movement to urban areas. The villagers perceived remittances flowing back to the village as the most positive result; they also approved of the new skills and ideas that migrants brought back with them. On the other hand, they saw out-migration as changing traditional values and behavior in such a way as to be disruptive when the migrants returned to the village. Premi (1976) suggests that the out-migration of younger sons and brothers may have an effect on family life; this possibility also needs to be assessed.

Migration from the village may have an impact as well on levels of skill and education. Simmons and Cardona (1972:179) point out that 
"the influence of rural-urban migration on skill levels in the [villages] must not be judged only in terms of the loss of skilled out-migrants, for some of these migrants later return with additional education and skills that would have otherwise been unavailable in rural areas." Caldwell (1969:144) investigated this possibility by asking the urban migrants, "Do you go back to practice the job you've learned?" At the same time that out-migrants from rural areas may be more educated than sedentary villagers, they have been found to be generally less educated than urban natives at destinations. These differences may not be accurately indicated, however, by data based on characteristics at the time of the survey since many migrants move to the city to receive further education (Simmons and Cardona, 1972). A question on educational level at the time of migration might provide more accurate information.

Finally, the most visible impact of migration on the cities of destination is the residential clustering of migrants in areas where they have ties to kin and friends. In Haiti, Locher (1977:8) observed that the high density of migrants in urban households was correlated with the presence of extended family members who had recently arrived in the city. Hugo (1978:213-20) also observed overcrowding in those kampung (settlements) of Jakarta in which newly arrived migrants had ties. At worst, these areas become shanty town and squatter settlements.

As Simmons (1970) points out, however, the impact of migration on places of origin and destination, no less than on individuals, can be inferred only from cross-sectional data. Retrospective questions are helpful, but only within the limits of the accuracy of answers about events and characteristics in the past. Only through a series of followup surveys over a number of years can we begin to evaluate the effects of migration realistically and accurately.

\section{OVER VIEW}

Growing attention is now focused on the relation between population movement and development in the Third World, on the ways in which migration contributes to the exacerbation of urban problems and the reduction of rural poverty, and how efforts at rural development are affected by migration and in turn may contribute to migration. In view of the continuing increases projected in both rural and urban populations as well as the continued grow th of big cities, these 
concerns take on special significance. Yet, efforts to assess the relationship between population movement and the problems of cities and rural areas, as well as the formulation of policies and programs designed to cope with these problems and to foster development, have been seriously hampered by the lack of data on the various forms of population movement, how they have changed over time, and what functions they perform for the individual and for the communities of origin and destination.

This review has demonstrated the wide range of efforts that have already been made on national, regional, and local levels to rely on sample surveys in developing countries as a source of information on how many move, who moves, why they move, to where, and for how long. In addition, interest has of ten extended to the impact of movement on the individual movers and their communities of origin and destination, both as a direct consequence of the move and through indirect links maintained and/or established because of the move.

Incomplete as this review has been, it has also demonstrated the tremendous diversity that characterizes the studies that have been undertaken - their purposes, theoretical relevance, scope, research design, sampling procedures, definitions of migration, coverage of other forms of movement, attention to determinants and consequences, and resulting policy relevance. The frequent lack of comparability among studies with respect to most of these dimensions may help to explain both the difficulties encountered in attempting to reach generalizations about the patterns and impact of population movement in the developing nations and the limited value of most studies to date for policy purposes. Given the relative newness of the widespread concem with population movement as a dynamic force in demographic change and development in the Third World, the diversity of study designs has undoubtedly also served to provide a wide range of experience on the basis of which more sophisticated approaches can now be designedwithin the context of the specific purposes of particular studies. But the challenges in achieving such sophistication remain great, given the complexity of the process of movement at the decision-making level, at the behavioral level, and in terms of the impact on places of origin and destination, as well as on the individual mover, the mover's family, and even succeeding generations of that family.

Although this paper has aimed at factual presentation rather than prescriptions, it does not seem inappropriate to stress the main concerns 
that have emerged, since they conform closely to the conclusions of another recent paper prepared for a UN/UNFPA Workshop on Population Distribution Policies in Development Planning, "Research Priorities and Data Needs for Establishing and Evaluating Population Redistribution Policies" (Goldstein, 1979). Evidence available from migration studies in less developed countries strongly documents the need for major attention to migration and other forms of population movement, including commuting and circulation, in all forthcoming efforts to assess demographic change. It supports inclusion in censuses of sufficient questions to allow some detection of the volume and character of movement. This should be done not just at the provincial level but for smaller units, and certainly for rural and urban areas. Although many less developed countries have already conducted national demographic surveys, migration has received different degrees of attention, ranging from a few questions to an important focus. The individual community studies undertaken are even more numerous. Both national surveys and community studies will continue and will offer opportunities to obtain a rich body of data on migration, circulation, and commuting, provided that the need for such data can be impressed upon the appropriate authorities and scholars and that adequate care is taken in execution of the study design. Yet, given the concerns expressed earlier about the value of existing studies for purposes of comparative analysis, generalization, and policy formation and evaluation, efforts must be exerted to create maximum opportunity for both indepth and comparative analyses of migration. In this way, the effects of differences in population scale and socioeconomic conditions both within countries and regions and between regions can be assessed, together with the effectiveness of different policies.

In all such efforts, data collection must be guided by both appropriate theoretical concerns and appropriate questions and measures. Building on the insights provided by the studies completed to date, the conditions under which different ty pes of movement occur need to be specified more clearly, and their links to the modernization process-as both cause and effect-need elaboration. There is a pressing need to conceptualize and measure rural-urban mobility to allow all types of movers to be identified so that the role of different types of movement in the total development process can be more meaningfully assessed.

In surveys, adequate attention to the individual movers and 
nonmovers and to their respective households, as well as to the characteristics and conditions of their places of origin and destination, should permit greater insight in to the conditions leading to the decision to stay or to move. If the decision is to move, it should be possible to ascertain what factors, both individual and environmental, account for the type of move chosen-commuting, circulation, or migrationand how the specific destination was chosen over the altermatives available. Furthermore, research should inquire into adjustment to the move, later decisions to change from one type of movement to another (e.g., from commuting to circulation, or from circulation to permanent migration), alterations in intentions with respect to permanence, and the decision on whether to return to the place of origin or to move on to a new destination. For all types of moves, it is necessary to assess fully the nature of the interaction with place of origin and the effect of that interaction on the stayers. In relying on surveys to obtain such data, the limitations inherent in surveys generally and in retrospective questions in particular must be recognized. Moreover every effort must be made to initiate and use innovative research methods, including the life cycle matrix, the multiplicity approach, and dual record systems, as a way of enhancing the quality of the data. Given the concern with retrospective data, including those related to short-term movement, prospective panel studies also have to be considered and designed, and conducted in such a way as to insure maximum opportunities for follow-up, so that the losses resulting from migration do not bias the data obtained in succeeding survey rounds.

The studies already completed provide valuable experience and models for future research. The time is now ripe to build on them through development of a comprehensive research agenda that takes proper account of conceptual, measurement, and policy concerns. In this manner, insights necessary to develop more effective redistribution policies will be gained and the basis will be established for enhancing the likelihood that population movement will play an appropriate role in reducing inequities in the quality of life within and between rural and urban populations. 
APPENDIX 1 Migration history format used by Malaysian Family Life Survey (Butz et al., 1978)

\section{Introduction}

Now, I want to ask you some questions about the places where you have stayed and the work you have done.

1(a) Have you ever lived in any place other than (PLACE OF INTERVIEW) for 3 months or more? IF 'NO' ASK (b) AND (c), THEN GO TO NEXT Q'AIRE.

\section{IF YES}

(b) Where were you born?

RECORD TOWN. (NEAREST TOWN IF RURAL), MUKIM, DISTRICT \& STATE. RECORD COUNTRY IF NOT MALAYSIA.

(c) And where were you living at the time of your 15 th birthday? (IF MARRIED BEFORE AGE 15 : At the time just before your (first) marriage?)

IF DIFFERENT FROM BIRTH PLACE, RECORD TOWN, MUKIM, DISTRICT AND STATE. IF SAME PLACE WRITE 'SAME'.

(d) At what age did you first shift house after age 15?

(The year? The month?)

(e) Where did you move to?

RECORD TOWN/NEAREST MUKIM AND STATE.

(f) At what age did you next shift house?

(The year? The month?)

\section{REPEAT (e) AND (f) UNTIL YOU REACH PRESENT HOUSE}

INTERVIEWER : Identify the most recent migration, i.e. the last time the respondent made a complete change of home and workplace. Indicate $\left(^{*}\right)$ this on the summary and EXPLAIN : 


\section{APPENDIX 1 (continued)}

\begin{tabular}{|c|c|c|c|c|c|c|}
\hline $\begin{array}{l}\text { PUNCHER : } \\
\text { START NEW } \\
\text { EVENT CARD } \\
\text { REPEAT }\end{array}$ & ICOM & $\begin{array}{r}\text { AGE } \\
\text { PLETED } \\
\text { JAN. } \\
\text { FEB. } \\
\text { MAR. } \\
\text { APR. } \\
\text { MAY } \\
\text { JUNE } \\
\text { JULY } \\
\text { AUG. } \\
\text { SEPT } \\
\text { OCT. } \\
\text { NOV } \\
\text { DEC. } \\
\text { EARL } \\
\text { MID }\end{array}$ & $\begin{array}{l}\text { YEARS) } \\
=01 \\
=02 \\
=03 \\
=04 \\
=05 \\
=06 \\
=07 \\
=08 \\
=09 \\
=10 \\
=11 \\
=12 \\
\text { LY } \\
=13 \\
=14\end{array}$ & PLACES LIVED IN & & \\
\hline \begin{tabular}{l|l|l|l|}
3 & 0 & 1 & \\
\end{tabular} & & & $E=15$ & & & \\
\hline 101 & $.07)$ & & & & OFFICE & E CODE \\
\hline $\begin{array}{l}\text { EVENT } \\
\text { NUMBER }\end{array}$ & AGE & YEAR & MONTH & $\begin{array}{l}\text { NAME OF TOWN/MUKIM, } \\
\text { DISTRICT AND STATE }\end{array}$ & $\begin{array}{l}\text { TOWN/ } \\
\text { MUKIM/ } \\
\text { DISTR. }\end{array}$ & \begin{tabular}{|l} 
STATE \\
OR \\
COUNTRY
\end{tabular} \\
\hline$(08-10)$ & $(11-12)$ & $(13-14)$ & $(15-16)$ & & $(17-18)$ & $(19-20)$ \\
\hline$i \quad i$ & $!$ & $\vdots$ & $\vdots$ & & $i$ & $i$ \\
\hline$\vdots \quad \vdots$ & $!$ & $i$ & $i$ & & $i$ & $\vdots$ \\
\hline$!$ & $i$ & $\vdots$ & $i$ & & $!$ & $\vdots$ \\
\hline 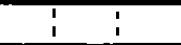 & $i$ & $i$ & $!$ & & $i$ & $i$ \\
\hline$i \quad i$ & $i$ & $i$ & $\vdots$ & & $!$ & $\vdots$ \\
\hline$! \quad !$ & $i$ & $\vdots$ & $!$ & & $!$ & $i$ \\
\hline$i \quad i$ & $!$ & $i$ & $!$ & & $\vdots$ & $!$ \\
\hline$!$ & $!$ & i & ; & & $i$ & $i$ \\
\hline $\begin{array}{l}1 \\
1\end{array}$ & $!$ & $i$ & $i$ & & $i$ & $\vdots$ \\
\hline$\vdots \quad \vdots$ & $!$ & $\vdots$ & $!$ & & $i$ & $!$ \\
\hline$\vdots \quad \vdots$ & $!$ & $i$ & $!$ & & $\vdots$ & $\vdots$ \\
\hline$i$ & $\overline{1}$ & $i$ & ! & & $i$ & $\vdots$ \\
\hline$i$ & $i$ & $i$ & $!$ & & $i$ & $\vdots$ \\
\hline$!$ & i & $i$ & 1 & & $!$ & $\vdots$ \\
\hline ! & i & $i$ & $!$ & & $\vdots$ & $i$ \\
\hline i $\quad 1$ & $!$ & $!$ & $\vdots$ & & $!$ & $\vdots$ \\
\hline$\vdots$ & $!$ & $i$ & $\vdots$ & & $!$ & : \\
\hline$!$ & $i$ & $i$ & $i$ & & $!$ & $i$ \\
\hline$\vdots \quad \vdots$ & $:$ & $!$ & $!$ & & $!$ & $\vdots$ \\
\hline$\vdots$ & $!$ & $i$ & $i$ & & $\vdots$ & $i$ \\
\hline ! & $i$ & $i$ & $i$ & & $i$ & $\vdots$ \\
\hline
\end{tabular}


APPENDIX 2 Migration-occupation history format used by Speare (Speare, 1976)

A1. Where were you bom?

Province

County/

City

Township/

cityl

district

A2. When were you born?

year month

A3. Are you single or married?

1. Single 2. Married

3. Widowed

4. Divorced

A4. What is the highest level of school you attended?
1. None
Attended
Graduated
Now Attending
2. Primary
3. Junior
4. Senior
5. College or university
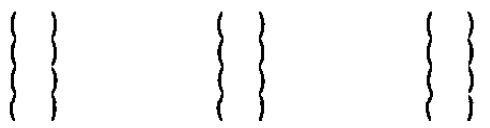

INTERVIEWER: IF R HAS COMPLETED JUNIOR SCHOOL, START WITH THE TIME WHEN HE FINISHED JUNIOR SCHOOL. ASK AS TO A 12. RECORD ON MIGRATION AND OCCUPATION HISTORY FORM.

IF R HAS NOT COMPLETED JUNIOR SCHOOL, START WITH THE TIME WHEN HE LEFT SCHOOL. ASK AS TO A 12. RECORD ON MIGRATION AND OCCUPATION HISTORY FORM

IF R HAS NO EDUCATION, START WITH PLACE WHERE HE WAS LIVING AT AGE 15. ASK AS TO A12. RECORD ON MIGRATION AND OCCUPATION HISTORY FORM.

I would like to ask you about all the cities or townships where you have lived since Don't count places where you lived for less than six months.

A5. What was the county (city) and township (district)? (RECORD ON FORM PAGE 2)

A6. Until what year did y ou con tinue to live at that place? (RECORD ON FORM PAGE 2)

A7. How many different dwelling units did you live in at that city or town? (RECORD ON FORM)

A8. Who was the head of household for the longest period of your residence?

A9. What other adults (aged 15 and over) lived in that household? (RECORD RELATIONSHIP TO HEAD OF HOUSEHOLD ON FORM)

A 10. Did the family own or rent the dwelling unit? (IF MORE THAN ONE DWELLING UNIT, OBTAIN FOR ONE OF LONGEST RESIDENCE)

A11. Were you working while you lived there? If yes, What was the occupation?

(IF MORE THAN ONE, GET OCCUPATION FOR LONGEST JOB)

A12. Why did you leave that place?

Please tell me all the cities, urban towns or rural towns which you have lived in since then, starting with the place you lived in after places where you lived for less than six months. Don't count

REPEAT QUESTIONS AS-A12 FOR EACH PLACE. 


\begin{tabular}{|c|c|c|c|c|c|c|c|c|c|c|c|c|c|c|c|}
\hline \multicolumn{16}{|c|}{ MIGRATION AND OCCUPATION HISTORY FORM } \\
\hline & \multirow[b]{2}{*}{$\begin{array}{l}\text { A5. } \\
\text { County } \\
\text { (City) }\end{array}$} & \multirow[b]{2}{*}{$\begin{array}{l}\text { A5. } \\
\text { Township } \\
\text { or district }\end{array}$} & \multicolumn{4}{|c|}{$\begin{array}{l}\text { A6. } \\
\text { Resident Period }\end{array}$} & \multirow{2}{*}{$\begin{array}{c}\text { A } 7 . \\
\text { No. of } \\
\text { Different } \\
\text { Places }\end{array}$} & \multirow[b]{2}{*}{$\begin{array}{c}\text { A8. } \\
\text { Head of } \\
\text { Houschold }\end{array}$} & \multirow[b]{2}{*}{$\begin{array}{l}\text { A9. } \\
\text { Other Adults } \\
\text { in Household }\end{array}$} & \multicolumn{4}{|c|}{$\begin{array}{c}\text { A } 10 . \\
\text { Housing is: }\end{array}$} & \multirow{2}{*}{$\begin{array}{c}\text { A11. } \\
\text { Occupation } \\
\text { (explain) }\end{array}$} & \multirow{2}{*}{$\begin{array}{l}\text { Al2. } \\
\text { Reason } \\
\text { for } \\
\text { Leaving }\end{array}$} \\
\hline & & & $\begin{array}{r}\mathrm{Re} \\
\mathrm{Fr} \\
\mathrm{Yr} .\end{array}$ & $\begin{array}{l}\text { siden } \\
\text { om } \\
\text { Mo. }\end{array}$ & $\begin{array}{r}\text { tPeri } \\
\text { Yr. }\end{array}$ & $\begin{array}{l}\text { od } \\
\text { Mo. }\end{array}$ & & & & 晃 & $\overrightarrow{\tilde{E}}$ & 芯怘 & ऐ্ّ & & \\
\hline 1 & & & & & & & & & & & & & & & \\
\hline 2 & & & & & & & & & & & & & & & \\
\hline 3 & & & & & & & & & & & & & & & \\
\hline 4 & & & & & & & & & & & & & & & \\
\hline 5 & & & & & & & & & & & & & & & \\
\hline 6 & & & & & & & & & & & & & & & \\
\hline 7 & & & & & & & & & & & & & & & \\
\hline 8 & & & & & & & & & & & & & & & \\
\hline 9 & & & & & & & & & & & & & & & \\
\hline 10 & & & & & & & & & & & & & & & \\
\hline 11 & & & & & & & & & & & & & & & \\
\hline 12 & & & & & & & & & & & & & & & \\
\hline 13 & & & & & & & & & & & & & & & \\
\hline 14 & & & & & & & & & & & & & & & \\
\hline 15 & & & & & & & & & & & & & & & \\
\hline 16 & & & & & & & & & & & & & & & \\
\hline 17 & & & & & & & & & & & & & & & \\
\hline 18 & & & & & & & & & & & & & & & \\
\hline 19 & & & & & & & & & & & & & & & \\
\hline 20 & & & & & & & & & & & & & & & \\
\hline
\end{tabular}


APPENDIX 3 Life history format used by Balan, Browning, and

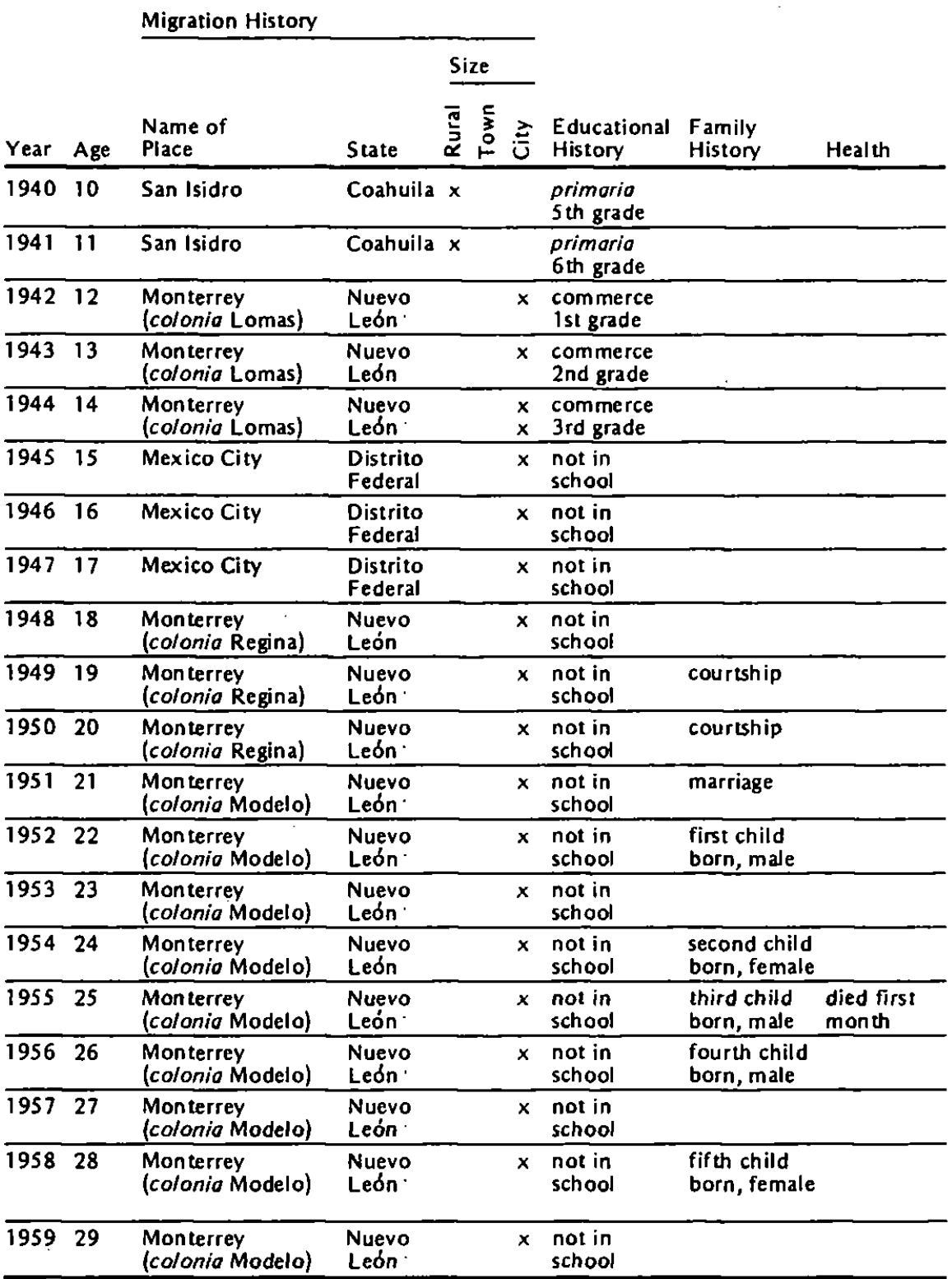

NOTE: Only twenty years of the respondent's life are presented in this illustrative life history. 
Jelin (Balan, Browning, and Jelin, 1973)

\begin{tabular}{|c|c|c|c|c|c|c|}
\hline \multicolumn{7}{|c|}{ Work History } \\
\hline \multirow[b]{2}{*}{$\begin{array}{l}\text { Name of } \\
\text { Occupation }\end{array}$} & \multirow[b]{2}{*}{$\begin{array}{l}\text { Description } \\
\text { of Duties }\end{array}$} & \multirow[b]{2}{*}{$\begin{array}{l}\text { Position } \\
\text { and } \\
\text { Dependent } \\
\text { Personnel }\end{array}$} & \multicolumn{3}{|l|}{ Enterprise } & \multirow[b]{2}{*}{$\begin{array}{l}\text { Income } \\
\text { (in pesos) }\end{array}$} \\
\hline & & & $\begin{array}{l}\text { Type.of } \\
\text { Industry }\end{array}$ & 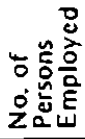 & 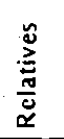 & \\
\hline $\begin{array}{l}\text { farm } \\
\text { worker }\end{array}$ & $\begin{array}{l}\text { helps his } \\
\text { father }\end{array}$ & $\begin{array}{l}\text { family } \\
\text { help }\end{array}$ & agricul ture & 3 & yes & none \\
\hline $\begin{array}{l}\text { farm } \\
\text { worker }\end{array}$ & $\begin{array}{l}\text { helps his } \\
\text { father }\end{array}$ & $\begin{array}{l}\text { family } \\
\text { help }\end{array}$ & agriculture & 3 & yes & none \\
\hline NOT & EMPLOYED & & & & & \\
\hline NOT & EMPLOYED & & & & & \\
\hline NOT & EMPLOYED & & & & & \\
\hline messenger & office boy & $\begin{array}{l}\text { employee } \\
0\end{array}$ & $\begin{array}{l}\text { railroad } \\
\text { office }\end{array}$ & 350 & no & 300 monthly \\
\hline messenger & office boy & $\begin{array}{l}\text { employee } \\
0\end{array}$ & $\begin{array}{l}\text { railroad } \\
\text { office }\end{array}$ & 350 & no & 300 monthly \\
\hline messenger & office boy & ${ }_{0}^{\text {employee }}$ & $\begin{array}{l}\text { railroad } \\
\text { office }\end{array}$ & 350 & no & 300 monthly \\
\hline
\end{tabular}

UNEMPLOYED FOR EIGHT MONTHS

\begin{tabular}{|c|c|c|c|c|c|c|}
\hline clerk & $\begin{array}{l}\text { types } \\
\text { letters }\end{array}$ & $\begin{array}{l}\text { employee } \\
0\end{array}$ & $\begin{array}{l}\text { mattress } \\
\text { factory }\end{array}$ & 50 & no & 150 weekly \\
\hline clerk & $\begin{array}{l}\text { types } \\
\text { letters }\end{array}$ & $\begin{array}{l}\text { employee } \\
0\end{array}$ & $\begin{array}{l}\text { mattress } \\
\text { factory }\end{array}$ & 50 & no & 150 weekly \\
\hline clerk & $\begin{array}{l}\text { types } \\
\text { letters }\end{array}$ & $\begin{array}{l}\text { employee } \\
0\end{array}$ & $\begin{array}{l}\text { mattress } \\
\text { factory }\end{array}$ & 50 & no & 180 weekly \\
\hline $\begin{array}{l}\text { purchasing } \\
\text { agent }\end{array}$ & $\begin{array}{l}\text { buys all } \\
\text { materials }\end{array}$ & $\begin{array}{l}\text { employee } \\
2\end{array}$ & $\begin{array}{l}\text { mattress } \\
\text { factory }\end{array}$ & 70 & no & 250 weekly \\
\hline $\begin{array}{l}\text { purchasing } \\
\text { agent }\end{array}$ & $\begin{array}{l}\text { buys all } \\
\text { materials }\end{array}$ & $\begin{array}{l}\text { employee } \\
2\end{array}$ & $\begin{array}{l}\text { mattress } \\
\text { factory }\end{array}$ & 70 & no & 250 weekly \\
\hline $\begin{array}{l}\text { owner of } \\
\text { small factory }\end{array}$ & manager & $\begin{array}{l}\text { employer } \\
5\end{array}$ & $\begin{array}{l}\text { plastic toy } \\
\text { factory }\end{array}$ & 6 & yes & 800 monthly \\
\hline $\begin{array}{l}\text { owner of } \\
\text { small factory }\end{array}$ & manager & $\begin{array}{l}\text { employer } \\
5\end{array}$ & $\begin{array}{l}\text { plastic toy } \\
\text { factory }\end{array}$ & 6 & yes & 800 monthly \\
\hline $\begin{array}{l}\text { owner of } \\
\text { small factory }\end{array}$ & manager & $\begin{array}{l}\text { employer } \\
5\end{array}$ & $\begin{array}{l}\text { plastic toy } \\
\text { factory }\end{array}$ & 6 & yes & 800 monthly \\
\hline $\begin{array}{l}\text { owner of } \\
\text { small factory }\end{array}$ & manager & $\begin{array}{l}\text { employer } \\
5\end{array}$ & $\begin{array}{l}\text { plastic toy } \\
\text { factory }\end{array}$ & 6 & yes & 800 monthly \\
\hline $\begin{array}{l}\text { owner of } \\
\text { small factory }\end{array}$ & manager & $\begin{array}{l}\text { employer } \\
3\end{array}$ & $\begin{array}{l}\text { plastic toy } \\
\text { factory }\end{array}$ & 4 & yes & $\begin{array}{l}\text { business losses } \\
\text { about } 1,500 \\
\text { monthly }\end{array}$ \\
\hline sales agent & $\begin{array}{l}\text { visits stores } \\
\text { selling skirts }\end{array}$ & $\begin{array}{l}\text { employee } \\
0\end{array}$ & $\begin{array}{l}\text { skirts } \\
\text { factory }\end{array}$ & 250 & no & \\
\hline
\end{tabular}

The last year recorded for all respondents was that of the survey, 1965. 
APPENDIX 4 Life history matrix used by Lauro (Lauro, 1979)

Interview Instrument for Life History Matrix Survey

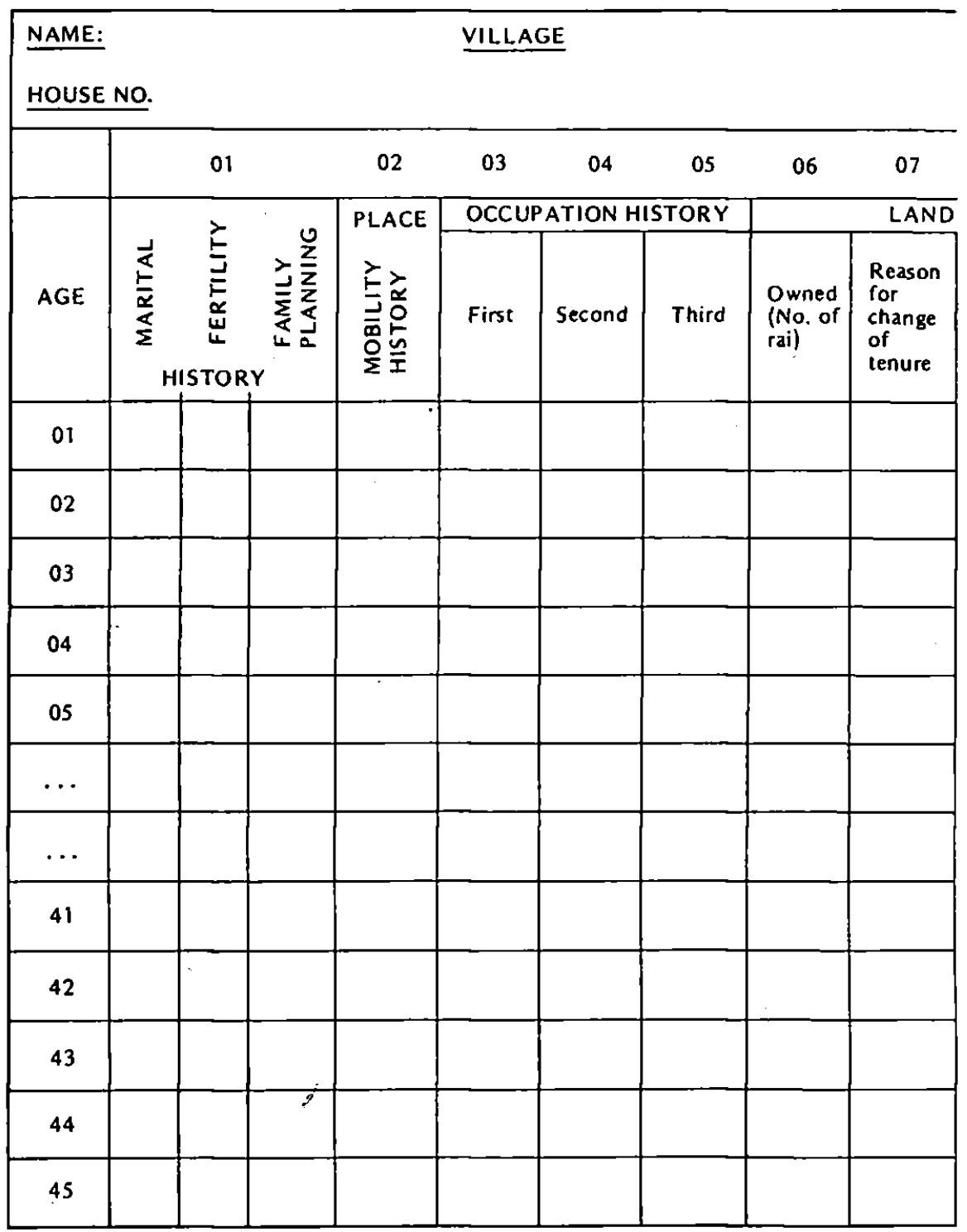




\begin{tabular}{|c|c|c|c|c|c|c|c|c|}
\hline \multicolumn{5}{|c|}{ IDENTIFICATION NUMBER } & & & \multicolumn{2}{|c|}{ BIRTHYEAR } \\
\hline 08 & 09 & 10 & 11 & 12 & 13 & 14 & 15 & 16 \\
\hline \multicolumn{2}{|l|}{ TENURE } & \multicolumn{3}{|c|}{ AGRICULT. TECHNIQUES } & \multicolumn{2}{|c|}{ DOUBLE CROPPING } & \multicolumn{2}{|c|}{ HEALTH HISTORY } \\
\hline $\begin{array}{l}\text { Rented } \\
\text { in } \\
\text { (No. of } \\
\text { rai) }\end{array}$ & $\begin{array}{l}\text { Rented } \\
\text { out } \\
\text { (No. of } \\
\text { rai) }\end{array}$ & $\begin{array}{l}\text { Method } \\
\text { of } \\
\text { plough- } \\
\text { ing }\end{array}$ & $\begin{array}{l}\text { Method } \\
\text { of } \\
\text { harvest }\end{array}$ & $\begin{array}{l}\text { Method } \\
\text { of } \\
\text { thresh- } \\
\text { ing }\end{array}$ & $\begin{array}{l}\text { No. of } \\
\text { rai }\end{array}$ & $\begin{array}{l}\text { Tech. } \\
\text { niques }\end{array}$ & $\begin{array}{l}\text { Serious } \\
\text { illness }\end{array}$ & $\begin{array}{l}\text { Medical } \\
\text { service }\end{array}$ \\
\hline & & & & & & & & \\
\hline & & & & & & & & \\
\hline & & & & & & & & \\
\hline & & & & & & & & \\
\hline & & & & & & & & \\
\hline & & & & & & & & \\
\hline & & & & & & & & \\
\hline & & & & & & & & \\
\hline & & & & & & & & \\
\hline & & & & & & & & \\
\hline & & & & & & & & \\
\hline & & & & & & & & \\
\hline
\end{tabular}


APPENDIX 5 Migrant classification scheme developed by Caldwell (Caldwell, 1969)

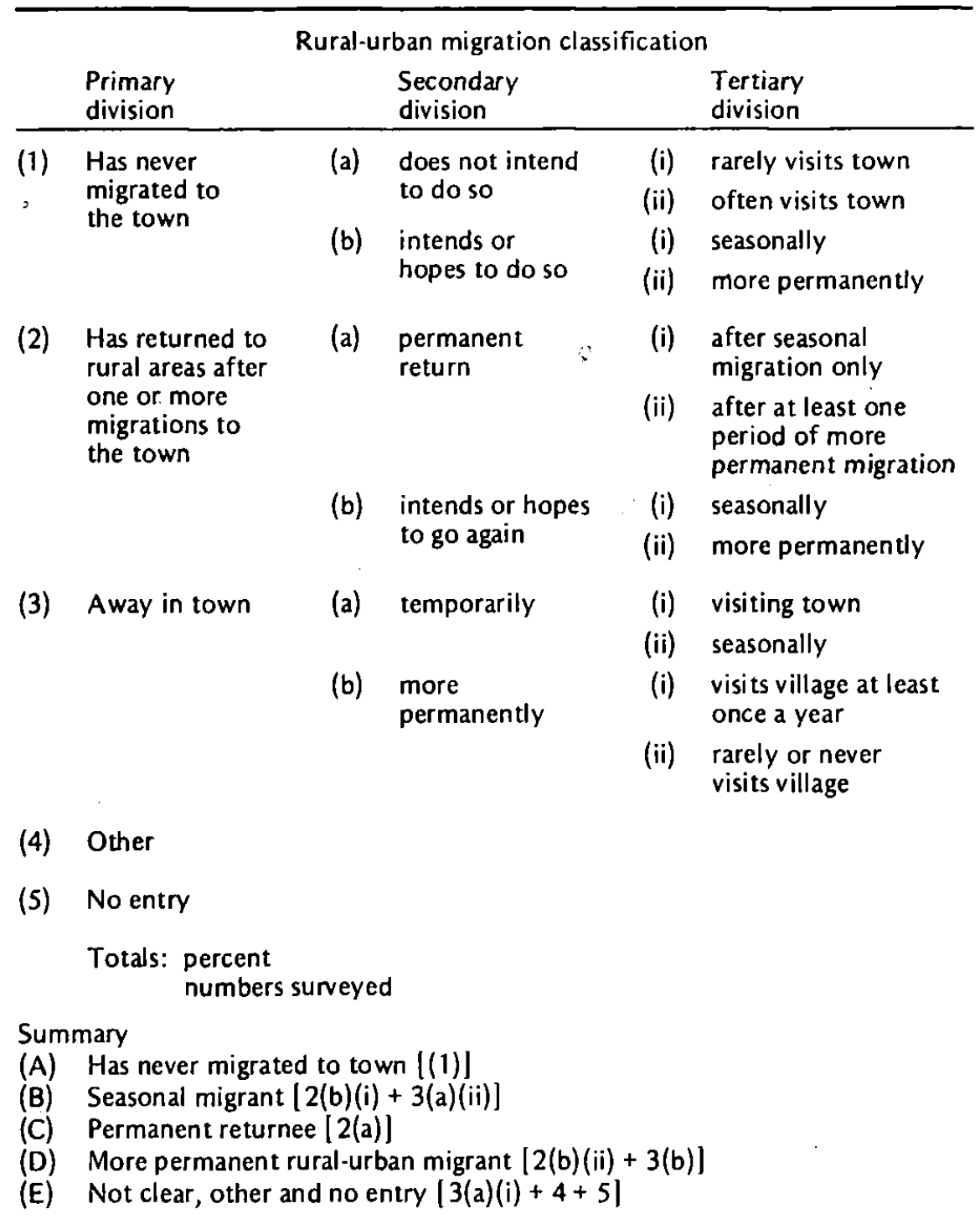

Definitions: 'Often visits town'-at least once a year on average; 'seasonally'-for periods of less than one year, but either for more than 3 months or securing employ ment; 'more permanently'-indefinitely or more than a year; 'visiting'-for less than 3 months providing no employ ment secured, other than as a household help for relatives or selling some things produced in the village or buying some goods for consumption or sale in the village; 'other'inclu des urban-nural migrants, especially teachers and other of ficials. 
APPENDIX 6 Variables collected in migration surveys as listed by Todaro (Todaro, 1976)

List of variables commonly collected, with both rural and urban components, in most migration surveys

Sex

Age

Ethnicity

Status in household

Maritál status

Number of children

Education

Variables collected by the urban components

Region of birth

Age on arrival in receiving area

Principal reason for moving

Year of arrival in town

Economic activity prior to migration

Income prior to migration

Intention to remain in receiving area

Expected reasons for leaving

Other migrants in family

Source of information regarding receiving area

Cost of transportation from source area

Source of finance for journey

Means of support on first arrival

Type of help from family and friends

Length of time to establish an.independent source of income

Marital status on arrival

Location of wife and children at time of migration

Frequency of visits to source area

Current assets in source area

Value of remittances to source area

Current employment status

Type of employer

Occupation

Size of firm

Wage income received

Supplementary benefits 


\section{APPENDIX 6 (continued)}

Hours worked

Job-search procedure

Past employment experience

Self-employment income

Value of assets

Number of employees

Length of time in activity

Barriers to entry

Variables collected by the rural components

Income from self-employment

Non-monetary income

$\checkmark$ alue of equipment

Size of plot

Wage income

Employment history

Mobility history

Intention to move

Perceptions of opportunities elsewhere 


\section{BIBLIOGRAPHY}

Abu-Lughod, Jane t

1975 The end of the age of innocence in migration theory. In Brian M. du Toit and Helen I. Safa, eds., Migration and Urbanization, pp. 201-6. Chicago: Aldine Press.

Adegbola, 0 .

1976 The migrants as a factor in regional development: the case of Ghana return migrants in Westem Nigeria. Jimlar Mutane 1(2).

Adepoju, Aderanti

1974 Socioeconomic links between migrants and home communities in Sou the ast Nigeria. Africa 44:383-96.

1976. Dynamics of urban population growth in Nigeria: the role of repeated migration. Jimlar Mutane 1(2):124-8.

1977 Migration and development in tropical Africa: some research priorities. African Affairs 73:210-25.

Agarwala, S.N.

n.d. Socioeconomic and demographic characteristics of the rural migrants and the non-migrants. Journal of Institute of Economic Research.

Aguirre, Cesar, and Marie Boleda

1975 Migraciones en la Provincia de Misiones, Vol. 2, La Encuesta de Migracienes de 1973: Aspectos Metodologicos. Buenos Aires: Direccion General de Estadistica y Censos.

Amin, Samir

1974 Modern migrations in Western Africa. In Samir Amin, ed., Modem Migrations in Western Africa, pp. 65-124. London: Ox ford University Press.

Arnold, Fred, and Suwanlee Piampiti

1979 Research and policy review of female migration in Thailand. Paper presented at Women in the Cities Working Group, East-West Population Institute, Honolulu, March.

Balan, Jorge, Harley L. Browning, and Elizabe th Jelin

1973 Men in a Developing Society: Geographic and Social Mobility in Monterrey, Mexico. Austin: University of Texas Press. 
Balan, Jorge, Harley L. Browning, Elizabeth Jelin, and Lee Litzler

1969 A computerized approach to the processing and analysis of life histories obtained in sample surveys. Behavioral Science 14: 105-19.

Bello Feitosa, Lucia Maria

1975 Internal migration in the Philippines: a study on migration differentials. Ph.D. dissertation, Department of Sociology, Brown University, Providence, RI.

Benyoussef, A., et al.

1974 Health effects of rural-urban migration in developing countriesSenegal. Social Science and Medicine 8:243-54.

Berquo, Elza S., Rubens Murillo Marques, Maria Lucila Milanesi, Jose de Souza Martins, Eunice Pinho, and Imre Simon

1968 Levels and variations in fertility in Såo Paulo. Milbank Memorial Fund Quarterly 46(2):167-85.

Butterworth, Douglas

1977 Selectivity of out-migration from a Mix tec community. Urban Anthropology 6:129-39.

Butz, William P., and Julie DaVanzo

1978 The Malaysian Family Life Survey: Summary Report. Santa Monica, CA: Rand Corporation.

Butz, William P., Julie DaVanzo, Dorothy Z. Fernandez, Robert Jones, and Nyle Spoelstra

1978 The Malaysian Family Life Survey: Appendix A, Questionnaires and Interviewer Instructions. R-2351/1-AID. Santa Monica, CA: Rand Corporation.

Byerlee, Derek, Joseph L. Tommy, and Habib Fatoo

1976 Rural-Urban Migration in Sierra Leone: Determinants and Policy Implications. Paper no. 13. East Lansing: African Rural Economy Program, Michigan State University.

Caldwell, John C.

1969 African Rural-Urban Migration: The Movement to Ghana's Towns. New York: Columbia University Press.

Chamratrithirong, Aphichat

1979 Recent migrants in Bangkok metropolis: a follow-up study of migran ts' adjustment, assimilation, and integration. Unpublished paper, Institute for Population and Social Research, Mahidol University, Bangkok. 
Chang, Ming-Cheng

1979 The economic adjustment of migrants in Taiwan. Working Paper no. 40. Ann Arbor: Population Studies Center, University of Michigan.

Chanlett, Eliska, and Marie Daniele Fichet

1976 The Dual Record System: Vital Event Recording Subsystem. Scientific Report Series no. 27. Chapel Hill: The Carolina Population Center, University of North Carolina.

Chapman, Murray

1975 Mobility in a non-literate society: method and analysis for two Guadalcanal communities. In Leszek A. Kosinski and R. Mansell Prothe ro, eds., People on the Move, pp. 129-45. London: Methuen \& Co.

1976 Tribal mobility as circulation: a Solomon Islands example of micro-macro linkages. In Leszek A. Kosinski and John W. Webb, eds., Population at Microscale, pp. 127-42. Hamilton: New Zealand Geographical Society.

- 1978 On the cross-cultural study of circulation. Intemational Migration Review 12:559-69.

Chapman, Murray, and R. Mansell Prothero

1977 Circulation between home places and towns: a village approach to urbanization. Paper presented at Working Session on Urbanization in the Pacific, Association for Social Anthropology in Oceania, Monterey, CA, March.

Chaudhury, Rafiqul Huda

1978 Determinants and consequences of rural out-migration: evidence from some villages in Bangladesh. In Economic and Demographic Change: Issues for the 1980's, vol. 2, pp. 213-28. Liège: International Union for the Scientific Study of Population.

Chi, Peter S.K., and Maryann D. Griffin

1976 A Study of Marginal Settlements in Puerto Limon, Costa Rica. Ithaca, NY: International Population Program.

Choucri, Nazli

1977 The new migration in the Middle East: a problem for whom?

International Migration Review 11:421-43.

Collier, David

1976 Squatter settlements and the incorporation of migrants into urban life: the case of Lima. Working Paper C/76-3. Cambridge, MA: Migration and Development Study Group, Massachusetts Institute of Technology. 
Connell, John, Biplab Dasgupta, Roy Laishley, and Michael Lipton

1977 Migration from Rural Areas: The Evidence from Village Studies. Delhi: Oxford University Press.

Conning, Arthur M.

1971 Rural community differentiation and the rate of rural-urban migration in Chile. Rural Sociology 36:296-314.

1972 Rural-urban destinations of migrants and community differentiation in a rural region of Chile. Intemational Migration Review $6: 148-57$.

Conroy, J.D.

1972 School leavers in Papua New Guinea: expectations and realities.

In M.W. Ward, ed., Change and Development in Rural Melanesia. Canberra: Australian National University.

1975 A model of education, expansion and unemployment. In J. Brammal and R.J. May, eds., Ectucation in Melanesia. Canberra: Australian National University.

1977 A longitudinal study of school leaver migration. In R.J. May, ed., Change and Movement, pp. 96-115. Canberra: Australian National University Press.

Cornelius, Wayne A.

1975 Urbanization and political demand making: political participation among the migrant poor in Latin American cities. Working Paper C/75-26. Cambridge, MA: Migration and Development Study Group, Massachusetts Institute of Technology.

Corno, Robert B.

1979 Migrant adjustment in Bogota, Colombia: occupation and health care. Ph.D. dissertation, Department of Sociology, Brown University.

Curtain, Richard

1975 Labor migration in Papua New Guinea: primary school leavers in the towns-present and future significance. In Helen I. Sa fa and Brian M. du Toit, eds., Migration and Development, pp. 269-93. Chicago: Aldine Press.

Dandekar, Kumudini, and Vaijayanti Bhate

1975 Socioeconomic change during three five-year plans. Artha Vijnane (Journal of the Gokhale Institute of Politics and Economics) 17:305-453. 
Day, Lincoln H.

1972 The newly-proposed United Nations recommendation for the improvement of migration statistics. Paper presented at Symposium on Migration, International Geographical Union Commission on Population, Edmonton, July-August.

De Jong, Gordon F., and James T. Fawcett

1979 Motivations for migration: an assessment and a value-expectancy research model. Paper prepared for Workshop on Micro-Level Approaches to Migration Decisions, East-West Population Institute, Honolulu.

Dietz, Henry

1976 Who, how, and why: rural migration to Lima. Working Paper C/76-4. Cambridge, MA: Migration and Development Study Group, Massachusetts Institute of Technology.

Ejiogu, C.N.

1968 African rural-urban migrants in the main migrant areas of the Lagos Federal Territory. In J.C. Cald well and C. Okonjo, eds., The Population of Tropical Africa, pp. 320-30. New York: Columbia University Press.

Ekanem, lta I., and Aderanti Adepoju

1976 A Study of Migration into Selected Capital Cities of Nigeria: Calabar and Morin. Ile-lfe: Department of Demography and Social Statistics, University of Ife.

Elizaga, Juan C.

1966. A study of migration to Santiago (Chile). Demography 3:352-77.

1972 Internal migration: an overview. International Migration Review: $6: 121-46$.

Feindt, Waltraut, and Harley L. Browning

1972 Return migration: its significance in an industrial metropolis and an agricultural town in Mexico. International Migration Review 6:158-65.

Flieger, Wilhelm

1979 Multiplicity survey in metropolitan Cebu City: preparatory activities. Un published report, University of San Carlos, Cebu City.

Flinn, William L.

1971 Rural and intra-urban migration in Colombia: two case studies in Bogota. In Francine F. Rabonovitz and Felicity M. Trueblood, eds., Latin American Urban Research, vol. 1, pp. 83-93. Beverly Hills, CA: Sage Publications. 
Freedman, Deborah, and Eva Mueller

1977 A Multi-Purpose Household Questionnaire. Washington, DC: World Bank.

Friberg, Justin

1978 Native, nonnative return and nonreturn migration to a Colombian metropolis. Paper presented to Population Association of America, Atlanta, GA.

Fuller, Theodore D.

1977 City ward migration and social stratification in Northeast Thailand. Ph.D. dissertation, Department of Sociology, University of Michigan.

1978 Patterns of urbanization and the economic adjustment of cityward migrants. Un published paper, University of Michigan.

George, M.V., and A.A. Eigefoh

1973 Population growth and migration in Lagos, 1911-1963. In Urbanization and Migration in Arab and African Countries, pp. 403-29. Cairo: Cairo Demographic Centre.

Girard, Alain

1977 Les immigrés du Maghreb: études sur l'adaption en milieu urbain. Population 32:405-10.

Goldscheider, Calvin

1971 Population, Modernization and Social Structure. Boston: Lit tle, Brown \& Co.

Goldstein, Sidney

1976 Facets of redistribution: research challenges and opportunities. Demography 13:423-34.

1977 Urbanization, migration, and fertility in Thailand. Report prepared for Center for Population Research, National Institute of Child Health and Human Development, Washington, DC.

1978 Circulation in the Context of Total Mobility in Southeast Asia, Paper no. 53. Honolulu: East-West Population Institute.

1979 Research priorities and data needs for establishing and evaluating population redistribution policies. Paper prepared for UNFPA Workshop on Population Distribution Policies in Development Planning, Bangkok, September.

Goldstein, Sidney, and Alice Goldstein

$1979 A$ Test of the Potential Use of Multiplicity in Research on Population Movement. Washington, DC: National Center for Health Statistics. 
Goldstein, Sidney, Pichit Pitaktepsombati, and Alice Goldstein

1976 Migration and urban growth in Thailand. In Anthony H. Richmond and Daniel Kubat, eds., Intemal Migration: the New World and the Third World, pp. 116-47. Beverly Hills: Sage Publications.

Goldstein, Sidney, and David F. Sly, eds.

1975a Basic Data.Needed for the Study of Urbanization: Liège: International Union for the Scientific Study of Population.

1975b The Measurement of Urbanization and Projection of Urban Population. Liège: International Union for the Scientific Study of Population.

Goldstein, Sidney, and Penporn Tirasawat

1977 The Fertility of Migrants to Urban Places in Thailand. Paper no. 43. Honolulu: East-West Population Institute.

Gould, W.T.S.

1976 Longitudinal studies of population mobility in tropical Africa.

Working Paper no. 29. Liverpool: African Population Mobility Project, University of Liverpool.

Gould, W.T.S., and R. Mansell Prothero

1973 Space and time dimensions in the study of population mobility in tropical Africa. Working Paper no. 1. Liverpool: African Population Mobility Project, University of Liverpool.

Green, Sarah C.

1978a Migrant adjustment in Seoul, Korea: employment and housing. Intemational Migration Review 12:70-81.

1978b Comparative studies of migrant adjustment in Asian cities. International Migration Review 12:66-9.

Gutkind, Pèter C.W.

1969 African urbanism, mobility, and the social network. In Gerald Breese, ed., The City in Newly Developing Countries, pp. 389400. Englewood Cliffs, NJ: Prentice-Hall.

Harrison, Robert S.

1967 Migrants in the city of Tripoli, Libya. The Geographical Review $57: 397-423$.

Hendershot, Gerry E.

1973 Fertility, social class, and outmigration: some Philippine data. Rural Sociology 38:312-24. 
1976 Social class, migration, and fertility in the Philippines. In The Dynamics of Migration: Intemal Migration and Migration and Fertility, Occasional Monograph Series, no. 5, vol. 1, pp. 197257. Washington, DC: Interdisciplinary Communications Program, Smithsonian Institution.

1978 Migrant-native differences in housing quality: Manila, 1973. Intemational Migration Review 12:104-13.

Herrick, Bruce $\mathrm{H}$.

1965 Urban Migration and Economic Development in Chile Cambridge, MA: Massachusetts Institute of Technology Press.

Hiday, Virginia A.

1975 Migration, urbanization, and fertility in the Philippines. International Migration Review 12:370-85.

Hill, Kenneth H., Guillermo A. Maccio, Abel Packer, and Jorge L. Somoza

1977 National Demographic Survey of Honduras: Methodology, Results, Indirect Estimates. Santiago: Centro Latino-Americano de Demografia.

Hogan, Daniel J., and Manuel T. Berlinck

1976

Conditions of migration, access to information and first jobs: a study of migrant adaptation in Såo Paulo, Brazil. In Anthony $\mathbf{H}$. Richmond and Daniel Kubat, eds., Internal Migration, the New World and the Third World, pp. 225-38. Beverly Hills: Sage Publications.

Hugo, Graeme

1978 Population Mobility in West Java. Yogyakarta: Gadjah Mada University Press.

1979 Village/community ties, village norms and village and ethnic social networks in migration decision making and behavior. Paper prepared for Workshop on Micro-Level Approaches to Migration Decisions, East-West Population Institute, Honolulu.

Hutchinson, Bertram

1961 Fertility, social mobility and urban migration. Population Studies 14:182-9.

Iutaka, Sugiyama, Barbara F. Bloomer, and Felix M. Berardo

1976 Fertility: natives and migrants in metropolitan Latin America. In Anthony $\mathrm{H}$. Richmond and Daniel Kubat, eds., Internal Migration, the New World and the Third World, pp. 239-65. Beverly Hills: Sage Publications. 
lutaka, Sugiyama, E.W. Bock, and W.G. Varnes

1971. Factors affecting fertility of natives and migrants in urban Brazil. Population Studies 25:55-62.

Jones, Robert, and Nyle Spoelstra

1978 The Malaysian Family Life Survey: Appendix C, Field and Technical Report. Santa:Monica, CA: Rand Corporation.

Kemper, Robert V.

1977 Migration and Adaptation: Tzintzuntzan Peasants in Mexico City. Beverly Hills: Sage Publications.

Kim, Kyong-Dong, and On-Jook Lee

1979 Adaptation to the city and retum home in the Republic of Korea.

International Social Science Journal 31:263-72.

Kosinski, Leszek A., and John W. Webb, eds.

1976 Population at Microscale. Hamilton, New Zealand: New Zealand Geographical Society.

Krausse, Gerald

1979 Economic adjustment of migrants in the city: the Jakarta experience. Intemational Migration Review 13:46-70.

Kritz, Mary M., and Douglas T. Gurak

1979 Intemational migration in Latin America. Intemational Migration Review 13:407-531.

Kuhn, W.E.

1978. Guest workers as an automatic stabilizer of cyclical unemployment in Switzerland and Germany. Intemational Migration Review $12: 210-24$.

Lauro, Donald J.

1979 The demography of a Thai village. Ph.D. dissertation, Department. of Demography, Australian National University.

Lee, Man-Gap, and Herbert R. Barringer

1978 Rural-Urban Migration and Social Mobility: Studies of Three South Korean Cities. Paper no. 51. Honolulu: East-West Population Institute.

Liberia: Ministry of Planning and Economic Affairs

1972 Demographic Annual of the Population Growth Survey, 1971. Series P-2. Monrovia. 
1973 Demographic Annual of the Population Growth Survey, 1971: Migration Profiles. Series M-2. Monrovia.

Lightfoot, R. Paul, and Theodore D. Fuller

1978 Affecting spatial pattems of rural to urban migration in Thailand. Unpublished manuscript.

Linder, Forrest E., and Joan W. Lingner

1975 Systems of Demographic Measurement, General Evaluation: The Measurement Problem. Scientific Report no. 22. Chapel Hill:

Laboratories for Population Statistics, University of North Carolina.

Locher, Uli

1977 Rural-urban migration and the alleged demise of the extended family: the Haitian case in comparative perspective. Working Paper no. 20. Montreal: Centre for Developing Area Studies, McGill University.

Lopez-Nerney, Susan

1977 Migrant Adjustment in Santa Mesa, Manila. Policy-Oriented Reanalysis Papers, no. 1. Manila: Population Center Foundation.

MacDonald, L.D., and J.S. MacDonald

1968 Motives and objectives of migration: selective migration and preferences toward rural and urban life. Social and Economic Studies 17:417-34.

Macisco, John J., Jr.

1975 Migrants to Metropolitan Lima. Santiago de Chile: Centro LatinoAmericano de Demografia.

Maclennan, Iva

1978 RETRO: A Computer Program for Processing Life History Data. Santa Monica, CA: Rand Corporation.

Madigan, Francis C., and Alejandro N. Herrin

1977 New Approaches to the Measurement of Vital Rates in Developing Countries. Reprint Series no. 18. Chapel Hill: Laboratories for Population Statistics, University of North Carolina.

Mantra, Ida Bagoes

1978 Population movement in wet-rice communities: a case study of two dukuh in Yogyakarta special region. Ph.D. dissertation, Department of Geography, University of Hawaii, Honolulu. 
Marks, Eli S., William Seltzer, and Karol J. Krotki

1974 Population Growth Estimates. New York: The Population Council.

Martine, George

1975 Migrant fertility adjustment and urban growth in Latin America. Intemational Migration Review 9:179-91.

McCutcheon, Laurie

1978 Occupation and housing adjustment of migrants to Surabaya, Indonesia: the case of a second city. International Migration Review 12:82-92.

McGee, T.G.

1975 Malay migration to Kuala Lumpur City: in dividual adaptation to the city. In Brian M. du Toit and Helen I. Safa, eds., Migration and Urbanization, pp. 143-78. Chicago: Aldine Press.

Miro, Carmen A.

1965 Some misconceptions disproved: a program of comparative fertility surveys in Latin America. In Bernard Berelson et al., eds., Family Planning and Population Programs, pp. 615-34. Chicago: University of Chicago Press.

Mitchell, J. Clyde

1961 The causes of labour migration. In Migrant Labour in Africa South of the Sahara. Publication no. 79, pp. 259-86. London: Commission for Technical Cooperation in Africa South of the Sahara.

Moon, Seung Gyu

1972 Outmigration from families of orientation in two rural communities: a case study of Korea. Publication Series no. 10. Seoul: The Population and Development Studies Center, Seoul National University.

Moots, Baron L.

1976 Migration, community of origin, and status attainment: a comparison of two metropolitan communities in developing societies. Social Forces 54:816-32.

Morgan, Robert W., and Vaino Kannisto

1973 A population dynamics survey in Lagos, Nigeria. Social Science and Medicine 7:1-30.

Morrison, Peter

1970 Implications of migration histories for model design. P-4342. Santa Monica, CA: Rand Corporation. 
Mowat, Susanne

1977 Education and the Urban Migrant. Bangkok: UNESCO Regional Office for Education in Asia.

Nagata, Judith A.

1974 Urban interlude: some aspects of internal Malay migration in West Malaysia. Intemational Migration Review 8:301-24.

Narain, Vatsala

1972 Rural out-migration in southern Maharashtra. Summarized in Indian Census Centenary Seminar, p. 89. Delhi: Registrar General of India.

National Statistical Office

1977 The Sunvey of Migration in Bangkok Metropolis, 1976. Bangkok.

1978 The Survey of Migration in Bangkok Metropolis, 1977. Bangkok.

Oberai, A.S.

1978 Determinants of rural-urban migration and its implications for nural areas with special reference to ILO research. In Economic and Demographic Change: Issues for the 1980's, vol. 2, pp. 229-42. Liège: International Union for the Scientific Study of Population.

Oey, Mayling, and Hananto Sigit

1977 Migration, economic development, and population growth: a case study of transmigrants in Lampung, Indonesia. Jakarta: Lembaga Penyelidikan Ekonomi dan Masyarakat, University of Indonesia.

Paydarfar, Ali A.

1974 Differential life styles between migrants and nonmigrants: a case study of the city of Shiraz, Iran. Demography 11:509-20.

1976 Fertility differences between migrants and non-migrants: a case study of the city of Shiraz, Iran. Institute for Research in Social Science, University of North Carolina, Chapel Hill. Mimeographed.

Perlman, Janice E.

1976 The Myth of Marginality: Urban Poverty and Politics in Rio de Janeiro. Berkeley: University of California Press.

Petersen, Karen Kay

1971 Villagers in Cairo: hypotheses versus data. American Joumal of Sociology 77:560-73. 
Prachuabmoh, Visid, et al.

1971 The Methodology of the Longitudinal Study of Social, Economic, and Demographic Change. Research Report no. 6. Bangkok: Institute of Population Studies, Chulalongkom Unive rsity.

Prachuabmoh, Visid, John Knodel, and Pichit Pitaktepsombati

1973 The Longitudinal Study of Social, Economic, and Demographic Change in Thailand: The Second Rounds. Paper no. 3. Bangkok: Institute of Population Studies, Chulalongkorn University.

Premi, Mahendra K.

1976 Out-migration from urban areas: a case study of an Indian town. In Anthony H. Richmond and Daniel Kubat, eds., Internal Migration, the New World and the Third World, pp. 103-15. Beverly Hills: Sage Publications.

1980 Urban Outmigration. A Study of Its Nature, Causes, and Consequences. New Delhi: Sterling Publishers.

Prescott, J.R.V.

1959 Migrant labour in the Central African Federation. The Geographic Review 49:424-7.

Prothero, R. Mansell

1968 Migration in tropical Africa. In J.C. Caldwell and C. Okonjo, eds., The Population of Tropical Africa, pp. 250-63. New York:

Columbia University Press.

Pryor, Robin J.

1975 The Motivation of Migration. Studies in Migration and Urbanization no. 1. Canberra: Department of Demography, Australian National University.

Pryor, Robin J., ed.

1979 Residence History Analysis. Studies in Migration and Urbanization no. 3. Canberra: Department of Demography, Australian National University.

Raczynski, Dagmar

1972 Migration, mobility, and occupational achievement: the case of Santiago, Chile. International Migration Review 6:182-98.

Rempel, Henry, and Richard A. Lobdell

1978 The role of urban-to-rural remittances in rural development. Joumal of Development Studies 14:324-41. 
Rempel, Henry, and Michael P. Todaro

1972 Rural-to-urban labour migration ir Kenya. In S.H. Ominde and C.N. Ejiogu, eds., Population Growth and Economic Development in Africa, pp. 214-31. London: Heinemann.

Rengert, A.C., and G.F. Rengert

1972 Distance and human migration: a study in rural Mexico. In W. Peter Adams and Frederick M. Helleiner, eds., International Geography 1972, vol. 1, pp. 488-90. Toronto: University of Toronto Press.

Rengert, George F., and Arlene C. Rengert

1971 Factors related to migration behavior. In Proceedings of the Association of American Geographers, pp. 10-14. New York: Columbia University Press.

Richardson, Bonham C.

1975 Plantation infrastructure and labor mobility in Guyana and Trinidad. In Helen I. Safa and Brian M. du Toit, eds., Migration and Development, pp. 204-24. Chicago: Aldine Press.

Roussel, Louis, Francois Turlot, and R. Vaurs

1968 La mobilité de la population urbaine en Afrique Noire: deux essais de mesure, Abidjan et Yaoundé. Population 23:332-52.

Rumford, John

1972 Factors influencing the casefinding of migrations in the Liberian fertility survey. Demography 9:431-42.

Rumford, John, and Samuel Greene

1979 A study of the correlation bias of unrecorded events by two independent enumeration systems. Population Studies 33:181-8.

Sabagh, Georges

n.d. Migration and fertility in Morocco. Department of Sociology, University of California at Los Angeles. Mimeographed.

1969 The measurement of migration in longitudinal surveys: the experience of the 1961-63 multipurpose sample survey of Morocco. Paper contributed at Intemational Union for the Scientific Study of Population General Conference, London.

Sahota, G.S.

1968 An economic analysis of internal migration in Brazil. The Joumal of Political Economy 76:218-45. 
Schnaiberg, Allan

1970 Rural-urban residence and modernism: a study of Ankara Province, Turkey. Demography 7:71-85.

Scrimshaw, Susan C.

1975 Families to the city: a study of changing values, fertility, and socioeconomic status among urban in-migrants. In Moni Nag, ed., Population and Social Organization, pp. 309-30. The Hague: Mouton Publishers.

Seetharan, K.S., K.E. Vaidy anathan, M.V. George, and O.F. Nassef

1973 Urbanization and migration in Arab countries: an overview. In Urbanization and Migration in Some Arab and African Countries, Research Monograph Series no. 4, pp. 473-504. Cairo: Cairo Demographic Centre.

Seok, Hyun-Ho

1972 Selectivity of out-migrants: a case of six villages study in Korea. Bulletin of the Population and Development Studies Center (Seoul National University) 1(1):16-26.

Simmons, Alan B.

1970 The Emergence of Planning Orientations in a Modernizing Community: Migration, Adaptation, and Family Planning in Highland Colombia. Dissertation Series no. 15. Ithaca: Latin American Studies Program, Cornell University.

Simmons, Alan B., and Ramiro Cardona G.

1972 Rural-urban migration: who comes, who stays, who returns? The case of Bogota, Colombia, 1929-1968. International Migration Review 6: 166-81.

Simmons, Alan, Sergio Diaz-Briquets, and Aprodicio A. Laquian

1977 Social Change and Internal Migration: A Review of Research Findings from Africa, Asia, and Latin America. Ottawa: International Development Research Centre.

Singhanetra-Renard, Anchalee

1977 Circular mobility of the northern Thai village. Mimeographed report, East-West Population Institute, Honolulu.

Sirken, Monroe G.

1970 Household surveys with multiplicity. Joumal of the American Statistical Association 65:257-66. 
Sjaastad, L.A.

1962 The costs and returns of human migration. Joumal of Political Economy 70:80-93.

Smith, E.R.

1977 Short-Term Circulation Movements at a Micro-Scale: Nima,

Liberia. African Population Mobility Project Working Paper No. 32.

Liverpool: Department of Geography, University of Liverpool.

Sovani, N.V.

1959 Potential out-migrants and removable surplus population in three districts of Orissa (India). Intemational Population Conference, Vienna, 1959, pp. 703-9. Vienna: International Union for the Scientific Study of Population.

Speare, Alden, Jr.

1971 A cost-benefit model of rural to urban migration in Taiwan. Population Studies 25:117-30.

1972 The determinants of migration to a major city in a developing country: Taichung, Taiwan. Population Papers no. 4. Taipei: Institute of Economics, Academia Sinica.

1976 Migration Decisions in Taiwan. Providence, RI: Population Studies and Training Center, Brown University.

Speare, Alden, Jr., and Sidney Goldstein

1978 Summary. International Migration Review 12:114-16.

Speare, Alden, Jr., Sidney Goldstein, and William H. Frey

1976 Residential Mobility, Migration, and Metropolitan Change. Cambridge, MA: Ballinger Publishing Co.

Speare, Alden, Jr., Mary C. Speare, and Hui-Sheng Lin

1973 Urbanization, non-familial work, education, and fertility in Taiwan. Population Studies 27:323-34.

Stark, Oded

1978 Desired fertility and rural-to-urban migration in LDCs: the positive connection. Paper no. 6/78. Tel Aviv: David Horowitz Institute for the Research of Developing Countries, Tel Aviv University.

Statistical Centre of Iran

1976 Population Growth of Iran: First Survey Year, 1973-1974. No. 624. Tehran.

1977 Population Growth of Iran: Second Survey Year, 1974-1975. No. 640. Tehran. 
Sternstein, Larry

1977 Internal migration and regional development: the Khon Kaen development centre of Northeast Thailand. Journal of Southeast Asian Studies 8:106-16.

Stoeckel, John, A.K.M. Alauddin Chowdhury, and K.M.A. Aziz

1972 Out-migration from a nural area of Bangladesh. Rural Sociology $37: 236-45$.

Stromberg, Jerome, Habib Peyman, and John E. Dowd

1974 Migration and health: adaptation experiences of Iranian migrants to the city of Teheran. Social Sciences and Medicine 8:309-23.

Suharso, Alden Speare, Jr., Han R. Redmana, and Imron Husin

1976 Rural-Urban Migration in Indonesia. Jakarta: National Institute of Economic and Social Research.

Tekse, Kalman

1975 Projections of urban population. In Sidney Goldstein and David F. Sly, eds., The Measurement of Urbanization and Projection of Urban Population, pp. 89-142. Liege: International Union for the Scientific Study of Population.

Thomas, Dorothy S.

1938 Research Memorandum on Migration Differentials. New York: Social Science Research Council.

Tirasawat, Penporn

1978 Economic and housing adjustment of migrants in greater Bangkok: International Migration Review 12:93-103.

Titus, M.J.

1978 Interregional migration in Indonesia as a reflection of social and regional inequalities. Tijdschrift voor Economische en Sociale Geografie 69:194-204.

Todaro, Michael P.

1976 Internal Migration in Developing Countries. Geneva: International Labor Office.

Tsay, Ching Lung

1979 Employment and earnings of cityward migrants: a study of individual outcomes of migration to Taipei. Ph.D. dissertation, Department of Sociology, Brown University. 
Ulack, Richard

1976 Migration to the slum and squatter communities of Cagayan de Oro City, The Philippines. Intemational Migration Review 10: 355-76.

United Nations

1970 Manual VI: Methods of Measuring Internal Migration. Population Studies no. 47. New York.

1974 Handbook of Population and Housing Census Methods. Pt. 4, Survey of Population and Housing Census Experience, 1955-1964. ST/STAT/Ser.F/16/Add.4. New York.

United Nations Department of Economic and Social Affairs

1973 The Determinants and Consequences of Population Trends. Vol. 1. Population Studies no. 50. New York: United Nations.

United Nations Department of International Economic and Social Affairs 1978

Statistics of Intemal Migration: A Technical Report. Studies in Methods Series F, no. 23, ST/ESA/STAT/Ser.F/23. New York: United Nations.

1980 World Population Trends and Policies, 1979 Monitoring Report, vol. 2, Population Policies. Population Studies no. 70. New York: United Nations.

United Nations Economic and Social Commission for Asia and the Pacific (ESCAP)

1979 A comparative study of the relationships of migration and urbanization to development in the ESCAP region. Unpublished manuscript, Bangkok, Thailand.

1980 National Migration Surveys. Manuals I-VII. New York: United Nations.

United Nations Economic and Social Council

1976 Social and economic statistics, migration studies, pp. 1-21.

E/CN.3/484. New York: United Nations.

Visaria, Pravin

1969 Urbanization, migration, and fertility in India. In The Family in Transition, Fogarty International Center Proceedings no. 3, pp. 257-83. Washington, DC: Government Printing Office.

Weisner, Thomas $\mathbf{S}$.

1973 Studying rural-urban ties: a matched network sample from Kenya. In William M. O'Barr, David H. Spain, and Mark A. Tessler, eds., Survey Research in Africa, pp. 122-34. Evanston, IL: Northwestern University Press. 
Weller, Robert H.

1974 The structural assimilation of in-migrants to Lima, Peru. Intemational Migration Review 8:521-42.

Wilkening, E.A.

1968: A comparison of migrants in two rural and an urban area of central Brazil. Research Paper no. 35. Madison: Land Tenure Center, University of Wisconsin.

Wilson, Godfrey

1941-42 An Essay on the Economics of Detribalization in Northern Rhodesia. Pts. 1 and 2. Rhodes-Livingstone Papers.nos. 5 and 6. Livingstone: Rhodes-Livingstone Institute.

World Fertility Survey

1975 Core Questionnaires. Basic Documentation no. 1. The Hague: International Statistical Institute.

Yap, Lorene Y.L.

1975 Intermal Migration in Less Developed Countries: A Survey of the Literature. Staff Working Paper no. 215. Washington, DC: World Bank.

Young, E.A.

1977 Population mobility in Agarabi/Gadsup, Eastem Highlands Province. In R.I. May, ed., Change and Movement: Readings on Internal Migration in Papua New Guinea, pp. 173-202. Canberra: Australian National University Press.

Yu, Eui Young

1972 Some notes on migration data from the 1966 Special Demographic Survey. Korean Joumal of Sociology 7:57-76.

Zachariah, K.C.

1966 Bombay migration study: a pilot analysis of migration to an Asian met ropolis. Demography 3:378-92.

Zaghhoul, S., Abdel Ghani Sallam, and Adel Bayyoumi

1973 Some demographic, social, and economic aspects of settlers in Tahrir Province, Egypt: 1973. In Urbanization and Migration in Some Arab and African Countries, pp. 251-64. Research Monograph Series no. 4. Cairo: Cairo Demographic Centre.

Zarate, Alvin $\mathrm{O}$.

1967 Differential fertility in Monterrey, Mexico: prelude to transition. Milbank Memorial Fund Quarterly 45:93-106. 
Zarate, Alvin O., and Alicia Unger de Zarate

1965 On the reconciliation of research findings of migrant-nonmigrant fertility differentials in urban areas. Intemational Migration Review 9:115-56. 


\section{-}




\section{RECENT AVAILABLE PAPERS OF THE EAST-WEST POPULATION INSTITUTE}

No.

77 An assessment of fertility and contraception in seven Philippine provinces: 1975, by Wilheim Flieger and Imelda Pagtolun-an, November 1981, x + 154 pp.

78 The population dynamics of Nepal, by Judith Banister and Shyam Thapa, December 1981 , viii + 119 pp.

79 Migration and unemployment in Hawaii, by Robert D. Retherford, January 1982, vi +18 pp.

80 The demographic situation in India, by Mahendra K. Premi, February 1982, x+152 pp.

60-E The changing value of children in Turkey, by Cigdem Kagitcibasi, June 1982, viii + 100 pp.

81 Labor markets, urban systems, and the urbanization process in Southeast Asian countries, by Terence G. McGee, July 1982, vi +28 pp.

82 Ethnicity, birthplace, and achievement: the changing Hawaii mosaic, by Paul Wright and Robert W. Gardner, February 1983, vi +41 pp.

83 Population distribution policies in Asia and the Pacific: current status and future prospects, by Roland J. Fuchs, February 1983, viii +40 pp.

84 Circulation and interpersonal networks linking rural and urban areas: the case of Roiet, Northeastern Thailand, by Paul Lightfoot, Theodore Fuller, and Peerasit Kamnuansilpa, March 1983, vi + 46 pp.

85 Development perspectives and population change, by Ozzie G. Simmons, April 1983, $\mathrm{vi}+41 \mathrm{pp}$.

86 The effects of induced abortion on subsequent reproductive function ánd pregnancy outcome: Hawaii, by Chin Sik Chung and Patricia G. Steinhoff in collaboration with Roy G. Smith and Ming Pi Mi, June 1983, xii + 144 pp.

60-F Influences on childbearing intentions across the fertility career: demographic and socioeconomic factors and the value of children, by Rodolfo A. Bulatao and James T. Fawcett, June 1983, $x+152$ pp.

87 Population mobility and wealth transfers in Indonesia and other Third World societies, by Graeme 1. Hugo, July 1983 , vi +50 pp.

88 Structural change and prospects for urbanization in Asian countries, by Gavin W. Jones, August 1983, vi $+46 \mathrm{pp}$.

89 Urban growth and local taxes in less developed countries, by Roy Bahl, Daniel Holland, and Johannes Linn, September 1983, vi +33 pp.

90 A false fertility transition: the case of American blacks, by Paul Wright and Peter Pirie, February 1984, viii +81 pp.

60-G The old-age economic security value of children in the Philippines and Taiwan, by Susan De Vos, March 1984, viii +72 pp.

91 A profile of Hawaii's elderly population, by Eleanor C. Nordyke, Richard K.C. Lee, and Robert W. Gardner, August 1984, viii +39 pp.

92 City characteristics, migration, and urban development policies in India, by Mahendra K. Premi with Judith Ann L. Tom, June 1985, viii + 127 pp.

93 Urbanization in China: new insights from the 1982 Census, by Sidney Goldstein, July $1985, \mathrm{vi}+73 \mathrm{pp}$.

94 Comparison of fertility trends estimated alter natively from birth histories and own children, by Robert D. Retherford and Iqbal Alam, July 1985, viii + 39 pp.

95 Population mobility in the People's Republic of China, by Sidney Goldstein and Alice Goldstein, October 1985, vi + 46 pp. 


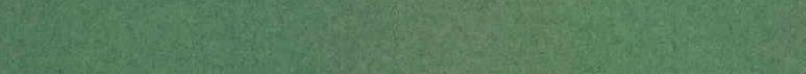

4.

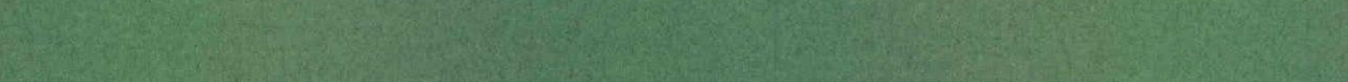
H. S.

2. 20.

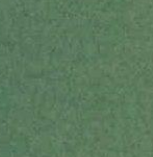

1.

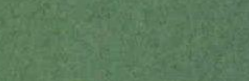

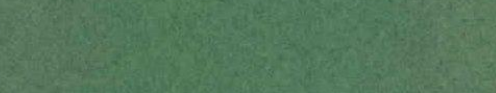

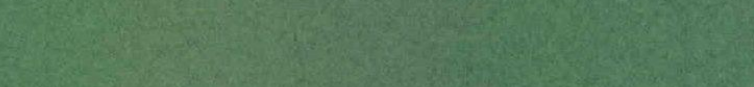

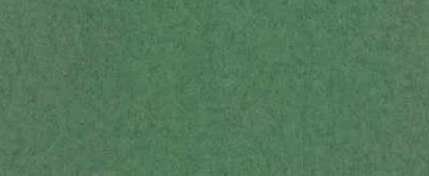

30.5.

3.1.2.

20.

(196.

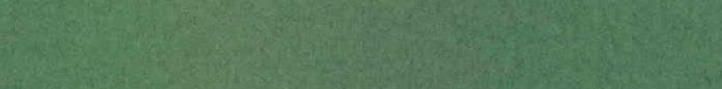

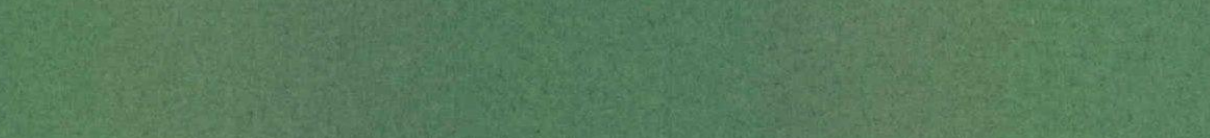

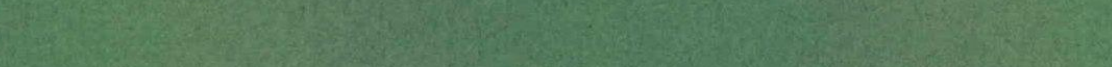

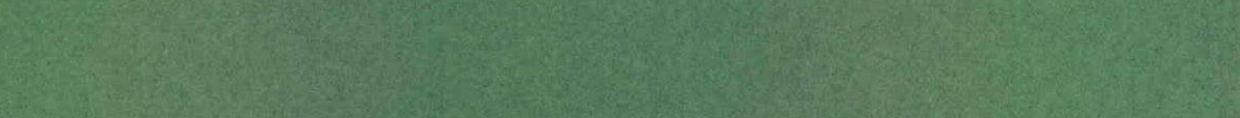
12. 25: 5 2.

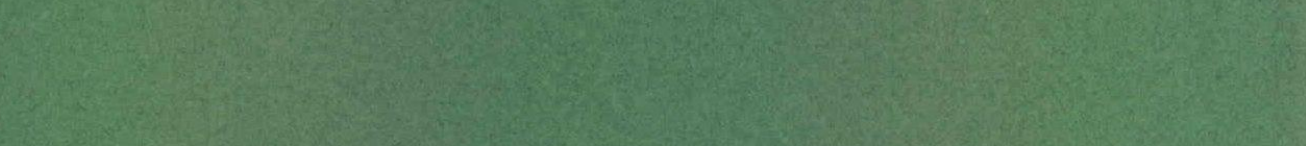
titis

in:

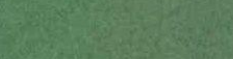

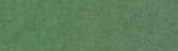

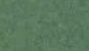

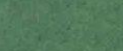

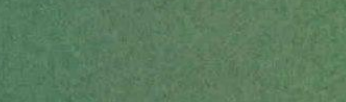
(2) 6.

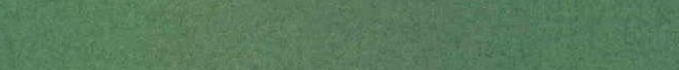

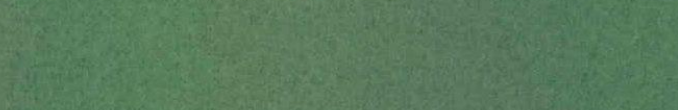

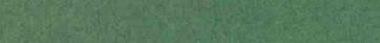

S.

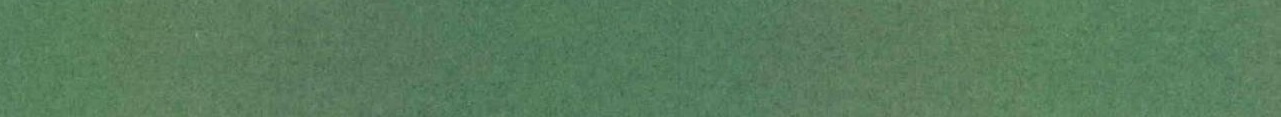

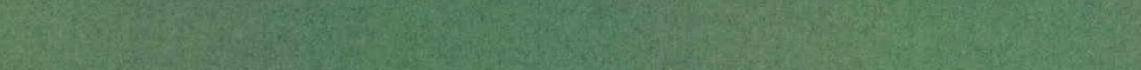
3.

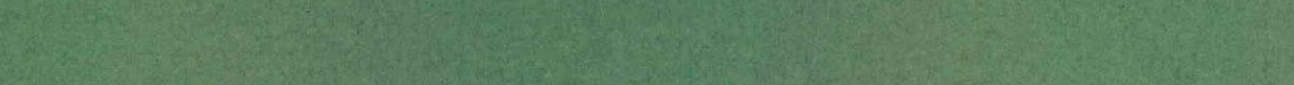

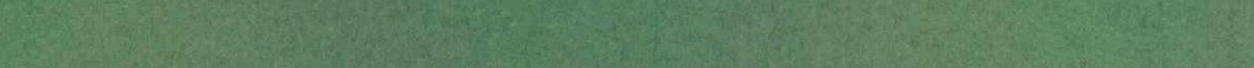


THE EAST-WEST CENTER is a public, nonprofit educational institution with an international board of governors. Some 2,000 research fellows, graduate students, and professionals in business and government each year work with the Center's international staff in cooperative study, training, and research. They examine major issues related to population, resources and development, the environment, culture, and communication in Asia, the Pacific, and the United States. The Center was established in 1960 by the U.S. Congress, which provides principal funding. Support also comes from more than 20 Asian and Pacific governments, as well as private agencies and corporations.

Situated on 21 acres adjacent to the University of Hawaii's Manoa Campus, the Center's facilities include a 300-room office building housing research and administrative offices for an international staff of 250 , three residence halls for participants, and a conference center with meeting rooms equipped to provide simultaneous translation and a complete range of audiovisual services.

THE EAST-WEST POPULATION INSTITUTE, established as a unit of the East-West Center in 1969, carries out multidisciplinary research, training, and related activities in the field of population, placing emphasis on economic, social, psychological, and environmental aspects of population problems in Asia, the Pacific, and the United States. 